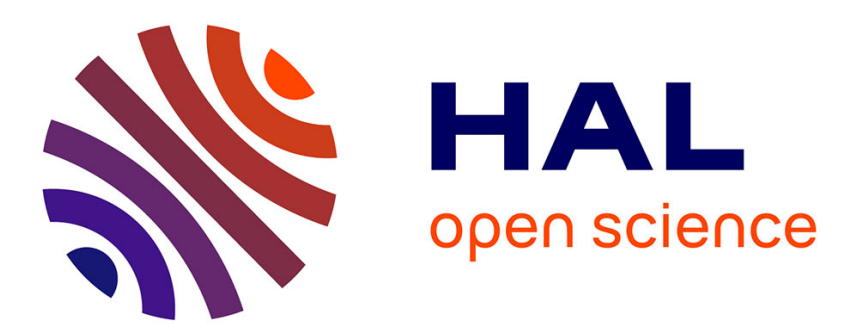

\title{
Titanium nanoparticles fate in small-sized watersheds under different land-uses
}

\author{
Jia-Lan Wang, Enrica Alasonati, Paola Fisicaro, Marc F. Benedetti
}

\section{To cite this version:}

Jia-Lan Wang, Enrica Alasonati, Paola Fisicaro, Marc F. Benedetti. Titanium nanoparticles fate in small-sized watersheds under different land-uses. Journal of Hazardous Materials, 2022, 422, pp.126695. 10.1016/j.jhazmat.2021.126695 . hal-03349279

\section{HAL Id: hal-03349279 \\ https://hal-univ-paris.archives-ouvertes.fr/hal-03349279}

Submitted on 20 Sep 2021

HAL is a multi-disciplinary open access archive for the deposit and dissemination of scientific research documents, whether they are published or not. The documents may come from teaching and research institutions in France or abroad, or from public or private research centers.
L'archive ouverte pluridisciplinaire HAL, est destinée au dépôt et à la diffusion de documents scientifiques de niveau recherche, publiés ou non, émanant des établissements d'enseignement et de recherche français ou étrangers, des laboratoires publics ou privés. 
Titanium nanoparticles fate in small-sized watersheds under different land-uses

Submitted to Journal of Hazardous material

Jia-Lan Wang ${ }^{1,2}$, Enrica Alasonati², Paola Fisicaro ${ }^{2}$, Marc F. Benedetti ${ }^{1 *}$

${ }^{1}$ Université de Paris, Institut de physique du globe de Paris, CNRS, UMR 7154, F-75238 Paris, France

2 Department of Biomedical and Inorganic Chemistry, Laboratoire National de Métrologie et d'Essais (LNE), 1 rue Gaston Boissier, Paris, 75015 France

*Corresponding author

Email: benedetti@ipgp.fr (M. F. Benedetti)

Phone number: +33183957695
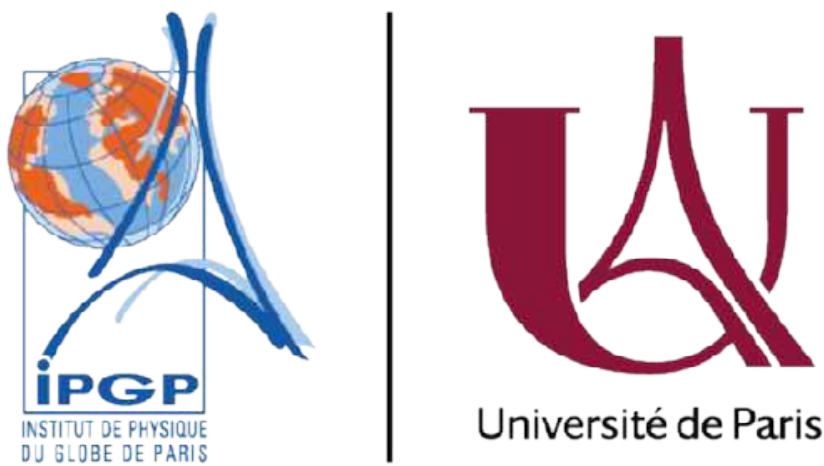
The land-use has an impact on the $\mathrm{TiO}_{2}$ nanoparticle concentrations, biogeochemistry, dynamics and exports rates.

- Higher amounts of small sized $\mathrm{TiO}_{2}$ nanoparticles are detected by sp-ICPMS.

- Ti speciation varies with the type of soils and land-use.

- DOM controls the number of $\mathrm{TiO}_{2}$ nanoparticles in surface water samples.

- Land-use impacts $\mathrm{TiO}_{2}$ nanoparticles concentrations, dynamics and exports rates. 


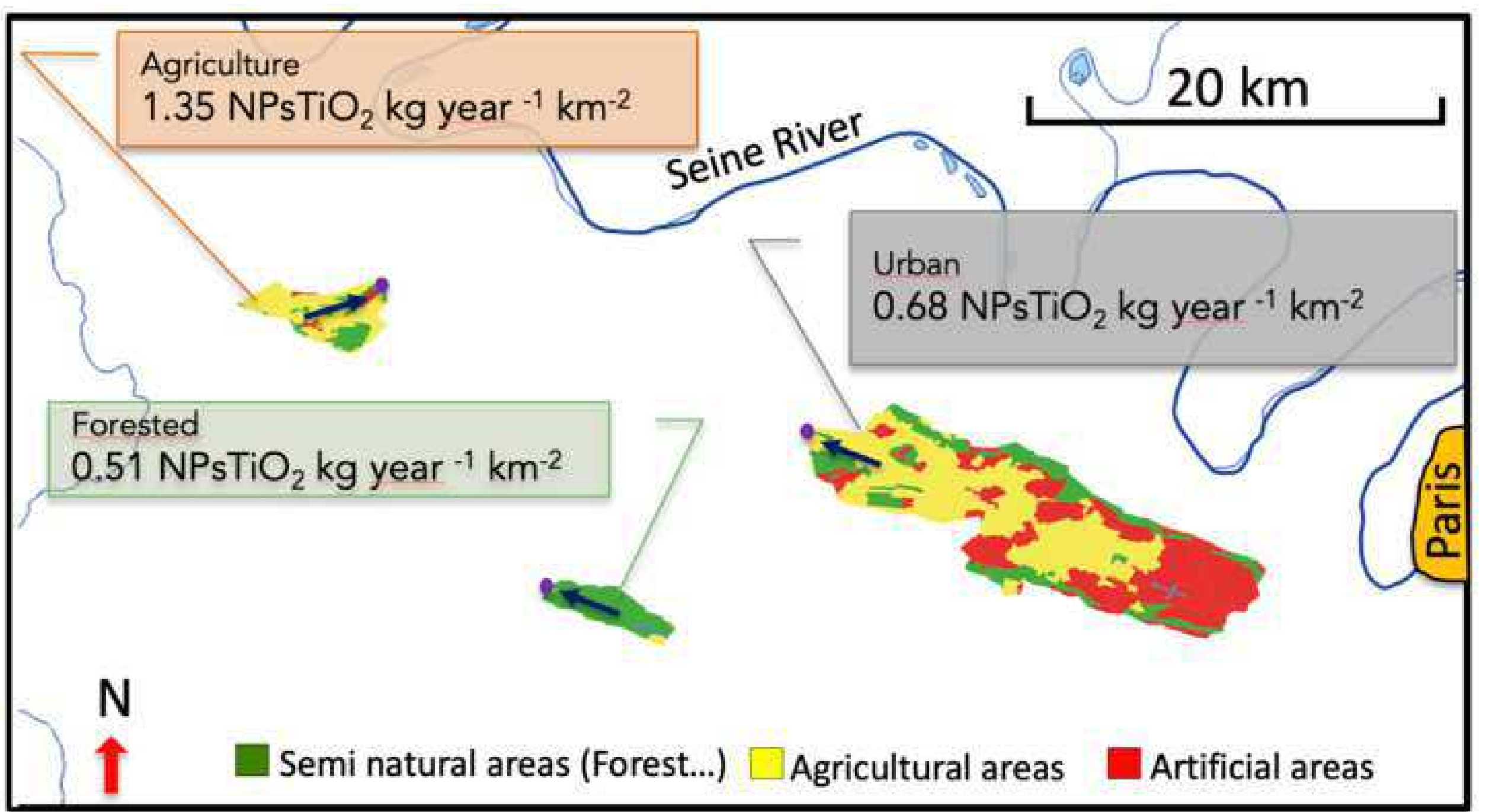


4 Abstract

5 Surface waters from three catchments having contrasting land-uses (forested, agricultural,

6 and urban) were sampled monthly and analysed for nanoparticulate titanium dioxide (NPs-

$7 \mathrm{TiO}_{2}$ ) by single particle ICPMS and electron microscopy. We report one-year of data for NPs-

$8 \mathrm{TiO}_{2}$ having average number and mass concentrations of $9.1 \times 10^{8} \mathrm{NPs}-\mathrm{TiO}_{2}$ particles $\mathrm{L}^{-1}$ and

$911 \mu \mathrm{g} \mathrm{NPs}-\mathrm{TiO}_{2} \mathrm{~L}^{-1}$ respectively. An increase in concentration during warmer months is 10 observed in the forested and agricultural catchments. Both concentrations of $\mathrm{NPs}-\mathrm{TiO}_{2}$ are 11 within the range of recently reported values using similar analytical approaches. The positive 12 correlations for $\mathrm{NPs}-\mathrm{TiO}_{2}$ mass concentration or particle number with the concentration of 13 some trace elements and DOC in the forested and agricultural catchments suggest the 14 detected $\mathrm{NPs}_{-} \mathrm{TiO}_{2}$ in these two systems are mostly from geogenic origin. Additionally, 15 microscopy imaging confirmed the presence of NPs in the three catchments. Furthermore, the 16 land-area normalized annual flux of $\mathrm{NPs}^{-\mathrm{TiO}_{2}}\left(1.65 \mathrm{~kg} \mathrm{TiO}_{2}\right.$ year-1 $\left.^{-1} \mathrm{~km}^{-2}\right)$ was highest for the 17 agricultural catchment, suggesting that agricultural practices have a different impact on the $18 \mathrm{NPs}_{-} \mathrm{TiO}_{2}$ dynamics and exports than other land-uses (urban or forestry). A similar trend is also 19 found by the reanalysis of recent literature data.

\section{0}

22 1. Introduction

23 Titanium dioxide $\left(\mathrm{TiO}_{2}\right)$ occurs naturally in rutile $\left(\mathrm{TiO}_{2}\right)$ and ilmenite $\left(\mathrm{FeTiO}_{3}\right)$ present in rocks 24 and soils, with Ti annual cycling in the global surficial environment equalling up to $48410^{6}$ 
25 tons $\mathrm{Ti}^{-1}[1]$. Since early in the $20^{\text {th }}$ century, particulate $\mathrm{TiO}_{2}$ has been largely used as

26 pigments in paints, papers and plastics because of its whiteness, high opacity and corrosion

27 resistance. Owing to later milestone breakthroughs in $\mathrm{TiO}_{2}$ research and the nanotechnology

28 revolution, engineered nano- $\mathrm{TiO}_{2}\left(\right.$ en- $\mathrm{TiO}_{2}$ ), defined as being $<100 \mathrm{~nm}$ in diameter, is more

29 and more applied in other industrial uses [2]. Applications include foods, cosmetics, solar

30 energy, and environmental remediation for instance. Engineered nano- $\mathrm{TiO}_{2}$ has been

31 reported as the most fabricated of all nanomaterial with $10^{5}$ tons of en- $\mathrm{TiO}_{2}$ used globally in

32 2015, and its production is predicted to increase at least by 2025 [3-4]. For France no such

33 estimation of future annual use exists, but using the data from Switzerland [5] and

34 extrapolating to France using its population as a scaling factor, an amount of 3,400 tons of en-

$35 \mathrm{TiO}_{2} \mathrm{Y}^{-1}$ is estimated for 2025 (i.e. 2,037 tons of $\mathrm{Ti}^{-1}$ ).

36

37 It is likely that en- $\mathrm{TiO}_{2}$ will be discharged during or after its use into terrestrial and aquatic

38 ecosystems, adding to the natural loads. For instance, in lab or land-scale studies, en- $\mathrm{TiO}_{2}$

39 release into receiving waters has been reported from: exterior paints [6], textiles during

40 washing [7], sunscreens [8], and construction and demolition landfills [9]. In addition, $\mathrm{TiO}_{2}$ is

41 a common food additive (known as E171 in Europe) and can be found in some dairy products,

42 such as candies, chocolates, chewing gums, soups, nuts, milk and yogurt. A typical exposure

43 of dietary $\mathrm{TiO}_{2}$ for a US adult is estimated $0.2-0.7 \mathrm{mg} \mathrm{TiO}_{2} \mathrm{~kg}^{-1}$ of body weight day-1 with most

44 entering into wastewater treatment plants (WWTPs) [10]. Nanoparticle removal efficiency

45 can be up to $96 \%$ [11-13] but the presence of en- $\mathrm{TiO}_{2}$ in effluents after treatment is still

46 identified at the level of $\mu \mathrm{L} \mathrm{L}^{-1}[13]$. These studies demonstrate that en- $\mathrm{TiO}_{2}$ has entered our

47 aquatic systems and therefore evaluating the potential risk to ecosystems, as well as to

48 humans, through bioaccumulation is of great importance. 
50 Manufactured $\mathrm{TiO}_{2}$ is not the only source of $\mathrm{Ti}$ in the environment. It is estimated that $375 \mathrm{x}$

$5110^{9} \mathrm{~kg}$ of Ti per year are displaced by soil erosion at the world scale [1]. Fifty percent of this

52 flux was of anthropogenic origin mostly because of the influence of agricultural practices on

53 erosion fluxes [1]. The GEMAS project reported the concentration of Ti in agricultural soils for

54 Northern Europe to be equal to $3.11 \mathrm{~g}$ of $\mathrm{Ti} \mathrm{kg}^{-1}$, accounting for the high erosion flux value

55 resulting from agricultural practices [14]. In addition, the flux of Ti due to coal burning was

56 estimated at $4.9 \times 10^{9} \mathrm{~kg}$ of Ti per year using a concentration of $0.8 \mathrm{mg} \mathrm{Ti} \mathrm{kg}^{-1} \mathrm{coal}$ [1]. The

57 other major global source of Ti flux are construction activities that correspond to a flux of 43

$58 \times 10^{9} \mathrm{~kg}$ of Ti per year [1]. All those fluxes are several orders of magnitude higher than an

59 annual global en- $\mathrm{TiO}_{2}$ flux equal to $409 \times 10^{6} \mathrm{~kg}$ per year based on Europe's estimation [4] and

60 extrapolated to the world using world population as a scaling factor. This complex global and

61 local biogeochemical Ti cycle complicates the understanding of the respective fate of en- $\mathrm{TiO}_{2}$

62 vs natural and/or other anthropogenic sources of nanoparticulate $\mathrm{TiO}_{2}$ in the critical zone [15].

63 The sum of the three potential types of nanoparticulate $\mathrm{TiO}_{2}$ is defined in this paper as NP-

$64 \mathrm{TiO}_{2}=$ en- $\mathrm{TiO}_{2}+$ natural $\mathrm{Ti}+$ other anthropogenic Ti sources.

65

66 To investigate $\mathrm{NP}_{-} \mathrm{TiO}_{2}$ fate and ecotoxicity in aquatic systems, quantitative measurement is a

67 primary step. However, it is a challenging issue because of low predicted concentrations and

68 high Ti background [16] and the analytical limitations for nanomaterials [17]. Although the

69 exposure of various types of en- $\mathrm{TiO}_{2}$ has been modelled based on their production volumes

70 and their foreseen pathways, these predictions must be validated by "real world" data [18].

71 There is a consensus that the lack of field data is always the key knowledge gap [19]. Few

72 relevant studies have been conducted at the field scale to detect nanoparticles (NPs) like 
73 Nano-Ag, $\mathrm{TiO}_{2}, \mathrm{CeO}_{2}$ or carbon nanotubes [8,20-26]. These field measurements begin to allow

74 construction of an $\mathrm{NP}^{-\mathrm{TiO}_{2}}$ database, which helps to better understand both their fate in the

75 environment and to conduct ecological risk assessments.

76

77 Few studies have investigated the temporal changes in $\mathrm{NP}^{-\mathrm{TiO}_{2}}$ concentrations arising due to

78 hydrological and meteorological variability along the year. Moreover, most field

79 measurements in freshwater were done at one or several sites but along the same river,

80 focusing mostly on the characterization of Ti-containing nano - or colloidal particles. The

81 identification of processes and drivers potentially controlling the fate of NPs is still lacking at

82 the field-scale. Additionally, natural contribution to environmental concentration, in the case

83 of $\mathrm{TiO}_{2}$, makes all abovementioned research more challenging. It is therefore complicated to

84 understand the variations in concentrations, not to mention identifying the possible drivers

85 of those changes against a high geochemical background [14-15]. However, recently the

86 contribution of en- $\mathrm{TiO}_{2}$ in sewage spills to impacted surface waters was identified and

87 quantified with single particle counting TOF-ICPMS (Time Of Flight Inductively Coupled Mass

88 Spectrometry). Concentration of en- $\mathrm{TiO}_{2}$ up to $95 \mu \mathrm{L} \mathrm{L}^{-1}$ were reported [24] which is a very

89 high value compared to predicted values [4].

90

91 Little is known about watershed scale processes regarding NP transport. With the data from

92 Peters et al.,[22] we calculated the mean annual mass of $\mathrm{NPs}^{-\mathrm{TiO}_{2}}$, leaving the ljssel and

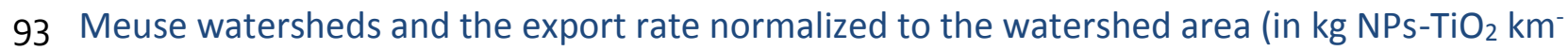

$\left.94^{2} \mathrm{y}^{-1}\right)$. The average annual discharge rate and watershed area for the ljssel and the Meuse are

$95390 \mathrm{~m}^{3} \mathrm{sec}^{-1}, 357 \mathrm{~m}^{3} \mathrm{sec}^{-1}$ and $4,270 \mathrm{~km}^{2}, 36,000 \mathrm{~km}^{2}$, respectively [27-29]. For the ljssel and

96 the Meuse rivers, the calculated flux annual, normalized export-rate are equal to $45.5 \mathrm{t}$ NPs- 
$97 \mathrm{TiO}_{2} \mathrm{y}^{-1}, 10.9 \mathrm{~kg} \mathrm{NPs}-\mathrm{TiO}_{2} \mathrm{~km}^{-2} \mathrm{y}^{-1}$ and 26.9 t NPs-TiO $2 \mathrm{y}^{-1}, 0.8 \mathrm{~kg} \mathrm{NPs}-\mathrm{TiO}_{2} \mathrm{~km}^{-2} \mathrm{y}^{-1}$, respectively.

98 The very different $\mathrm{NPs}-\mathrm{TiO}_{2}$ normalized export-rate values obtained for both rivers suggest

99 that different processes or sources regulate the concentrations of $\mathrm{NPs}-\mathrm{TiO}_{2}$ in those two 100 watersheds.

101

102 It is hard to identify sources and/or processes regulating $\mathrm{NP}^{-\mathrm{TiO}_{2}}$ concentrations by 103 performing measurements at a single or even multiple points along a river without taking into 104 account land-use and the annual hydrological variability and their geochemical implications. 105 Field sites under different land-uses, from less-impacted environments to catchments heavily 106 impacted by urban activities, need to be investigated for a better understanding of NP- $\mathrm{TiO}_{2}$ 107 dynamics. The present study had 3 mains objectives: $1^{\text {st }}$ to collect 1 year of $\mathrm{NP}-\mathrm{TiO}_{2}$ 108 measurements in three catchments with variable geochemical characteristics and diverse 109 land-uses to monitor the relevant concentration of $\mathrm{NP}^{-\mathrm{TiO}_{2}}$ in freshwaters; $2^{\text {nd }}$ to assess the 110 potential processes controlling $\mathrm{NP}_{-} \mathrm{TiO}_{2}$ in natural waters from small watersheds with variable 111 local weather, hydrology and anthropogenic activities and $3^{\text {rd }}$ to address the impact of land112 use, at the scale of small size sub-basins, on the export-rates of $\mathrm{NPs}^{-\mathrm{TiO}_{2}}$ and total $\mathrm{Ti}$ from the 113 catchment. Given that NP- $\mathrm{TiO}_{2}$ have been suggested to serve as a tracer of other engineered 114 nanomaterials [11], these investigations could be useful for evaluate the general transport 115 and fate of widely used engineered nanoparticles in aquatic systems.

116

117 2. Materials and Methods

$118 \quad 2.1$ Sampling and analysis

119 2.1.1 Sampling sites 
120 Stream waters were sampled from three sub-basins in the Seine River watershed located in

121 the West of Paris, France (Fig. 1). The Seine River watershed has a total area of about 67,500

$122 \mathrm{~km}^{2}$ and is located in a sedimentary basin [29]. Sampling of smaller sized sub-basins is justified

123 because they are prone to react more quickly to hydrological, meteorological and

124 anthropogenic effects. The three selected watersheds had been used in previous studies on

125 the origin and dynamics of trace metals and silver nanoparticles [25,30-31]. They have

126 different lithologies (i.e. sandy vs carbonate) and land-uses, namely forested, agricultural and

127 artificial surfaces. Their characteristics are detailed in Fig. 1 and Table S1. The urban watershed

128 is a good analogue of the larger Seine river watershed as it is a representative mixture of the

129 overall Seine watershed land-uses (i.e. the ratio of artificial areas vs agricultural areas) [25,30-

$13031]$.

131

132

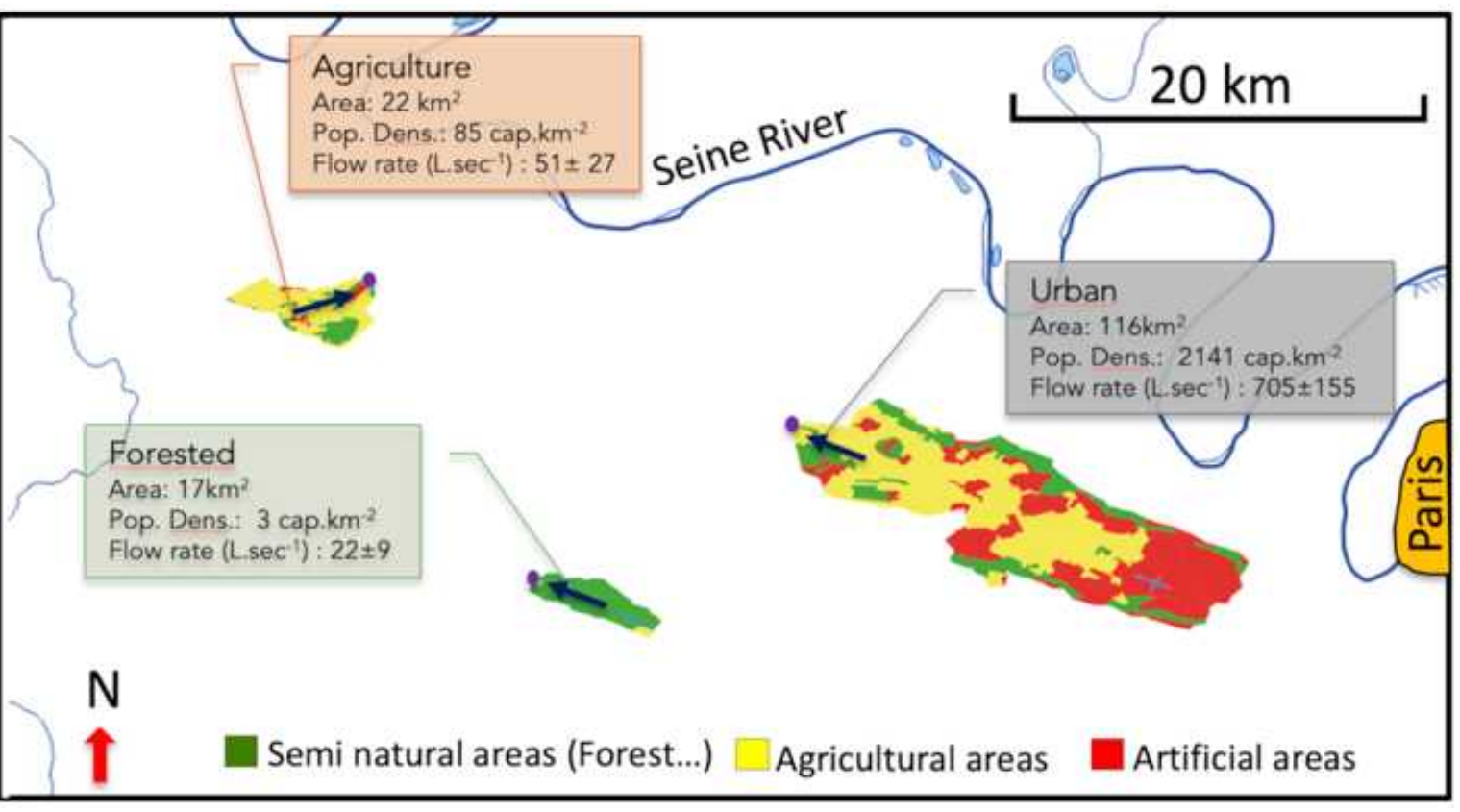

133 Fig. 1: Sampling location and their land-use. Blue arrows indicate the direction of the water

134 flow. Coloured boxes report the area of the watershed, the average population density (Pop.

135 Dens.) and measured annual average water flow rate $\left(\right.$ L.sec $\left.{ }^{-1}\right)$ for each watershed. 
137 2.1.2 Sample collection and analysis

138 Water samples were collected once per month from November 2016 to December 2017. Grab

139 surface water samples were collected in 1 L HDPE bottles pre acid-washed ( $\mathrm{HCl} 1 \mathrm{~N}$ for 2 days)

140 and rinsed in ultrahigh purity water (Milli Q water). Various physicochemical parameters were

141 monitored to comprehensively characterize the aquatic geochemistry. They include $\mathrm{pH}$,

142 dissolved oxygen, conductivity, alkalinity, dissolved organic carbon (DOC), major anions,

143 cations, trace elements and rare earth elements (REEs). The detailed analytical protocols and

144 data can be found elsewhere [25]. In the laboratory, $500 \mathrm{~mL}$ of each bulk water sample used

145 for nanoparticle analysis was ultra-filtered through a $1 \mathrm{kDa}$ regenerated cellulose membrane,

146 which corresponds to about $1.3 \mathrm{~nm}$ in membrane pore size [32], in order to remove all the

147 particles smaller than a few nanometres. This ultra-filtrate was further used as the matrix to

148 prepare all standards and solutions for single particle ICPMS analysis.

149

150 2.1.3 Bulk water chemical analysis

151 The total concentrations of Ti, $\mathrm{Ni}, \mathrm{Cu}, \mathrm{Zn}, \mathrm{As}, \mathrm{Sb}, \mathrm{Cd}, \mathrm{Pb}$ in bulk water samples were determined 152 by ICPMS after complete acid digestion. A mixture of $3 \mathrm{~mL} \mathrm{HCl}, 1 \mathrm{~mL} \mathrm{HNO}$ and $0.5 \mathrm{~mL} \mathrm{HF} \mathrm{(ACS}$ 153 grade acids distilled in the laboratory) was added to $10 \mathrm{~mL}$ of raw water into a $30 \mathrm{~mL}$ PFA 154 Savillex digestion vessel. The well-closed Savillex vessel was heated at $105^{\circ} \mathrm{C}$ during 24 hours. 155 After digestion, the mixture was evaporated at $85{ }^{\circ} \mathrm{C}$ to dryness. The residue was then re156 dissolved in $10 \mathrm{~mL}$ of $2 \% \mathrm{HNO}_{3}$. The blank of the digestion procedure was evaluated with ultra157 pure water by following the same procedure. Each sample digestion was performed in 158 triplicate. The protocol was validated by digestion of commercial standards of $\mathrm{TiO}_{2}$ 
159 nanoparticles (P25 and AERODISP-W740-X) at concentrations ranging from $20 \mu \mathrm{g} \mathrm{L}^{-1}$ to 400

$160 \mathrm{mg} \mathrm{L}^{-1}$. Satisfactory recovery factors above $90 \%$ were obtained (Table S2).

161

1622.2 Quantification of $\mathrm{TiO}_{2}$ NPs by single particle ICPMS (sp-ICPMS)

1632.2 .1 Instrumental operating parameters

164 A sector-field ICPMS (Element II, Thermo Scientific) was used for sp-ICPMS measurement of $165 \mathrm{NPs}_{-} \mathrm{TiO}_{2}$. Before sample analysis, the ICPMS instrument was first tuned to ensure a good 166 sensitivity, stability and low oxide formation. The instrument was operated in medium 167 resolution mode, which provides sufficient resolution ( $>4,000$ ) to avoid isobaric or 168 polyatomic interferences on ${ }^{48} \mathrm{Ti}$. The operating conditions are detailed in Table 1 . The sample 169 uptake flow was determined by weighing the sample before and after a fixed period (i.e. 15 170 minutes), then dividing the mass difference by time. These measurements were systematically 171 performed at the beginning, middle and end of analysis sequence.

172

173 Table 1: Experimental conditions of sp-ICPMS measurement.

174

\begin{tabular}{ll}
\hline Parameter & $\begin{array}{l}\text { Experimental } \\
\text { conditions }\end{array}$ \\
\hline Spray chamber & Quartz cyclonic \\
Nebulizer & PFA MicroFlow \\
Plasma power & $1315 \mathrm{~W}$ \\
Cool Gas & $16 \mathrm{~L} \mathrm{~min}^{-1}$ \\
Auxiliary Gas & $1 \mathrm{~L} \mathrm{~min}^{-1}$
\end{tabular}




$\begin{array}{ll}\text { Peristaltic pump rate } & 12 \mathrm{rpm} \\ \text { Uptake flow } & \approx 0.2 \mathrm{~mL} \mathrm{~min}^{-1} \\ & \text { Low Resolution: } \\ \text { Monitored isotope \& } & 197 \mathrm{Au} \\ \text { resolution } & \text { Medium } \\ & \text { Resolution:47Ti } \\ \text { Dwell time } & 1 \mathrm{~ms} \\ \text { Settling time } & 1 \mathrm{~ms} \\ \text { Data number } & 10,000\end{array}$

175

176 2.2.2 Standard and sample preparation

177 A suspension of $60 \mathrm{~nm}$ gold nanoparticles (NIST, RM8013) was used to determine the 178 transport efficiency. The working standard was freshly prepared by diluting the stock 179 suspension to about $200 \mathrm{ng} \mathrm{L}^{-1}$ with the ultra-filtrate of stream waters. Ionic calibration 180 standards ( $\mathrm{Au}: 50$ to $5000 \mathrm{ng} \mathrm{L}^{-1}$; Ti: 0.2 to $10 \mu \mathrm{g} \mathrm{L}^{-1}$ ) were prepared to determine element 181 sensitivity (dissolved or particulate form) by diluting the stock standards at $1000 \mathrm{mg} \mathrm{L}^{-1}$ in the 182 ultra-filtered matrix. Transport efficiency was calculated for each sampling mission and the 183 value was equal to $9 \% \pm 2 \%[25]$.

184 The dilution of raw waters was usually performed to reach the proper number of particles for 185 accurate sp-ICPMS measurements. Here, dilution by 10, 50, 100, 500 times were tested, with 186 the best dilution factor varying from one sampling collection date and/or sampling site to 187 another. During each analysis the raw waters were diluted with the ultra-filtered matrix (i.e. 188 fraction of the water $<1 \mathrm{kDa}$, as previously described) and dilutions were performed until the 189 size distribution of the $\mathrm{NPs}_{-}-\mathrm{TiO}_{2}$ did not change. The samples were not sonicated prior to 
190 measurements to be as close as possible to the field conditions. All standards and samples 191 were prepared daily, with the minimum delay until sp-ICPMS measurements.

192

193 2.2.3 Data analysis

194 Theoretical descriptions and calculations of sp-ICPMS are well established in literature [33-39].

195 The data analysis in this study is mainly based on procedure described by Pace [39]. The only 196 difference is that a different method called "subtraction method", extensively described 197 elsewhere [25], is applied here to distinguish NPs from the background. The method is 198 summarized in the supplementary material section 1 and [25].

199 The annual average enrichment factor (EF) is calculated by a double normalization of the 200 average annual total element concentration ([Me]) in the sample ([Me]/[Y])sample) to the 201 same element ratio in a reference sample (([Me]/[Y])reference),

202

$203 \mathrm{EF}[\mathrm{Me}]=([\mathrm{Me}] /[\mathrm{Y}])$ sample $/([\mathrm{Me}] /[\mathrm{Y}])$ reference

204

205 Yttrium was chosen as the reference element since the usual reference elements (Th, Al) were 206 not measured. In addition, Yttrium has no known biological role that would prevent it use as 207 a reference element.

208

209 2.2.4 Evaluation of the uncertainty on nanoparticles' number

210 According to the Guide to the expression of Uncertainty in Measurement (GUM), the standard 211 uncertainty of measurand can be obtained by propagating the variances of the related 212 parameters [40]. Several factors are identified as contributors to the uncertainty in case of sp213 ICPMS measurements of nanoparticles in natural waters such as the solution preparation, 
214 calibration, sensitivity of ICPMS, field sampling and sample stability. Two main contributions

215 are taken into account in this paper i.e., the measurement repeatability (u1) and the sampling 216 variability effect (u2), for the concentration of nanoparticles determined by sp-ICPMS. The 217 calculation procedure is developed in the supplementary section and an example of 218 calculation is given in Fig S5.

2202.3 Electron Microscopy observations

221 A Carl Zeiss Auriga Field Emission Gun - Scanning Electron Microscope (FEG-SEM) was used to 222 image Ti-bearing particles. It is equipped with secondary and backscattered detectors for the 223 morphology and contrast in chemical composition of analysed particles. The FEG-SEM analysis 224 was performed at electron energy of 5 to $15 \mathrm{keV}$. The coupled energy dispersive X-ray 225 spectroscopy (EDX) provided elemental compositions of detected particles. The microscopy 226 analysis was performed randomly on two out of ten samples (i.e. 25/09/17 and 19/12/17)) to 227 confirm the presence of $\mathrm{NPs}^{-\mathrm{TiO}_{2}}$ detected by sp-ICPMS and to gain qualitative knowledge on 228 their shapes and sizes. The fresh raw waters were first filtered through $0.45 \mu \mathrm{m}$ 229 (Polycarbonate) and a $0.2 \mu \mathrm{m}$ (acetate cellulose) and then a $1 \mathrm{kDa}$ polyether sulfone filters. 230 These filtration steps were meant to collect the particles on the filters and subsequently 231 observe the particles on the filters. The filters were air-dried overnight in a clean room. The 232 dried filters were then cut into $1 \mathrm{~cm}$ per $1 \mathrm{~cm}$ squares and coated with gold. Each filtration of 233 raw water was performed in triplicate together with one blank of ultrapure water.

236 3. Results and Discussion

2373.1 Physicochemical characteristics of three catchment waters 
238 The three watersheds, where freshwater samples were taken, have different percentages of 239 three land-uses (i.e., forested, agricultural and artificial; Table S1) and are thus impacted by 240 natural processes or anthropogenic activities to different degrees. Our previous studies on the 241 same sites demonstrated that they differ in terms of geochemical background and heavy 242 metal sources (ex. Zn dynamics) or silver NPs (Ag-NPs) dynamics [31,25]. Number and mass 243 concentration of $\mathrm{NPs}^{-\mathrm{TiO}_{2}}$ derived from these watersheds should vary along the year and 244 differ among sites. In addition, the fate and the behaviour of $\mathrm{NPs}^{-\mathrm{TiO}_{2}}$ should be influenced 245 by matrix properties, such as $\mathrm{pH}$, ions (identity and concentration) and dissolved organic 246 matter (i.e. DOC). The properties of catchment's water are summarized in Table 2 according

247 to previously published data [25]. The water of the forested catchment has a near-neutral pH 248 and the lowest ionic strength (as represented by conductivity), but higher DOC concentrations 249 due to the sandy nature of the soils (Table S1). The urban and agricultural watersheds water 250 samples have a higher alkalinity and ionic strength since their pedology is dominated by 251 carbonate soils (Table S1). It's also noteworthy that DOC concentrations of urban waters are 252 close to that of forested ones, but with much smaller seasonal variations. Those values are 253 within the range of values previously recorded and are characteristic of Seine River watershed 254 waters [29,301].

255

256 Table 2: Average (range) of some physicochemical properties of three catchment waters.

257 Original data taken from Wang et al. (2020) (Table S2 in supplementary information [25]). 


\begin{tabular}{lccc}
\hline & Forested water & Agricultural water & Urban water \\
\hline $\mathrm{pH}$ & 7.1 & 7.8 & 8.4 \\
& $(6.3-7.7)$ & $(7.1-8.8)$ & $(8.0-9.0)$ \\
Conductivity $(\mu \mathrm{s} / \mathrm{cm})$ & 247 & 666 & 1117 \\
& $(195-320)$ & $(527-777)$ & $(877-1270)$ \\
DOC $(\mathrm{mg} / \mathrm{L})$ & 5.6 & 3.5 & 5.2 \\
& $(3.4-9.1)$ & $(2.5-4.7)$ & $(4.4-6.1)$ \\
Alkalinity $(\mu \mathrm{M})$ & 885 & 3659 & 4457 \\
& $(661-1072)$ & $(2260-4663)$ & $(3397-5299)$ \\
\hline
\end{tabular}

2593.2 Concentration of $\mathrm{NPs}-\mathrm{TiO}_{2}$ detected in three catchments

260 By comparing sp-ICPMS data for the ultrafiltered water $(<1 \mathrm{kDa})$ and the raw water, we can 261 confirm the presence of $\mathrm{NPs}-\mathrm{TiO}_{2}$ in sampled waters (Fig. S1). The detected NPs-TiO 2 particle 262 number concentration (PNC) ranges from $9 \times 10^{8}$ to $9 \times 10^{10}$ particle $\mathrm{L}^{-1}$, with an average value 263 of $2 \times 10^{10}$ particle $\mathrm{L}^{-1}$. The mass concentration corresponds to a range of 0.5 to $70 \mu \mathrm{g}$ NPs$264 \mathrm{TiO}_{2} \mathrm{~L}^{-1}$, using the ionic $\mathrm{Ti}$ calibration curve and the procedure given in [25] and in the 265 supplementary information. Few field data of $\mathrm{NPs}^{-\mathrm{TiO}_{2}}$ in surface waters are available in 266 literature (Table 3). Despite the variability in these reported literature values, we found higher 267 values for the PNC of $\mathrm{NPs}_{-}-\mathrm{TiO}_{2}$ in the catchments. This difference can be attributed to the 268 nature of sampling site (i.e., small watersheds vs larger rivers), sample preparation, and for 269 the larger part most probably related to the sp-ICPMS analysis data processing. Indeed, given 270 the very low concentration of dissolved Ti (i.e. $\left.50 \mathrm{ng} \mathrm{Ti} \mathrm{L}^{-1}\right)$, consistent with the thermodynamic 271 solubility data of $\mathrm{TiO}_{2}$ [41], a different data treatment method could be applied. This method 272 is based on the subtraction of the background ion counts of the ultrafiltered matrix $(<1 \mathrm{kDa})$ 
273 from those of the bulk sample to calculate PNC [25] (supplementary information section gives

274 details on its validation as well as reference [25]). With this method, the smallest Ti-containing 275 particles, which are usually eliminated as part of the so-called dissolved background by 276 classical data treatment [39], are now measured. Additionally, as a result of using this new 277 procedure, the measured NPs- $\mathrm{TiO}_{2}$ PNC covers a wider size distribution. The data treatment 278 impacts the mass concentration measurement only slightly, since very small particles account 279 only for a small part of the NPs- $\mathrm{TiO}_{2}$ mass concentrations. The mass concentration measured

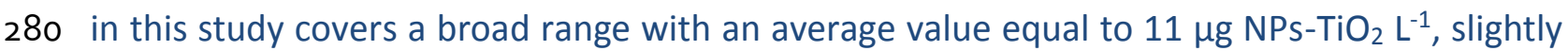
281 higher than previously published values (Table 3). In addition, the different geological setting 282 of these sites may also account for such differences, since NPs-TiO 2 PNC or mass concentration 283 can be the result of past and/or present, natural and/or other anthropogenic inputs, mostly 284 arising from the influence of agricultural practices on erosion fluxes taking place within the 285 watersheds [1].

288 Table 3: Concentrations of $\mathrm{NPs}^{-\mathrm{TiO}_{2}}$ measured in surface water from the literature and this 289 study. n.g.: not given. n.a.: not analysed. ${ }^{*}$ Ti: total content of filtered fraction after digestion. $290 * *$ Engineered nanoparticles only as defined in [24].

\begin{tabular}{llll}
\hline Study site & Sample & Range/Average & Range/Average \\
analysis & & \\
& $10^{8}$. particle L ${ }^{-1}$ & $\mu g N P s-\mathrm{TiO}_{2} \mathrm{~L}^{-1}$ \\
& & \\
\hline
\end{tabular}




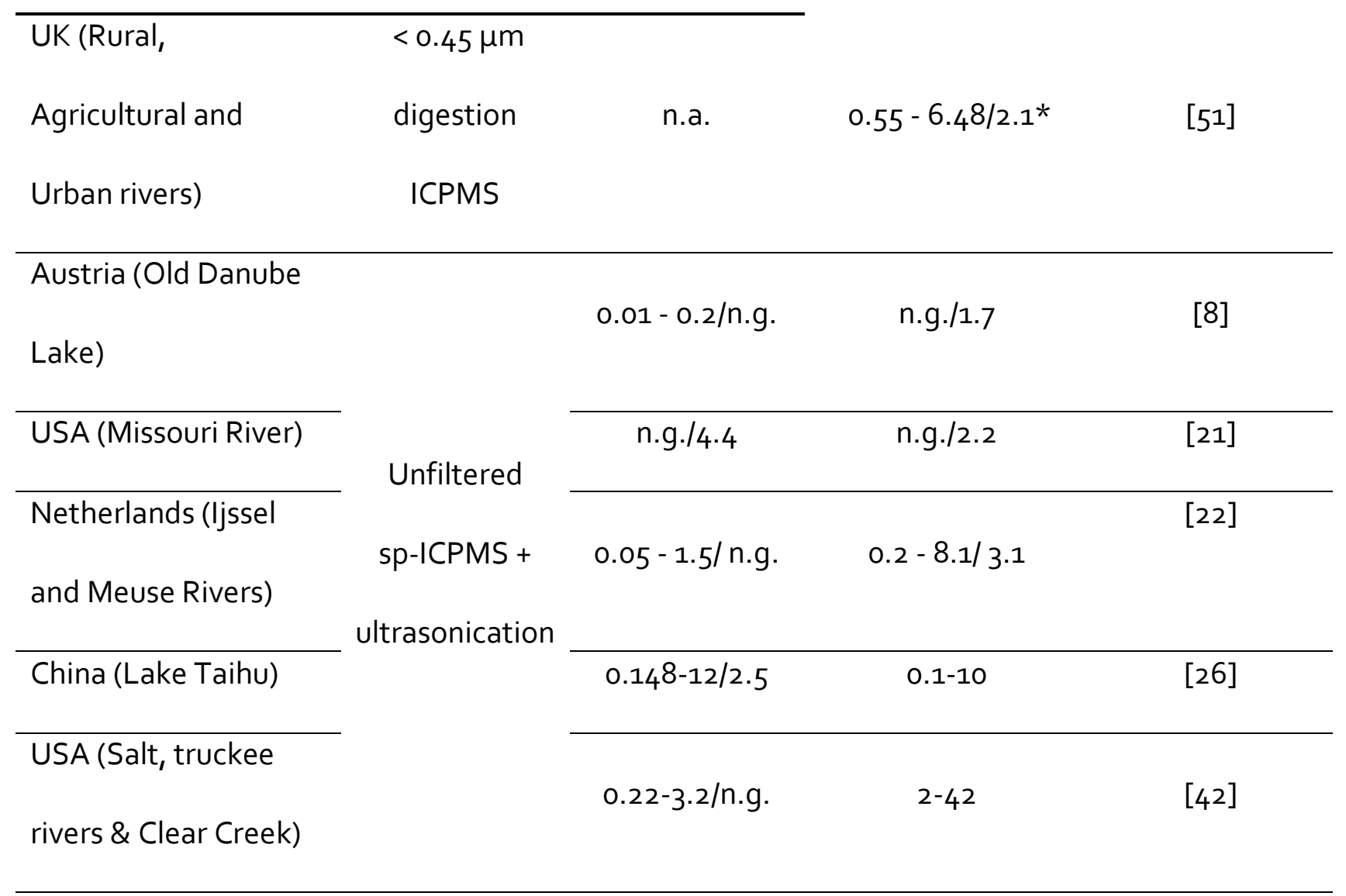

Treated

USA (Crane, Stoop $\quad \mathrm{Na}_{4} \mathrm{P}_{2} \mathrm{O}_{7}$

and Gills Creeks, sonicated and $\quad$ o.05-7.15/4.4 $\quad$ [24]

South Carolina) centrifuged

TOF-ICPMS

\section{France (Forested,}

brook)

$$
60-720 / 280 \quad 3.5-23.4 / 10.2
$$

France (Agricultural, Unfiltered sp-

stream)

ICPMS

$16-862 / 231 \quad 1.4-69.6 / 21.1 \quad$ This study

France (Urban,

stream)

$$
9-39 / 27 \quad 0.5-5.9 / 3.1
$$


293 Our results show that when looking only at our urbanized watershed (Table 3), all samples

294 are in the range of mass concentration reported in the literature. This study provides the first 295 dataset of $\mathrm{NPs}^{-\mathrm{TiO}_{2}}$ in aquatic environment under different land-use in France. However, for 296 the most recent man-made nanoparticles production estimations [4] the mean concentration 297 of en- $\mathrm{TiO}_{2}$ in European surface waters was estimated at $2.17 \mu \mathrm{g}$ en- $\mathrm{TiO}_{2} \mathrm{~L}^{-1}$. Our value for NPs$298 \mathrm{TiO}_{2}$, in the urban watershed is within this range but the total amount of $\mathrm{TiO}_{2}$ (obtained by 299 acid digestion and ICP-MS analysis) in those water samples is much higher (see section 3.3 in 300 this paper). These NPs-TiO 2 concentrations are much lower than values corresponding to en$301 \mathrm{TiO}_{2}$ only concentrations that can go up to $95 \mu \mathrm{g}$ en- $\mathrm{TiO}_{2} \mathrm{~L}^{-1}$ as detected with a specific sample 302 pre-treatment targeting a large recovery of engineered $\mathrm{TiO}_{2}[24]$.

304 The agricultural and forested stream samples have a wider mass concentration range with

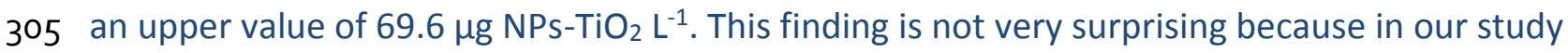
306 the $\mathrm{TiO}_{2}$ contributions from the natural geological background or other anthropogenic 307 activities (construction, agriculture...) are taken into account. However, it is to be noted that 308 higher simulated concentrations equal to 16 and $24.5 \mu \mathrm{g}$ en- $\mathrm{TiO}_{2} \mathrm{~L}^{-1}$ have been reported $309[43,44]$.

311 Concerning the differences between the three watersheds, we can see that regardless of the 312 time of the sampling, the urban stream samples always contain less NPs- $\mathrm{TiO}_{2}$ than the stream 313 samples from the other two watersheds either as $\mathrm{NPs}_{-} \mathrm{TiO}_{2}$ number (Fig. 2) or mass 314 concentration (Fig. S6). The high values also reported for the forested watershed samples 315 could be due to naturally occurring $\mathrm{NPs}^{-\mathrm{TiO}_{2}}$ since natural concentrations of colloids and 316 nanoparticles largely exceed that of engineered nanoparticles $[45,15]$. Likely causes are high 

concentrations of Ti in soils from Northern Europe combined with high anthropogenic erosion 318 rates, which generate larger amounts of nanoparticles $[14,46]$.

320 Looking at the three watersheds individually, some temporal trends for $\mathrm{NPs}-\mathrm{TiO}_{2}$ 321 concentrations are observed (Fig. 2). A seasonal variability is detected for stream water 322 samples taken in the forested and agricultural watersheds. In the forested catchment, NPs-

$323 \mathrm{TiO}_{2}$ concentrations increase from winter to spring, and then remain relatively constant. A 324 similar trend is observed for the agricultural catchment samples, but the highest 325 concentrations are measured in summer. These trends could be linked to supply-depletion 326 issues in the soils or the sediments. Under such situation, the highest PNC could be expected 327 during the rising stage of these small sub-basins $\left(<20 \mathrm{~km}^{2}\right)$ might have the highest PNC when 328 supply-depletion is minimal and dilution potential is small. This effect could be combined with 329 seasonal farming activities to affect the temporal distribution of the PNC for the agricultural 330 catchment.

332 In contrast, the PNC of the NPs-TiO 2 in the urban catchment are less variable (Fig. 2). Firstly, 333 because the larger area $\left(116 \mathrm{~km}^{2}\right)$ of this watershed could integrate the inputs of different 334 sources controlling the PNC throughout the year. Secondly, this larger stream would allow a 335 more efficient combination of different processes contributing to the stabilization of the PNC 336 values with time. Thirdly, a more diffuse source of $\mathrm{NPs}^{-\mathrm{TiO}_{2}}$ resulting from the constant wash337 off of $\mathrm{TiO}_{2}$ particles used in common exterior paints and plasters on facades could reach 338 surface waters via urban transport pathways [47-50]. It is worth noting that no correlations of $339 \mathrm{NP}-\mathrm{Ti}$ concentrations were found with meteorological conditions parameters (rainfall 340 amounts, wind speed, temperature, humidity, cloud cover from https://www.historique- 
341 meteo.net/france/ile-de-france/) during / before the sampling campaigns limiting our 342 understanding of the role played by those meteorological drivers (Table S8).

343

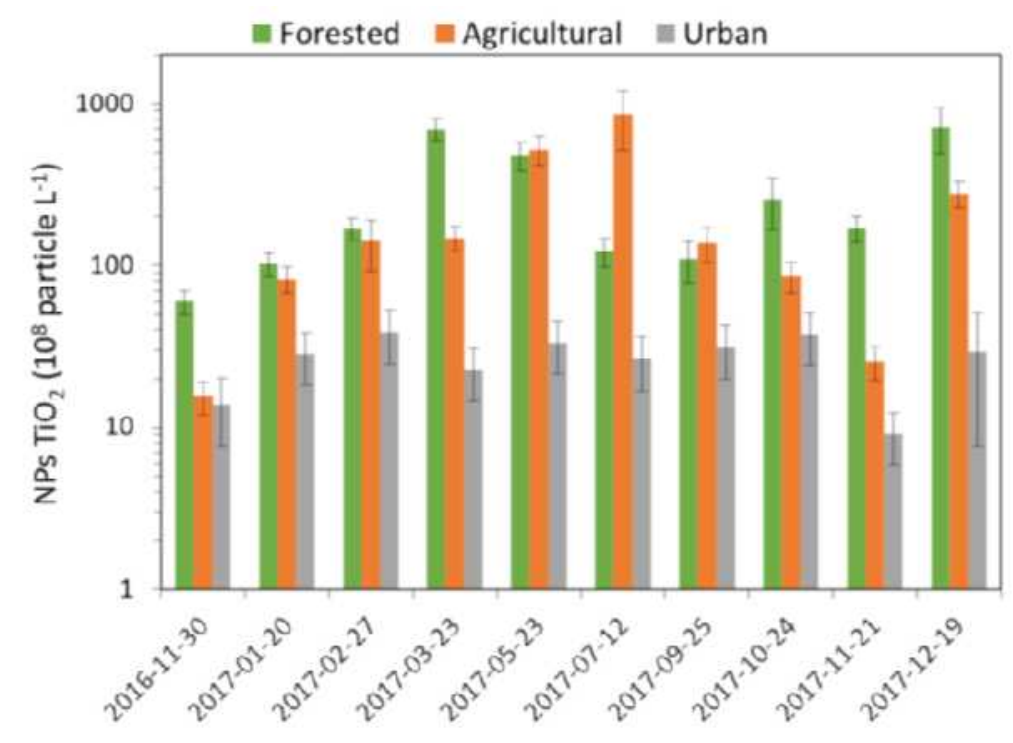

344

345 Figure 2: Particle number concentration (PNC) of $\mathrm{NPs}^{-\mathrm{TiO}_{2}}$ measured at the three sites during 346 one-year of sampling. Samples were taken once per month, except for three months which 347 are missing.

348

3493.3 Speciation and distribution of $\mathrm{Ti}$

350 The dissolved (fraction $<1 \mathrm{kDa}$ ) and total Ti after acid digestion were quantified by ICPMS and 351 their concentrations together with $\mathrm{NPs}^{-\mathrm{TiO}_{2}}$ are given in Table $\mathrm{S} 7$ and Fig. 3. The dissolved Ti 352 concentration ranges from 11 to $93 \mathrm{ng} \mathrm{Ti} \mathrm{L}^{-1}$ with an annual mean value of 35, 39 and $56 \mathrm{ng} \mathrm{Ti}$

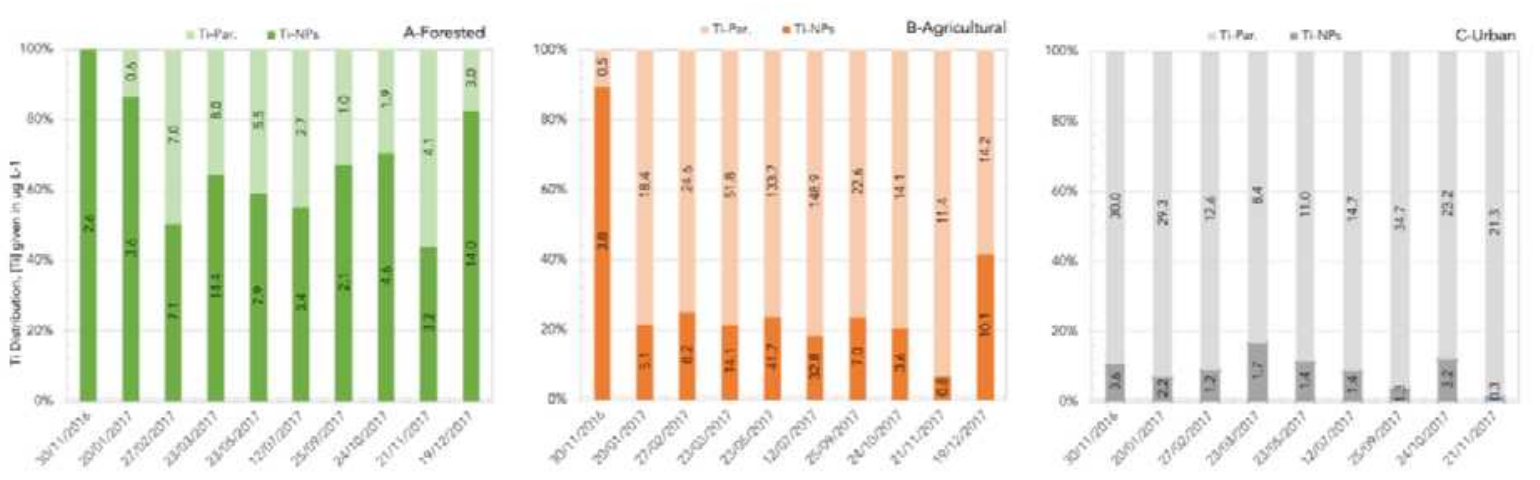


$353 \mathrm{~L}^{-1}$ for forested, agricultural and urban catchments, respectively. Using current 354 thermodynamic data [41] the calculated dissolved Ti concentrations are around $50 \mathrm{ng} \mathrm{Ti} \mathrm{L^{-1 }}$ 355 within the $\mathrm{pH}$ range of the stream water samples (Table 1), suggesting that solubility 356 equilibrium is reached in these stream waters. Other studies have reported higher 357 concentrations or [Ti] in $<1 \mathrm{kDa}$ fractions sampled in rural, agricultural and urban/industrial

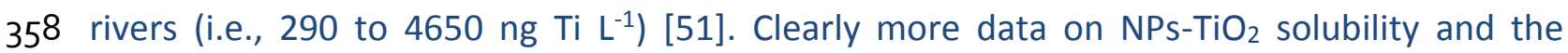
359 potential role of organic ligands that could increase Ti solubility are needed to better 360 understand both results. This dissolved fraction accounts on average for only $0.5 \%, 0.3 \%$ and $3610.3 \%$ of the total Ti measured in bulk water samples (i.e., after total mineralization) from the 362 forested, agricultural and urban catchments, respectively and these small values are not 363 displayed in Fig. 3.

364 Figure 3: Ti distribution (\%) of total Ti for two fractions i.e., the $\mathrm{NPs}^{-\mathrm{TiO}_{2}}$ fraction (Ti-NPs) and 365 large particles (Ti-Par) in three waters for one-year sampling, in which Ti-Par = Ti total - Ti NPs 366 - Ti dissolved with Ti dissolved less than $1 \%$ of tot. Panel A, B and C showing the data of the 367 forested, agricultural and urban watersheds, respectively. The numbers inserted in each bar 368 correspond to the mass concentration given in $\mu \mathrm{gTi} \mathrm{L}^{-1}$ of measured Ti-NPs and calculated Ti369 Par.

370

371 The total amount of Ti obtained by acid mineralization (Table S7), for the three watersheds,

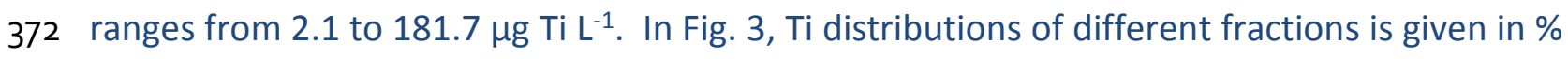
373 of total Ti. On average, the NPs-Ti fraction (obtained by spICP-MS) represents $70 \%, 30 \%$ and $3749 \%$ of the total Ti for the forested, agricultural and urban catchment samples, respectively. 375 Using the average concentration of Ti in suspended matter (SPM) (i.e. $2942 \mathrm{mg} \mathrm{kg}^{-1}$ SPM), and 376 the range of SPM content in the Seine river [29-31], the calculated Ti concentrations from 
377 suspended matter would range from 6 to $495 \mu \mathrm{g} \mathrm{Ti} \mathrm{L-1}$, showing that there is clearly a large

378 reservoir of $\mathrm{Ti}$ in the SPM, in the range of the measured Ti-Par fraction (Fig.3). These results

379 are different from previous findings [51] showing that $79 \%$ of $\mathrm{Ti}$ is colloidal for rural areas and

$38028 \%$ for urban rivers, then again, in [51] authors focused on the filterable fraction and not on

381 the total Ti that includes particulate $\mathrm{Ti}$ and $\mathrm{NPs}^{-\mathrm{TiO}_{2}}$ [51]. The filtration cut-off (i.e., $<0.45 \mu \mathrm{m}$ )

382 most probably stopped a large part of the NPs-TiO 2 [8], as in the case of Ag NPs $[23,25]$. The

383 difference between the sp-ICPMS measure of $\mathrm{Ti}$ mass concentration and the total $\mathrm{Ti}$

384 concentration (illustrated in Fig. 3) also shows that a large amount of $\mathrm{Ti}$ is not detected by sp-

385 ICPMS and is likely present in the form of larger homo or hetero aggregates that cannot be

386 detected or quantified by this technique.

387

388 Assuming that the Ti detected in the NPs is present as $\mathrm{TiO}_{2}$, an equivalent spherical $\mathrm{TiO}_{2}$ 389 diameter can be calculated using the bulk density of $\mathrm{TiO}_{2}\left(4.23 \mathrm{~g} \mathrm{~cm}^{-3}\right)$. In Fig. 4, we can see 390 that the average size of the $\mathrm{TiO}_{2}$-NPs is smaller than the previously reported literature values $391[21,24,26,42]$. This result may indicate that particle size may vary regionally. However, we 392 believe that the data treatment (subtraction method) has a greater effect on the particle size 393 distribution calculation. Some investigators use manufacturers' software $[21,42]$ but the 394 corrections applied to estimate the background may differ even with the same software $395[21,42]$ preventing direct comparison. Others use home-made spreadsheets or software $396[17,22,25]$ with no general consensus as to how to assign a size cut-off $(3 \sigma, 5 \sigma$, frequency 397 histogram subtraction). Another reason for the discrepancy is the sample pre-treatment 398 before sp-ICPMS analysis and deviation mays also arise because particles are not spherical 399 [17]. Some publications use sonication but with different frequencies and duration that again 400 prevent direct comparisons $(26,42)$, others researchers have also not sonicated the sample 
401 while others use complex extraction protocols [24] and some even use pre-filtration [26]. This

402 means that the community of scientists using sp-ICPMS should reach a consensus on how to 403 treat the samples and the data or at least to have a common protocol to test their data 404 treatment that will allow intercomparison between publications.

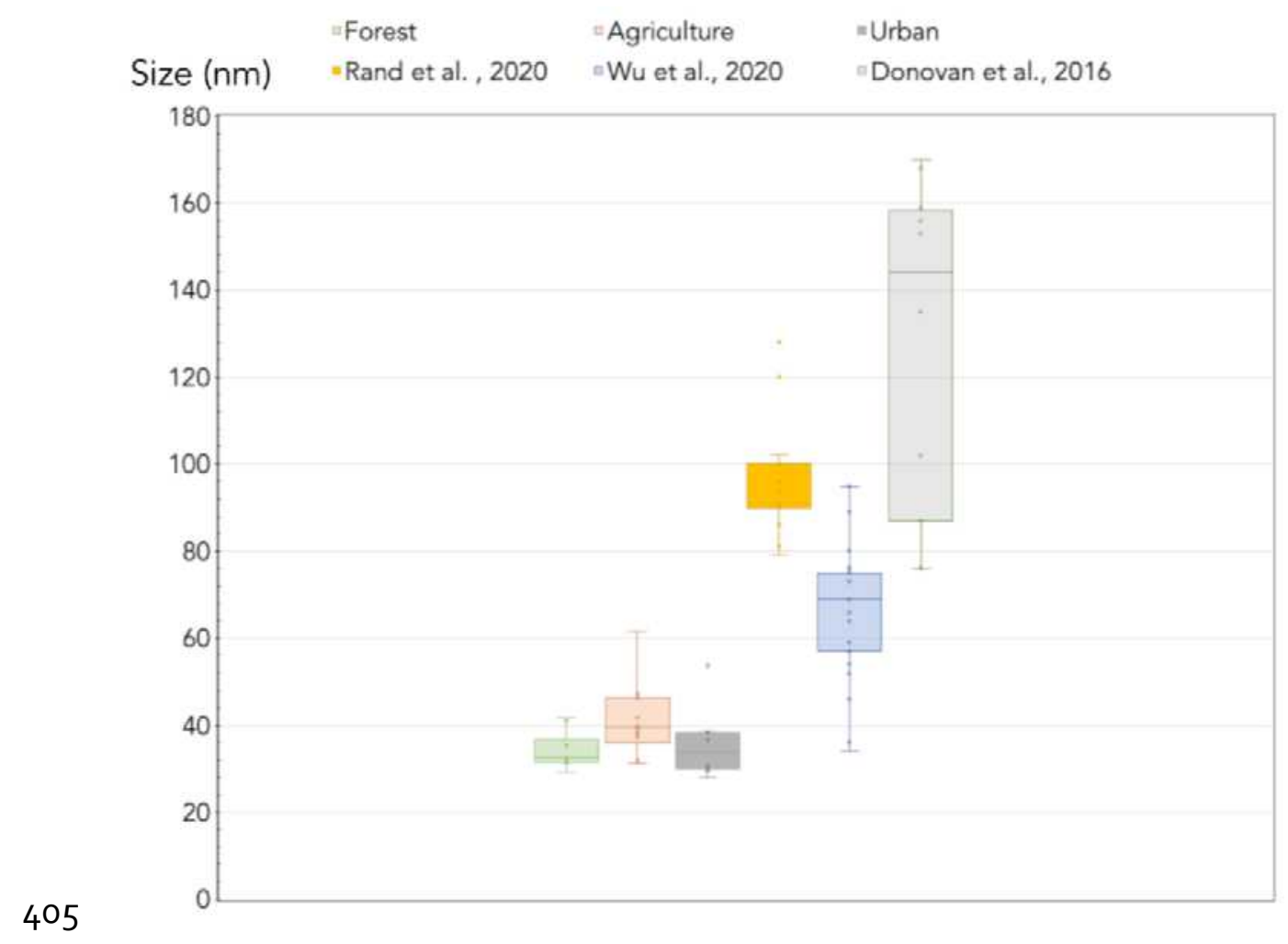

406 Figure 4: Calculated diameters of the $\mathrm{TiO}_{2}-\mathrm{NPs}$ detected by sp-ICPMS and comparison with 407 recently published data (see supplementary section for detailed size calculation procedure). 408 [21]: Donovan et al., 2016; [26]: Wu et al., 2020; [42]: Rand et al., 2020.

409

$410 \quad 3.4$ Ti-bearing particles by SEM-EDX analysis

411 The SEM imaging and EDX analyses were performed to qualitatively confirm the presence of 412 the NPs-TiO 2 detected by sp-ICPMS and to characterize their size, morphology, and elemental 413 composition. The observed particles differ in shape and size (Fig. 5 and Fig. S9), ranging from 414 nanoscale up to several micrometres, in the form of either individual particles or hetero415 aggregates/agglomerates in agreement with the data of Fig. 4. Moreover, most detected 
416 particles are found associated with other elements, such as Al, Si, K, Ca, Fe. Their coexistence

417 with Ti reveals that they are most probably naturally occurring particles, derived from ilmenite $418\left(\mathrm{FeTiO}_{3}\right)$ and clay minerals [52]. These observations are in agreement the results given in Fig. 4193 showing that a large part of $\mathrm{Ti}$ is not present as $\mathrm{NPs}^{-\mathrm{TiO}_{2}}$ but as larger objects. A recent study 420 proposed that the morphology of $\mathrm{TiO}_{2}$ particles and their status in unperturbed mineral421 organic assemblages may provide insights on their source [53]. Our observations (Fig. 5 and 422 Fig. S9) are not sufficient to come to the same conclusion. Moreover, observations could be 423 undermined by sample storage as stated in [53]. Our findings are, however, similar to the ones 424 reported for pure and Ti rich hetero-aggregates [24,26,42].

426 Although SEM-EDX cannot provide a quantitative measurement of Ti speciation, a few pure $427 \mathrm{TiO}_{2}$ nanoparticles, that could correspond to en- $\mathrm{TiO}_{2}$ as identified by [24], were detected 428 suggesting but not confirming some anthropogenic origin. In addition, these images can help 429 us to understand why sp-ICPMS failed to detect larger aggregates. Indeed, during the 430 nebulization step, a size fractionation could occur sending the largest particles $(>5 \mu \mathrm{m})$ to the 431 drain [54]. The ionization efficiency of a single $\mathrm{NPs}^{-\mathrm{TiO}_{2}}$ would also not be the same as that of 432 the same NPs- $\mathrm{TiO}_{2}$ imbedded in a much larger hetero-aggregate composed of oxides and clays 433 and organic matter. To our knowledge no one has examined those effects for sp-ICPMS 434 measurements. 

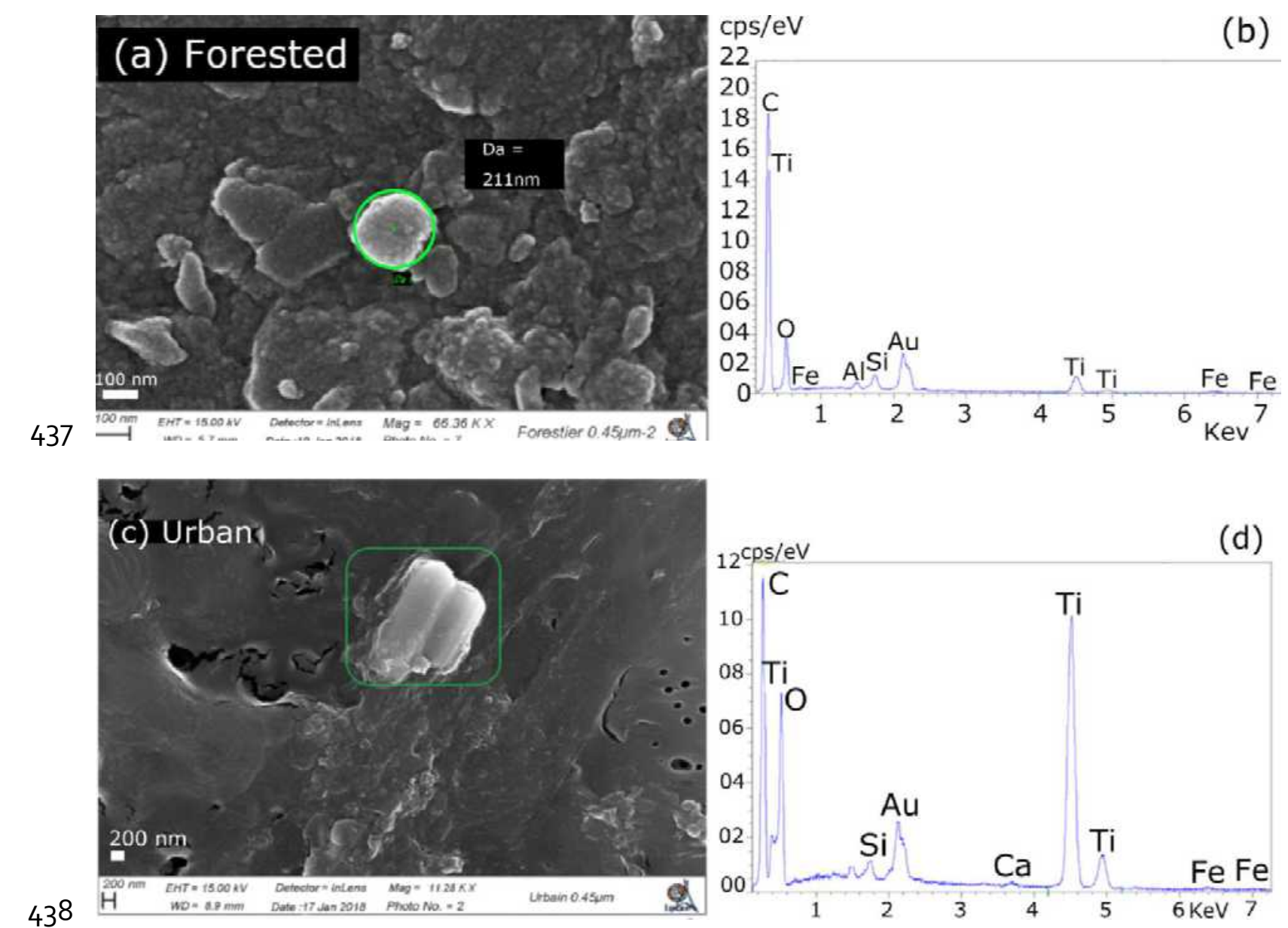

439 Figure 5: Left: SEM images of filters retaining suspended particles containing $\mathrm{TiO}_{2}$, with

440 different shapes, present in sampled waters. Panels (a) and (c) showing a sample from the

441 forested and urban watersheds, respectively. Right: Panel (b) and (d) showing the EDX analysis

442 of corresponding particles highlighted by the green circle in panel (a) and the green square in

443 panel (c).

444

445 Keeping in mind the limitation of the above approaches our observations raise a series of 446 questions. Why do the agricultural and forested samples have much higher $\mathrm{NPs}^{-\mathrm{TiO}_{2}}$

447 concentrations (both PNC and mass concentration) than the urban watershed samples? Is this

448 difference due to source and/or related watershed processes related to one another? Can we

449 estimate land-use specific export rates using the present data set? 
4513.5 Biogeochemical factors controlling $\mathrm{NPs}^{-\mathrm{TiO}_{2}}$ in three watersheds.

452 Correlation between elements and $\mathrm{NPs}^{-} \mathrm{TiO}_{2}$ concentrations (i.e., number or mass) can be 453 interpreted within a mass balance approach or used to identify driving parameters or 454 processes for small watersheds [55]. It should be noted that the correlation coefficient $r$, 455 together with $p$-value are evaluated. With $r \geq 0.77$ and $p$-value $\leq 0.05$ significant at the $95 \%$ 456 confidence level, the correlation is considered statistically significant [56]. In addition, the 457 absence of correlations between the NPs- $\mathrm{TiO}_{2} \mathrm{PNC}$, mass concentration, any other metal ions 458 and anions, especially chloride ions, suggests that dilution is not responsible for the trends 459 that are subsequently discussed. In fact, if $\mathrm{NPs}^{-\mathrm{TiO}_{2}}$ concentrations were a result of varying 460 degrees of dilution of the soil water entering the streams, background electrolytes (i.e. $\mathrm{Cl}^{-}$) 461 concentrations would likely covary. No such covariation or correlation was observed.

462

463 Our previous study on the same watersheds demonstrated a strong positive correlation 464 between DOC concentrations and silver nanoparticles concentration (i.e. [Ag-NPs]) reflecting 465 the control of the dissolved organic matter (DOM) on the number and mass concentration of 466 Ag-NPs [25]. The more DOM, the more Ag-NPs were detected, although this occurs mainly in 467 the forested water samples.

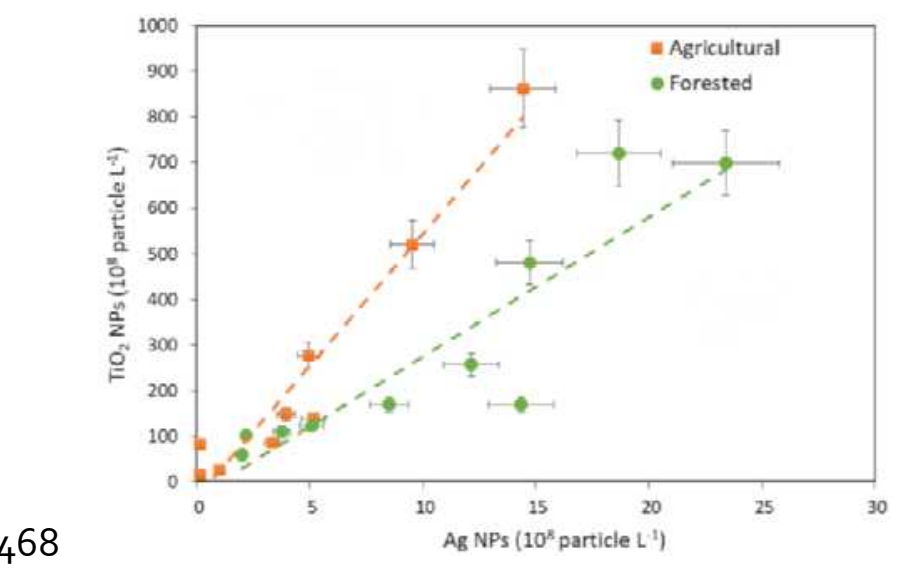


469 Figure 6: Particle number concentration (PNC) of $\mathrm{NPs}^{-\mathrm{TiO}_{2}}$ as function of that of $\mathrm{Ag} \mathrm{NPs}$ in

470 agricultural and forested watersheds. Ag-NPs concentrations are from [25]. The correlation

471 coefficients $r$ corresponding to Agricultural orange and Forested green broken lines are equal to $r_{\text {Agricultural }}=0.96$

472 and $r_{\text {forested }}=0.89$. Their corresponding $p$ value are equal to 0.00003 and 0.0004 for a sampling size $\mathrm{n}=9$ and 10 ,

473 respectively.

474

475 Positive correlations with $r \geq 0.89$ are observed between the Ag-NPs PNC and the NPs-TiO 2

476 PNC for the agricultural and forested catchments (Fig. 6). Consistently, for the forest water 477 samples, a strong positive correlation $(r=0.91)$ between $\mathrm{NPs}^{-\mathrm{TiO}_{2}}$ and $\mathrm{DOC}$ concentrations is 478 observed (Fig. 7). Like for silver [25], it would be evidence of dynamic control of DOM on NPs$479 \mathrm{TiO}_{2}$ in this watershed. The stabilization effect of DOM mainly accounts for this trend and it 480 has been reported in simplified and relevant freshwater matrix [57-60]. DOM can suppress 481 the dissolution/aggregation processes by electrostatic repulsion, steric stabilization and 482 hydrophobic interaction. This could also explain the high fraction of total Ti (i.e. $70 \%$ ) detected 483 as $\mathrm{NPs}^{-\mathrm{TiO}_{2}}$ in the forested catchment. This can cannot be explained by dilution because if the 484 range in $\mathrm{NP}-\mathrm{TiO}_{2}$ concentration was the result of varying degrees of dilution of the soil water 485 entering the streams, variations in background electrolytes (i.e. $\mathrm{Cl}^{-}$) would likely covary. In 486 addition, it cannot be explained by the effect of any metrological drivers that would lead to 487 high runoff of all constituent from soils including organic matter and its associated NPs-TiO 2 $488[25]$. 


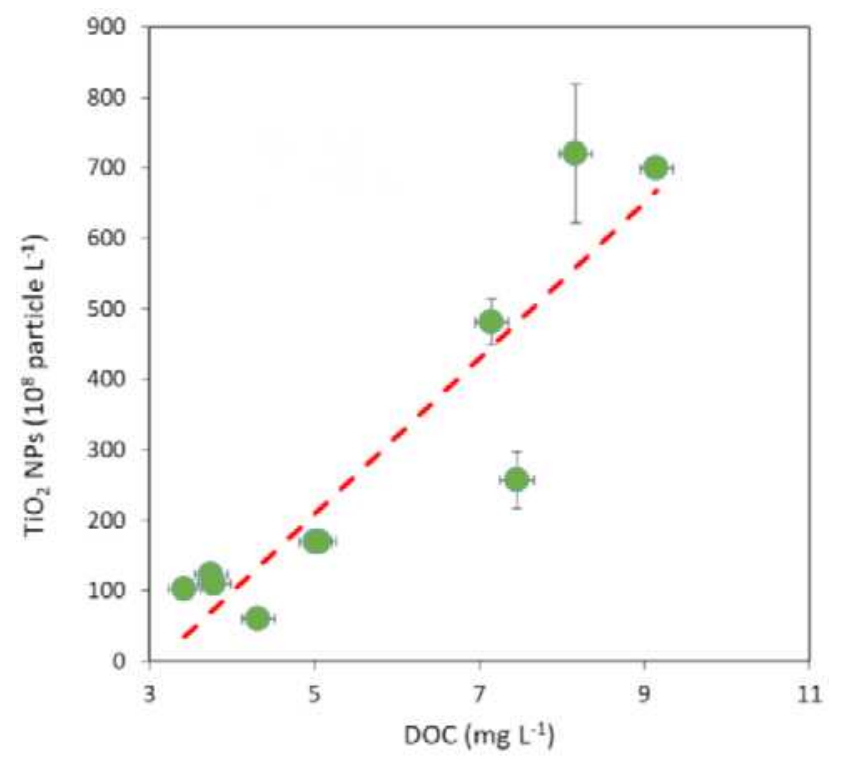

489

490 Figure 7: Mass concentration of $\mathrm{NPs}^{-\mathrm{TiO}_{2}}$ as function of $\mathrm{DOC}$ concentration in water samples

491 from the forested watershed. The correlation coefficient $r$ corresponding to the orange broken line is equal

492 to $r=0.91$ and it corresponds to a $p$ value equal to 0.0002 and a sampling size $n=9$

493

494 There is no obvious trend in $\mathrm{NP}^{-\mathrm{TiO}_{2}}$ concentration with $\mathrm{DOC}$ for the agricultural stream 495 samples. Other factors, such as ionic strength, may also partly control the fate of the NPs- $\mathrm{TiO}_{2}$ 496 in this watershed. A negative trend between $\mathrm{NPs}^{-\mathrm{TiO}_{2}}$ and conductivity $(r=0.77)$ (Fig. S7) is 497 reported. A higher ionic strength and higher divalent cations concentrations favour the 498 aggregation/flocculation of $\mathrm{NPs}_{-} \mathrm{TiO}_{2}[58,61-62]$. The decreasing $\mathrm{NPs}-\mathrm{TiO}_{2}$ concentration 499 therefore most likely results from the enhanced aggregation by the increasing IS and divalent 500 cations concentrations. Such effect of IS on aggregation is associated with the compression of 501 the diffuse layer and decreasing of surface charge [62]. Under the field pH range, NPs-TiO 2 502 should have a negative charge according to their Point of Zero Charge (i.e., 6.5 or 4.5 for 503 anatase or rutile, respectively), the presence of higher divalent cations electrostatically bound 504 to the negatively charged $\mathrm{NP}_{-} \mathrm{TiO}_{2}$ would favour an increase (i.e. going from negative values 505 to less negative ones or even positive values) in zeta potential of the NPs- $\mathrm{TiO}_{2}[63]$. 
507 In urban stream samples, since DOC, IS and cations concentrations barely vary, there is no 508 clear relationship between the $\mathrm{NPs}_{-} \mathrm{TiO}_{2} \mathrm{PNC}$ or mass concentration associated with these 509 factors. Moreover, the fraction of Total Ti under the form of $\mathrm{NPs}^{-\mathrm{TiO}_{2}}$ is very small $(9 \%)$, it is 510 therefore difficult to discuss processes affecting the $\mathrm{NPs}^{-\mathrm{TiO}_{2}}$ even if the SEM images clearly 511 show that part of the total Ti is in the form of aggregates of smaller objects (Fig. 5, Fig. S9). 512 Caution must be taken when interpreting the observations made by SEM-EDX on filtered 513 samples since the observed aggregates could be artefacts caused by filtration. Large objects 514 above $100 \mathrm{~nm}$ are however observed (Fig. 5, Fig. S9) and will be part of the total Ti pool. 515 Remarkably, the average percentage of the total $\mathrm{Ti}$ under the form of $\mathrm{NPs}-\mathrm{TiO}_{2}$ for each 516 watershed is negatively correlated $(r=0.98)$ to the average conductivity measured for each 517 watershed (Table S7) suggesting that similar processes are at work in the three watersheds 518 favouring their transfer in the particulate fraction by aggregation of smaller $\mathrm{NPs}^{-\mathrm{TiO}_{2}}$ with 519 other colloids such as clays or organic matter [64-67].

521 In addition to process indicators discussed above, the correlation between $\mathrm{NPs}^{-} \mathrm{TiO}_{2}$ and other 522 elements can be used to identify the potential sources of $\mathrm{NPs}_{-} \mathrm{TiO}_{2}$. First, the global Seine river 523 watershed has a long historical record of pollution lasting from more than 300 centuries $524[68,69]$. Speleothems in Paris record the historical pollution of $\mathrm{Pb}, \mathrm{V}, \mathrm{Cu}, \mathrm{Cd}$ due to the 525 increased urbanization of Paris mega city [68]. In the Orge river catchment (close to the 526 studied catchments), with a contrasted land-use pattern (forested, agricultural and urban 527 areas), trace elements ( $\mathrm{Pb}, \mathrm{Zn}, \mathrm{Cu}$ and $\mathrm{Sb}$ ) concentrations are drastically elevated in the SPM 528 fraction due to urbanization of the catchment, as urban run-off and sewage strongly influence 529 the river geochemistry $[69,70]$. The main sources of the pollution in the catchment are: 

atmospheric emissions due to individual and industrial combustion release, erosion of run-off

531 of urban surfaces (building walls, roofs, roads) and remobilization of historical deposits by

532 resuspension of bottom sediments [70,71]. A previous study, concluded that $\mathrm{Cu}, \mathrm{Pb}, \mathrm{Sb}$ and

533 Zn were urban trace elements, while $\mathrm{Cr}$, Co and Ni were more closely related to alumino-

534 silicates sources [70].

535 The influence of pollution affecting the geochemistry and the total content of elements in the

536 collected stream samples can be assessed by calculating the annual average enrichment factor

537 (EF) $[72,73]$.

538 One reference material was used in this study, a Seine riverbed sediment (SRBS) collected N $53948^{\circ} 24^{\prime} 39^{\prime \prime}, \mathrm{E}^{\circ} 24^{\prime} 05^{\prime \prime}$ at Fontaine, France [73] before the river enters the anthropogenically 540 impacted area of the Région île de France including Paris mega city where the studied

541 watersheds are located (Fig. 1). EF[Me] values are given in Table 4 for $\mathrm{Cd}, \mathrm{Pb}, \mathrm{Ni}, \mathrm{Cu}, \mathrm{Zn}, \mathrm{Sb}$ 542 and As. The urban catchment samples are the only ones that have significant EF values

543 indicating contamination (i.e. EF > 2 [74]) for all elements, even Ni which was associated more 544 closely related to alumino-silicates rather than urbanization [70]. However, a part of the 545 watershed is covered by agricultural activities that could account for an EF[Ni] $>2$ because of 546 increased soil erosion due to agricultural practices [1] (Fig. 1). This means that on average for 547 the forested and agricultural sites the influence of anthropogenic activities is not seen even if 548 sewage sludge is dispersed on the soils because of a higher natural background signal. This

549 conclusion would also stand for the $\mathrm{NPs}^{-\mathrm{TiO}_{2}}$ (including en- $\mathrm{TiO}_{2}$ ) introduced by biosolids that 550 are used for agriculture [75].

551

552 Table 4: Average enrichment factor (EF) of selected elements in three small catchments 553 normalized to suspended matter particles (SRSM) of Seine River. 
554

\begin{tabular}{lccccccc}
\hline & $\mathrm{Cd}$ & $\mathrm{Pb}$ & $\mathrm{Ni}$ & $\mathrm{Cu}$ & $\mathrm{Zn}$ & $\mathrm{Sb}$ & As \\
\hline Forested & 2.0 & 0.3 & 2.5 & 1.0 & 0.9 & 2.2 & 2.4 \\
\hline Agricultural & 1.5 & 0.9 & 1.6 & 1.8 & 0.7 & 4.8 & 4.2 \\
\hline Urban & 6 & 6 & 8 & 11 & 20 & 40 & 8
\end{tabular}

555

556

557 Another mean of tracking the source of the $\mathrm{NPs}^{-\mathrm{TiO}_{2}}$ is to look for correlations between NPs-

$558 \mathrm{TiO}_{2}$ concentration and bulk content of elements linked to natural or anthropogenic sources.

559 This is valid especially in the case of the forested and agricultural watersheds samples since $560 \mathrm{NPs}-\mathrm{TiO}_{2}$ account for $70 \%$ and $30 \%$ of the total Ti on average, respectively.

561 


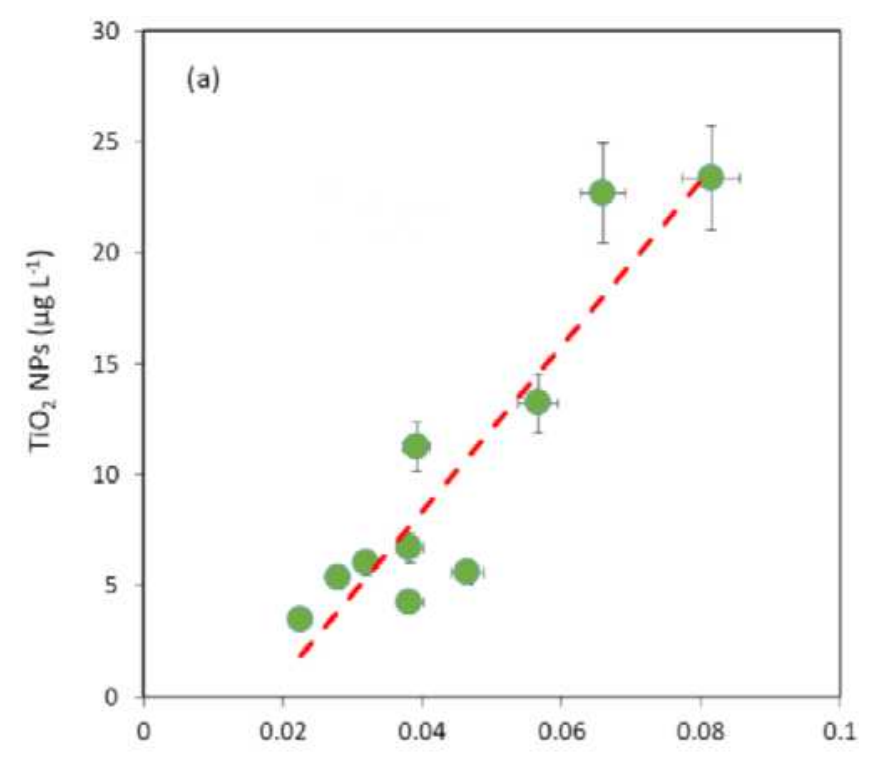

562

[Sb] $\left(\mu \mathrm{g} \mathrm{L}{ }^{-1}\right)$

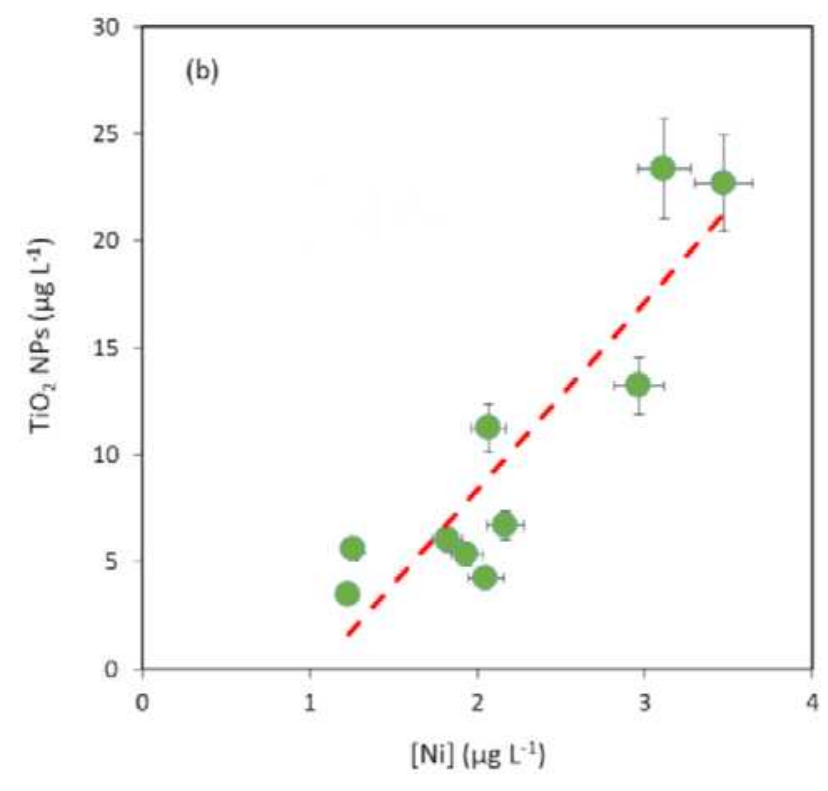

564

565 Figure 8: Mass concentration of $\mathrm{TiO}_{2} \mathrm{NPs}$ as function as that (bulk minus dissolved) of (a) $\mathrm{Sb}$

566 and (b) Ni in forested water. The correlation coefficients $r$ corresponding to the orange broken line are

567 equal to $r=0.91$ and $r=0.89$ in panel (a) and (b), respectively. They correspond to a $p$ value equal to 0.0002 and 5680.0005 with a sampling size $n=10$.

569

570 In Fig. 8, strong correlations are observed between $\mathrm{NPs}^{-\mathrm{TiO}_{2}}$ and $\mathrm{Sb}$ and $\mathrm{Ni}$ for the forested 571 catchment samples. Lepape et al. [70] concluded that $\mathrm{Ni}$ is more closely related to alumino- 
572 silicates sources: this could mean that our correlation is pointing towards a natural source for

573 the $\mathrm{NPs}-\mathrm{TiO}_{2}$ in this watershed. The other explanation, suggested by the correlation with $\mathrm{Sb}$

574 (Fig 8a) is that a similar process controls the fate of both elements and the $\mathrm{NPs}^{-\mathrm{TiO}_{2}}$. Here

575 organic matter binding for Sb [75-77] or stabilization of natural clays for $\mathrm{Ni}$ are realistic

576 processes that would generate such trends since a very strong correlation is seen with NPs-

$577 \mathrm{TiO}_{2}$ and $\mathrm{DOC}$ (Fig. 7).

578

579 In the case of the agricultural catchment samples the correlation is strong with $\mathrm{As}, \mathrm{Zn}$ and $\mathrm{Ni}$ 580 (Fig. S8)

581 Only Sb and As have an EF > 2 which could be related to inputs by an external source like 582 biosolid application. These trends cannot be explained by dilution, no correlation with $\mathrm{Cl}^{-}$ions 583 is found [25], or with metrological drivers that would lead to high runoff of all constituent 584 from soils including trace metal pollutants and the associated $\mathrm{NPs}^{-\mathrm{TiO}_{2}}$ [78] it is most probably 585 the erosion controlled by agricultural processes $[46,78]$ that accounts for the release of NPs$586 \mathrm{TiO}_{2}$.

587

588 When it comes to urban stream water samples, no clear correlations, between $\mathrm{NPs}^{-\mathrm{TiO}_{2} \text { and }}$ 589 elements from anthropogenic origin, are seen. The small amount of total Ti in the form of NPs$590 \mathrm{TiO}_{2}$ explains this lack of correlation. This smaller contribution of the $\mathrm{NPs}-\mathrm{TiO}_{2}$ pool to the bulk $591 \mathrm{Ti}$ could be the consequence of the instability of the $\mathrm{NPs}-\mathrm{TiO}_{2}$ aggregates from different 592 sources as well as the variability of hydrological factors along the flow as $\mathrm{NPs}^{-\mathrm{TiO}_{2}}$ are 593 transported downstream of effluent sources $[51,65,66]$. Despite the difficulty in identifying all 594 potential sources (natural vs anthropogenic contamination for all three watersheds), the 595 effect of land-use can be addressed by calculating the normalized fluxes that can be obtained 
by integrating the monthly river discharge volume of each sampling period and the respective

597 watersheds areas.

598

599 3.6 Exportation flux of $\mathrm{TiO}_{2}$ from each watershed

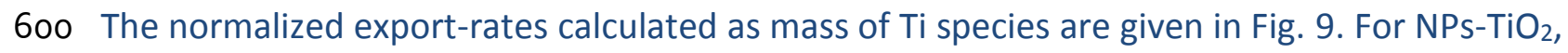

601 the agricultural watershed has the highest average value equal to $0.8 \mathrm{~kg} \mathrm{Ti} \mathrm{year}^{-1} \mathrm{~km}^{-2}$, with a

602 significant temporal variability. Forested and urban catchments have similar export-rates,

603 which are respectively 0.3 and $0.4 \mathrm{~kg} \mathrm{Ti}_{\text {year-1 }} \mathrm{km}^{-2}$. When compared to our calculated

604 normalized export rates for the ljssel and Meuse rivers, $10.9 \mathrm{~kg} \mathrm{Ti} \mathrm{year-1}^{-1} \mathrm{~km}^{-2} \mathrm{and} 0.8 \mathrm{~kg}$ Ti year-

$605{ }^{1} \mathrm{~km}^{-2}$, respectively, we are in the same range and closer to the one obtained for the Meuse

606 river. Interestingly, the ljssel watershed is characterized by intensive agricultural practices

607 with croplands covering $70 \%$ of the basin and has the highest normalized export-rate of NPs-

$608 \mathrm{TiO}_{2}$, much like our much smaller agricultural watershed [28]. These results clearly show that

609 agricultural practices have a different impact on $\mathrm{NPs}^{-\mathrm{TiO}_{2}}$ export than the other land-use types

610 either because of specific processes occurring in the watershed or specific sources associated

611 with fertilizer use or application of biosolids. It was demonstrated, for instance in the Meuse

612 River [27], that soil erosion by agricultural management practices favoured the transfer of

613 terrestrial organic matter and therefore associated $\mathrm{NPs}^{-\mathrm{TiO}_{2}}$ via the suspended particulate

614 matter.

615
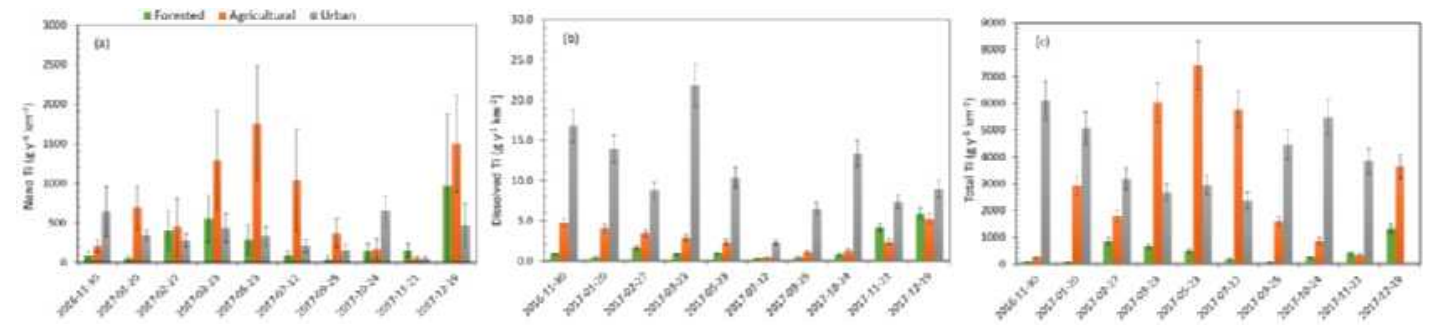

616 
617 Figure 9: Export-rate of (a) nanoparticulate (b) dissolved $<1 \mathrm{kDa}$ (c) total Ti detected in three

618 waters along the sampling year.

619

620 For dissolved $\mathrm{Ti}$, the urban stream has a higher average export rate equal to $11.0 \mathrm{~g} \mathrm{Ti}$ year ${ }^{-1}$

$621 \mathrm{~km}^{-2}$ than forested and agricultural stream with respective export rates equal to 1.6 and $2.8 \mathrm{~g}$

$622 \mathrm{Ti}$ year ${ }^{-1} \mathrm{~km}^{-2}$. The same trend is calculated for total Ti export, equal to $4.0,3.0$ and $0.4 \mathrm{~kg} \mathrm{Ti}$

623 year $^{-1} \mathrm{~km}^{-2}$ for urban, agricultural and forested streams, respectively. If we look at the

624 calculated export rates along the year of sampling, the forested and agricultural watersheds

625 clearly show a similar temporal variation with high export fluxes for the $\mathrm{NPs}^{-\mathrm{TiO}_{2}}$ in the

626 warmer months while the highest export rates are observed in the cold months for the

627 dissolved fraction (Fig. 9). This could be due to the much smaller size of those two watersheds,

628 which therefore have a much higher reactivity under changing meteorological or hydrological

629 conditions. In the warmer months the NPs concentration would increase due to lower water

630 flow but increased management practices (agriculture or forestry). No clear trend is observed

631 for the urban watershed with meteorological or hydrological stages. It suggests that in this

632 larger catchment sources and processes affecting $\mathrm{Ti}$ in general are more complex and that the

633 variability of hydrological factors along the flow modifies them downstream of effluent

634 sources.

635

636 These output fluxes can be compared to estimated output of Ti. For instance, for France

637 annual soil loss by erosion on arable land is equal to 200 tons of soil year-1 $\mathrm{km}^{-2}$ [46]. This

638 corresponds to an output flux of $628 \mathrm{~kg} \mathrm{Ti} \mathrm{year}^{-1} \mathrm{~km}^{-2}$ using an average concentration of Ti in

639 agricultural soils in France equal to $3.11 \mathrm{~g} \mathrm{Ti} \mathrm{kg}^{-1}$ [14]. The present estimations demonstrate

640 that most part of outgoing fluxes are not in the form of $\mathrm{NPs}^{-\mathrm{TiO}_{2}}$ but rather in the form of 
641 larger particulate (i.e. > $100 \mathrm{~nm}$ ) or homo or hetero-aggregates, as seen in this work (Fig. 5)

642 and previous studies [24,53].

\section{3}

\section{Conclusions}

$645 \mathrm{NPs}^{-\mathrm{TiO}_{2}}$ have been identified in creek waters from three small sub-basins. The highest

646 concentrations occurred in forested and agricultural catchments. For the former, it is mostly

647 due to the high natural background, biogeochemical activity, and conditions that favours

648 stable NP-TiO 2 . For agricultural watershed, it is likely related to seasonal farming practices and

649 erosion controlling $\mathrm{TiO}_{2}$ from natural sources mostly. Moreover, environmental processes

650 controlled by DOC, IS, and divalent cations have been identified in real-world natural systems,

651 suggesting the complexity of the fate of $\mathrm{NPs}^{-\mathrm{TiO}_{2}}$ in aquatic systems influenced by diffuse

652 sources, like in the urban catchment. A similar process and fate of other engineered

653 nanoparticles could be expected since $\mathrm{TiO}_{2}$ can potentially serve as sentinel because of its

654 long-history and large commercial use. Regarding the unexpected lower concentration of NPs$655 \mathrm{TiO}_{2}$ present in urban water, it's very likely related to the 656 aggregation/flocculation/sedimentation that can help large particles/aggregates to be

657 removed from the surface water layer that was sampled in this study, resulting in short 658 residence time of discharged $\mathrm{NPs}^{-\mathrm{TiO}_{2}}$. Additionally, microscopy imaging confirmed the 659 presence of NPs in the three catchments. Furthermore, the land-area normalized annual flux 660 of $\mathrm{NPs}^{-\mathrm{TiO}_{2}}\left(1.65 \mathrm{~kg} \mathrm{TiO}_{2}\right.$ year $\left.^{-1} \mathrm{~km}^{-2}\right)$ was highest for the agricultural catchment, suggesting

661 that agricultural practices have a different impact on the $\mathrm{NPs}^{-\mathrm{TiO}_{2}}$ dynamics and exports than

662 other land-uses (urban or forestry). A similar trend is also found by the reanalysis of recent 663 literature data.

\section{4}


665 In the future anthropogenic nanoparticles will be continuously produced, distributed and rival

666 the amount of naturally occurring nanoparticles. Therefore, further studies and measurement

667 of $\mathrm{NPs}_{-} \mathrm{TiO}_{2}$ need to be performed in suspended matter, sediments and soils to better

668 characterize their origin and fate. Given that the introduction of nanotechnology-derived NPs

669 is a more recent event that natural NPs, the issue of anthropogenic nanoparticles in natural

670 system is more likely dynamic. New survey with state the art techniques like TOF-sp-ICPMS,

671 which provides a multiple element analysis for each NPs, will allow a better understanding

672 their impacts and fate on longer time scales.

673

674 Acknowledgements

675 This project has been supported by lle de France Region through the DIM Analytics program

676 (Convention ESPCI-RVT-IPGP-N²015-3). Part of this work was supported by grants from

677 Région Ile-de-France R2DS and PIREN Seine programs. Parts of this work were supported by

678 IPGP multidisciplinary program PARI, and by Paris-IdF region SESAME Grant no. 12015908.

679 This study contributes to the IdEx Université de Paris ANR-18-IDEX-0001. Professor Jim

680 Ranville is greatly acknowledged for proof reading the English but mostly for very helpful 681 editorial suggestion to improve the present article.

682 
684 References

6851 Sen, I.S., Peucker-Ehrenbrink, B., 2012. Anthropogenic disturbance of element cycles 686 at the earth's surface. Environ. Sci. Technol., 46, 8601-8609.

687 https://doi.org/10.1021/es301261x

688

6892 Sang, L., Zhao, Y., Burda, C., 2014. TiO2 Nanoparticles as Functional Building Blocks. 690 Chem. Rev. 114, 9283-9318. https://doi.org/10.1021/cr400629p

691

6923 Jankovic, N., Plata, D. 2019. Engineered nanomaterials in the context of global element 693 cycles. Environ. Sci. nano. 6, 2697. https://doi.org/10.1039/c9en00322c

694

6954 Sun, T.Y., Bornhöft, N.A., Hungerbühler, K., Nowack, B., 2016. Dynamic Probabilistic 696 Modeling of Environmental Emissions of Engineered Nanomaterials. Environ. Sci. Technol. 50, 697 4701-4711. https://doi.org/10.1021/acs.est.5b05828

698

6995 Picciono, F., Gottschalk, F., Segger, S., Nowack, B. 2012. Industrial production 700 quantities and uses of ten engineered nanomaterials in Europe and the world. J. Nanopart. 701 Res. 14, 1109-1120. https://doi.org/10.1007/s11051-012-1109-9

702

7036 Kaegi, R., Boller, M., 2008. Synthetic TiO2 nanoparticle emission from exterior facades 704 into the aquatic environment. Environ. Pollut. 156, 233-239. 705 https://doi.org/10.1016/j.envpol.2008.08.004 706 
7077 Windler, L., Lorenz, C., Von Goetz, N., Hungerbühler, K., Amberg, M., Heuberger, M., 708 Nowack, B., 2012. Release of titanium dioxide from textiles during washing. Environ. Sci. 709 Technol. 46, 8181-8188. https://doi.org/10.1021/es301633b

710

7118 Gondikas, A.P., Von Der Kammer, F., Reed, R.B., Wagner, S., Ranville, J.F., Hofmann, T., 712 2014. Release of TiO2 nanoparticles from sunscreens into surface waters: A one-year survey 713 at the old danube recreational lake. Environ. Sci. Technol. 48, 5415-5422. 714 https://doi.org/10.1021/es405596y

715

7169 Kaegi, R., Englert, A., Burkhardt, M., 2017. Release of $\mathrm{TiO}_{2}$ - (Nano) particles from 717 construction and demolition landfill. Nanolmpact 8, 73-79. 718 https://doi.org/10.1016/j.impact.2017.07.004

719

72010 Weir, A., Westerhoff, P., Fabricius, L., Hristovski, K., Von Goetz, N., 2012. Titanium 721 dioxide nanoparticles in food and personal care products. Environ. Sci. Technol. 46, 2242722 2250. https://doi.org/10.1021/es204168d

723

72411 Kiser, M.A., Westerhoff, P., Benn, T., Wang, Y., Pérez-Rivera, J., Hristovski, K., 2009. 725 Titanium nanomaterial removal and release from wastewater treatment plants. Environ. Sci. 726 Technol. 43, 6757-6763. https://doi.org/10.1021/es901102n

727

72812 Polesel, F., Farkas, J., Kjos, M., Almeida Carvalho, P., Flores-Alsina, X., Gernaey, K. V., 729 Hansen, S.F., Plósz, B.G., Booth, A.M., 2018. Occurrence, characterisation and fate of 
730 (nano)particulate $\mathrm{Ti}$ and $\mathrm{Ag}$ in two Norwegian wastewater treatment plants. Water Res. 141,

731 19-31. https://doi.org/10.1016/j.watres.2018.04.065

732

73313 Westerhoff, P., Song, G., Hristovski, K., Kiser, M.A., 2011. Occurrence and removal of

734 titanium at full scale wastewater treatment plants: Implications for $\mathrm{TiO}_{2}$ nanomaterials. J.

735 Environ. Monit. 13, 1195-1203. https://doi.org/10.1039/c1em10017c

736

73714 Reiman, C. de Caritat, P., GEMAS Project Team, NGSA Project Team, 2012. New soil 738 composition data for Europe and Australia: Demonstrating comparability, identifying

739 continental -scale processes and learning lessons for global geochemical mapping. Science of

740 the Total Environment 416, 239-252. https://doi.org/10.1016/j.scitotenenv.2011.11.019

741

74215 Hochella M. F. Jr, Mogk D. W., Ranville J., Allen I. C., Luther G. W., Marr L. C., McGrail

743 B. P., Murayama M., Qafoku N. P., Rosso K. M., Sahai N., Schroeder P. A., Vikesland P.,

744 Westerhoff P. and Yang Y. (2019) Natural, incidental, and engi-neered nanomaterials and their

745 impacts on the Earth system. Science 363, eaau8299-12.

746

74716 Wagner, S., Gondikas, A., Neubauer, E., Hofmann, T., Von Der Kammer, F., 2014. Spot

748 the difference: Engineered and natural nanoparticles in the environment-release, behavior,

749 and fate. Angew. Chemie - Int. Ed. 53, 12398-12419. https://doi.org/10.1002/anie.201405050

750

75117 Tharaud, M., Gondikas, A.P., Benedetti, M.F., von der Kammer, F., Hofmann, T., 752 Cornelis, G., 2017. TiO 2 nanomaterial detection in calcium rich matrices by spICPMS. A matter 
753 of resolution and treatment. J. Anal. At. Spectrom. 32, 1400-1411.

754 https://doi.org/10.1039/C7JA00060J

755

75618 Nowack, B., Baalousha, M., Bornhöft, N., Chaudhry, Q., Cornelis, G., Cotterill, J., 757 Gondikas, A., Hassellöv, M., Lead, J., Mitrano, D.M., Von Der Kammer, F., Wontner-Smith, T., 758 2015. Progress towards the validation of modeled environmental concentrations of 759 engineered nanomaterials by analytical measurements. Environ. Sci. Nano 2, 421-428. 760 https://doi.org/10.1039/c5en00100e

761

76219 Lead, J.R., Batley, G.E., Alvarez, P.J.J., Croteau, M.-N., Handy, R.D., McLaughlin, M.J., 763 Judy, J.D., Schirmer, K., 2018. Nanomaterials in the Environment: Behavior, Fate, 764 Bioavailability, and Effects An Updated Review. Environ Toxicol Chem, 37: 2029-2063. 765 https://doi.org/10.1002/etc.4147

766

76720 Aznar, R., Barahona, F., Geiss, O., Ponti, J., José Luis, T., Barrero-Moreno, J., 2017. 768 Quantification and size characterisation of silver nanoparticles in environmental aqueous 769 samples and consumer products by single particle-ICPMS. Talanta 175, 200-208. 770 https://doi.org/10.1016/j.talanta.2017.07.048

771

77221 Donovan, A.R., Shi, H., 2016. Single particle ICP-MS characterization of titanium dioxide, 773 silver, and gold nanoparticles during drinking water treatment. Chemosphere 144, 148-153.

774 https://doi.org/10.1016/j.chemosphere.2015.07.081 
77622 Peters, R.J.B., van Bemmel, G., Milani, N.B.L., den Hertog, G.C.T., Undas, A.K., van der 777 Lee, M., Bouwmeester, H., 2018. Detection of nanoparticles in Dutch surface waters. Sci. Total 778 Environ. 621, 210-218. https://doi.org/10.1016/j.scitotenv.2017.11.238

779

78023 Yang, Y., Long, C-L., Li , H-P., Wang , Q., Yang, Z-G., 2016. Analysis of silver and gold 781 nanoparticles in environmental water using single particle-inductively coupled plasma-mass 782 spectrometry. Science of The Total Environment 563-564 (1), 996-1007. 783 doi:10.1016/j.scitotenv.2015.12.150.

784

78524 Loosli, F., Wang, J., Rothenberg, S., Bizimis, M., Winkler, C., Borovinskaya, O., 786 Flamignie, L., Baalousha, M., 2019. Sewage spills are a major source of titanium dioxide 787 engineered (nano)-particle release into the environment. Environ. Sci.: Nano, 2019,6, 763-777 788 https://doi.org/10.1039/C8EN01376D

789

79025 Wang, J., Alasonati, E., Tharaud, M., Gelabert, A., Fisicaro, P., Benedetti, M.F., 2020. 791 Flow and fate of silver nanoparticles in small French catchments under different land-uses: 792 The first one-year study. 2020. Water Research Water Res 176, 115722. 793 https://doi.org/10.1016/j.watres.2020.115722

794

79526 Wu, S., Zhang, S., Gong, Y., Shi, L., Zhou, B. 2020 Identification and quantification of 796 titanium nanoparticules in surface waters: A cases study in Lake Taihu, China. Journal of 797 hazardous Materials, 382, 121045.

798 
79927 Lambert, T., Bouillon, S., Darchambeau, F., Morana, C., Roland, F.A.E., Descy, J.P.,

800 Borges, A. V., 2017. Effects of human land use on the terrestrial and aquatic sources of fluvial 801 organic matter in a temperate river basin (The Meuse River, Belgium). Biogeochemistry 136, 802 191-211. https://doi.org/10.1007/s10533-017-0387-9

803

80428 Verwijmeren, J., Wiering, M., 2007. Many rivers to cross. Cross border co-operation in

805 river management. Eburon Academic, Delft

806

807

80829 Roy S., Gaillardet J. and Allegre C. J. (1999) Geochemistry of dissolved and suspended

809 loads of the Seine river, France: anthropogenic impact, carbonate and silicate weathering.

810 Geochimica Et Cosmochimica Acta 63, 1277-1292.

811

81230 Bonnot, C., 2015. L’origine des métaux et la dynamique du zinc dans le bassin de la 813 Seine. PhD, Université Paris Diderot, 205p.

814

81531 Bonnot, C.A., Gélabert, A., Louvat, P., Morin, G., Proux, O., Benedetti, M.F., 2016. Trace

816 metals dynamics under contrasted land uses: contribution of statistical, isotopic, and EXAFS

817 approaches. Environ. Sci. Pollut. Res. 1-21. https://doi.org/10.1007/s11356-016-6901-0

818

81932 Guo, L. and Santschi, P.H. (2007). Ultrafiltration and its Applications to Sampling and 820 Characterisation of Aquatic Colloids. In Environmental Colloids and Particles (eds J. Buffle, H.P. 821 van Leeuwen, K.J. Wilkinson and J.R. Lead). doi:10.1002/9780470024539.ch4 
82333 Degueldre, C., Favarger, P.Y., Rossé, R., Wold, S., 2006a. Uranium colloid analysis by

824 single particle inductively coupled plasma-mass spectrometry. Talanta 68, 623-628.

825 https://doi.org/10.1016/j.talanta.2005.05.006

826

82734 Degueldre, C., Favarger, P.Y., Wold, S., 2006b. Gold colloid analysis by inductively 828 coupled plasma-mass spectrometry in a single particle mode. Anal. Chim. Acta 555, 263-268.

829 https://doi.org/10.1016/j.aca.2005.09.021

830

83135 Degueldre, C., Favarger, P-Y., Bitea, C., 2004. Zirconia colloid analysis by single particle 832 inductively coupled plasma-mass spectrometry. Anal. Chim. Acta 518, 137-142.

833 https://doi.org/10.1016/J.ACA.2004.04.015

834

83536 Degueldre, C., Favarger, P.Y., 2004. Thorium colloid analysis by single particle 836 inductively coupled plasma-mass spectrometry. Talanta 62, 1051-1054. 837 https://doi.org/10.1016/j.talanta.2003.10.016

838

83937 Degueldre, C., Favarger, P.Y., 2003. Colloid analysis by single particle inductively 840 coupled plasma-mass spectroscopy: A feasibility study. Colloids Surfaces A Physicochem. Eng. 841 Asp. 217, 137-142. https://doi.org/10.1016/S0927-7757(02)00568-X

842

84338 Mitrano, D.M., Lesher, E.K., Bednar, A., Monserud, J., Higgins, C.P., Ranville, J.F., 2012.

844 Detecting nanoparticulate silver using single-particle inductively coupled plasma-mass

845 spectrometry. Environ. Toxicol. Chem. 31, 115-121. https://doi.org/10.1002/etc.719

846 
84739 Pace H. E., Rogers N. J., Jarolimek C., Coleman V. A., Higgins C. P. and Ranville J. F. (2011)

848 Determining Transport Efficiency for the Purpose of Counting and Sizing Nanoparticles via

849 Single Particle Inductively Coupled Plasma Mass Spectrometry. Analytical Chemistry 83, 9361-

850 9369. https://doi.org/10.1021/ac300942m

851

85240 BIPM, IEC, IFCC, ILAC, ISO, IUPAC, IUPAP and OIML, Guide to the Expression of

853 Uncertainty in Measurement, JCGM 100:2008 (GUM 1995 with minor corrections), 2008.

854

85541 Schmidt, J., Vogelsberger, W., 2009. Aqueous long-term solubility of titania

856 nanoparticles and titanium(IV) hydrolysis in a sodium chloride system studied by adsorptive

857 stripping voltammetry. J. Solution Chem. 38, 1267-1282. https://doi.org/10.1007/s10953-

$858 \quad 009-9445-9$

859

86042 Logan N. Rand, Yuqiang Bi, Andrew Poustie, Anthony J. Bednar, David J. Hanigan, Paul

861 Westerhoff, James F. Ranville, 2020. Quantifying temporal and geographic variation in

862 sunscreen and mineralogic titanium-containing nanoparticles in three recreational rivers,

863 Science of The Total Environment, Volume 743, 140845,

864 https://doi.org/10.1016/j.scitotenv.2020.140845.

865

86643 Mueller, N.C., Nowack, B., 2008. Exposure modelling of engineered nanoparticles in

867 the environment. Environ. Sci. Technol. 42, 44447-53. https://doi.org/10.1021/es7029637 
86944 Silva, B.F. da, Pérez, S., Gardinalli, P., Singhal, R.K., Mozeto, A.A., Barceló, D., 2011.

870 Analytical chemistry of metallic nanoparticles in natural environments. TrAC - Trends Anal.

871 Chem. https://doi.org/10.1016/j.trac.2011.01.008

872

87345 Wigginton, N.S., Haus, K.L., Hochella Jr, M.F., 2007. Aquatic environmental

874 nanoparticles. J. Environ. Monit. 9, 1306. https://doi.org/10.1039/b712709j

875

87646 Panagosa, P., Borrellia, P., Poesen, J., Ballabioa, C., Lugatoa, E., Meusburger, K.,

877 Montanarella, L., Alewell, C. The new assessment of soil loss by water erosion in Europe.

878 Environmental Science \& Policy Volume 54, December 2015, Pages 438-447.

879 https://doi.org/10.1016/j.envsci.2015.08.012

880

88147 Choi, S., Johnston, M., Wang, G., Huang, C.P., 2018. A seasonal observation on the

882 distribution of engineered nanoparticles in municipal wastewater treatment systems

883 exemplified by TiO2 and ZnO. Science of the Total Environment 625, 1321-1329

884

88548 Zhang, X., Wang, M., Guo, S., Zhang, Z., Li, H., 2017. Effects of weathering and rainfall

886 conditions on the release of $\mathrm{SiO} 2, \mathrm{Ag}$, and $\mathrm{TiO} 2$ engineered nanoparticles from paints. J.

887 Nanopart. Res. 19, 338-347. https://doi.org/10.1007/s11051-017-4022-4

888

88949 Azimzada, A., Farner, J. M., Hadioui, M., Liu-Kang, C., Jreije, I., Tufenkji, N., Wilkinson, 890 K. J., 2020. Relase of TiO2 nanoparticles from painted surfaces in cold cli-mates: 891 characterization using a high sensitivity single-particle ICP-MS. Environ. Sci.: Nano, 7, 139-148.

892 https://doi.org/10.1039/C9EN00951E 
89450 Hischier, R., Nowack, B., Gottschalk, F., Hincapie, I., Steinfeldt, M. \& Som, C. Life cy-cle 895 assessment of façade coating systems containing manufactured nanomaterials. J Nanopart 896 Res 17, 68 (2015). https://doi.org/10.1007/s11051-015-2881-0

\section{7}

89851 Neal, C., Jarvie, H., Rowland, P., Lawler, A., Sleep, D., Scholefield, P., 2011. Titanium in 899 UK rural, agricultural and urban/industrial rivers: Geogenic and anthropogenic colloidal/sub900 colloidal sources and the significance of within-river retention. Sci. Total Environ. 409, 1843901 1853. https://doi.org/10.1016/j.scitotenv.2010.12.021

902

90352 Greenwood, N.N., Earnshaw, A., 2012. Chemistry of the Elements. Elsevier.

904

90553 Pradas del Real, A.E., Castillo-Michel, H., Kaegi, R., Larue, C., de Nolf, W., Reyes-Herrera, 906 J., Tucoulou, R., Findling, N., Salas-Colera, E., Sarret, G., 2018. Searching for relevant criteria 907 to distinguish natural vs. anthropogenic TiO 2 nanoparticles in soils. Environ. Sci. Nano. 908 https://doi.org/10.1039/C8EN00386F

909

91054 Goodall, P., Foulkes, M.E., Ebdon, L., 1993. Slurry nebulization inductively coupled 911 plasma spectrometry-the fundamental parameters discussed. Spectrochim. Acta Part B At. 912 Spectrosc. 48, 1563-1577. https://doi.org/10.1016/0584-8547(93)80143-I

913

91455 Benedetti, M.F., Dia, A., Riotte, J., Chabaux, F., Gérard, M., Boulègue, J., Fritz, B., 915 Chauvel, C., Bulourde, M., Déruelle, B., Ildefonse, P., 2003. Chemical weathering of basaltic 
916 lava flows undergoing extreme climatic conditions: The water geochemistry record. Chem.

917 Geol. 201, 1-17. https://doi.org/10.1016/S0009-2541(03)00231-6

918

91956 Xiao, C., Ye, J., Esteves, R. M., and Rong, C. (2016) Using Spearman's correlation 920 coefficients for exploratory data analysis on big dataset. Concurrency Computat.: Pract. Exper., 921 28: 3866- 3878. doi: 10.1002/cpe.3745.

922

92357 Domingos, R.F., Tufenkji, N., Wilkinson, K.J., 2009. Aggregation of titanium dioxide 924 nanoparticles: Role of a fulvic acid. Environ. Sci. Technol. 43, 1282-1286. 925 https://doi.org/10.1021/es8023594

926

92758 Topuz, E., Sigg, L., Talinli, I., 2014. A systematic evaluation of agglomeration of Ag and $928 \mathrm{TiO}_{2}$ nanoparticles under freshwater relevant conditions. Environ. Pollut. 193, 37-44. 929 https://doi.org/10.1016/j.envpol.2014.05.029

930

93159 Topuz, E., Talinli, I., 2015. Agglomeration of $\mathrm{Ag}$ and $\mathrm{TiO}_{2}$ nanoparticles in surface and 932 wastewater: Role of calcium ions and of organic carbon fractions. Environ. Pollut. 204, 313933 323. https://doi.org/10.1016/j.envpol.2015.05.034

934

93560 Chen, Y., Gao, Q., Chen, W., Wu, F., Yang, Y., Werner, D., Tao, S., Wang, X., 2018. A 936 mechanistic study of stable dispersion of titanium oxide nanoparticles by humic acid. Water 937 Res. 135, 85-94. https://doi.org/10.1016/j.watres.2018.02.018 
93961 Shih, Y. hsin, Zhuang, C. ming, Peng, Y.H., Lin, C. han, Tseng, Y. ming, 2012. The effect 940 of inorganic ions on the aggregation kinetics of lab-made $\mathrm{TiO}_{2}$ nanoparticles in water. Sci. Total 941 Environ. 435-436, 446-452. https://doi.org/10.1016/j.scitotenv.2012.06.076

942

94362 Zhang, Y., Chen, Y., Westerhoff, P., Crittenden, J., 2009. Impact of natural organic 944 matter and divalent cations on the stability of aqueous nanoparticles. Water Res. 43, 4249945 4257. https://doi.org/10.1016/j.watres.2009.06.005

946

94763 French, R. A., Jacobson, A.R., Kim, B., Isley, S.L., Penn, R.L.E.E., Baveye, P.C., 2009. 948 Influence of ionic strength, $\mathrm{pH}$, and cation valence on aggregation kinetics of titanium dioxide 949 nanoparticles. Environ. Sci. Technol. 43, 1354-1359. https://doi.org/10.1021/es802628n 950

95164 Ilina, S.M., Lapitskiy, S.A., Alekhin, Y. V., Viers, J., Benedetti, M., Pokrovsky, O.S., 2016. 952 Speciation, Size Fractionation and Transport of Trace Elements in the Continuum Soil Water953 Mire-Humic Lake-River-Large Oligotrophic Lake of a Subarctic Watershed. Aquat. 954 Geochemistry 22, 65-95. https://doi.org/10.1007/s10498-015-9277-8 955

95665 Praetorius, A., Labille, J., Scheringer, M., Thill, A., Hungerbühler, K., Bottero, J.Y., 2014. 957 Heteroaggregation of titanium dioxide nanoparticles with model natural colloids under 958 environmentally relevant conditions. Environ. Sci. Technol. 48, 10690-10698. 959 https://doi.org/10.1021/es501655v

960 
96166 Labille, J., Harns, C., Bottero, J.Y., Brant, J., 2015. Heteroaggregation of titanium dioxide 962 nanoparticles with natural clay colloids. Environ. Sci. Technol. 49, 6608-6616. 963 https://doi.org/10.1021/acs.est.5b00357

964

96567 Wang, H., Adeleye, A.S., Huang, Y., Li, F., Keller, A.A., 2015. Heteroaggregation of 966 nanoparticles with biocolloids and geocolloids. Adv. Colloid Interface Sci. 226, 24-36.

967 https://doi.org/10.1016/j.cis.2015.07.002

968

96968 Le Cloarec, M.F., Bonte, P.H., Lestel, L., Lefèvre, I., Ayrault, S., 2011. Sedimentary 970 record of metal contamination in the Seine River during the last century. Phys. Chem. Earth 971 36, 515-529. https://doi.org/10.1016/j.pce.2009.02.003

972

97369 Pons-Branchu, E., Ayrault, S., Roy-Barman, M., Bordier, L., Borst, W., Branchu, P., 974 Douville, E., Dumont, E., 2015. Three centuries of heavy metal pollution in Paris (France) 975 recorded by urban speleothems. Sci. Total Environ. 518-519, 86-96. 976 https://doi.org/10.1016/j.scitotenv.2015.02.071

977

97870 Le Pape, P., Ayrault, S., Quantin, C., 2012. Trace element behavior and partition versus 979 urbanization gradient in an urban river (Orge River, France). J. Hydrol. 472-473, 99-110. 980 https://doi.org/10.1016/j.jhydrol.2012.09.042

981

98271 Meybeck, M., Lestel, L., Bonté, P., Moilleron, R., Colin, J.L., Rousselot, O., Hervé, D., de 983 Pontevès, C., Grosbois, C., Thévenot, D.R., 2007. Historical perspective of heavy metals 984 contamination $(\mathrm{Cd}, \mathrm{Cr}, \mathrm{Cu}, \mathrm{Hg}, \mathrm{Pb}, \mathrm{Zn}$ ) in the Seine River basin (France) following a DPSIR 
985 approach (1950-2005). Sci. Total Environ. 375, 204-231.

986 https://doi.org/10.1016/j.scitotenv.2006.12.017

987

98872 Viers, J., Dupré, B., Gaillardet, J., 2009. Chemical composition of suspended sediments 989 in World Rivers: New insights from a new database. Sci. Total Environ. 407, 853-868. 990 https://doi.org/10.1016/j.scitotenv.2008.09.053

991

99273 Chen, J. Bin, Gaillardet, J., Bouchez, J., Louvat, P., Wang, Y.N., 2014. Anthropophile 993 elements in river sediments: Overview from the Seine River, France. Geochemistry, Geophys. 994 Geosystems 15, 4526-4546. https://doi.org/10.1002/2014GC005516

995

99674 Barbieri M, 2014 The Importance of Enrichment Factor (EF) and Geoaccumulation 997 Index (Igeo) to Evaluate the Soil Contamination. J Geol Geophys 2016, 5:1 ,https://doi.org $998 / 10.4172 / 2381-8719.1000237$

99975 Besold J., Kumar N., Scheinost A. C., Lezama Pacheco J., Fendorf S., and Planer-Friedrich 1000 B. Environmental Science \& Technology 201953 (9), 5005-5015

1001

100276 Biswas A., Besold J., Sjöstedt C., Gustafsson J., Scheinost A. C. and Planer-Friedrich B. 1003 Environmental Science \& Technology 201953 (18), 10723-10731

1004 DOI: 10.1021/acs.est.9b03020

1005

100677 Besold J., Eberle A., Noël V., Kujala K., Kumar N., Scheinost A. C., Lezama Pacheco J., 1007 Fendorf S., and Planer-Friedrich B. Environmental Science \& Technology 201953 (18), 10792 100810802 DOI: 10.1021/acs.est.9b03924 
1009

101078 Sharma, B., Sarkar, A., Singh, P., Singh, R.P., 2017. Agricultural utilization of biosolids:

1011 A review on potential effects on soil and plant grown. Waste Manag. 64, 117-132.

1012 https://doi.org/10.1016/i.wasman.2017.03.002

1013 
Table 1: Experimental conditions of sp-ICPMS measurement.

Table 2: Average (range) of some physicochemical properties of three catchment waters.

Original data taken from Wang et al. (2020) (Table S2 in supplementary information [25]).

Table 3: Concentrations of $\mathrm{NPs}-\mathrm{TiO}_{2}$ measured in surface water from the literature and this study. n.g.: not given. n.a.: not analysed. *Ti: total content of filtered fraction after digestion. ** Engineered nanoparticles only as defined in [24].

Table 4: Average enrichment factor (EF) of selected elements in three small catchments normalized to suspended matter particles (SRSM) of Seine River. 
Fig. 1: Sampling location and their land-use. Blue arrows indicate the direction of the water flow. Coloured boxes report the area of the watershed, the average population density (Pop. Dens.) and measured annual average water flow rate $\left(\right.$ L.Sec $\left.^{-1}\right)$ for each watershed.

Figure 2: Particle number concentration (PNC) of NPs-TiO2 measured at the three sites during one-year of sampling. Samples were taken once per month, except for three months which are missing.

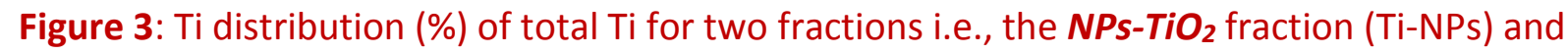
large particles (Ti-Par) in three waters for one-year sampling, in which Ti-Par $=$ Ti total - Ti NPs - Ti dissolved with Ti dissolved less than $1 \%$ of tot. Panel A, B and C showing the data of the forested, agricultural and urban watersheds, respectively. The numbers inserted in each bar

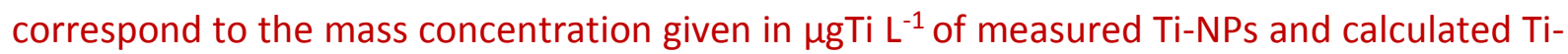
Par.

Figure 4: Calculated diameters of the $\mathrm{TiO}_{2}$-NPs detected by sp-ICPMS and comparison with recently published data (see supplementary section for detailed size calculation procedure). [21]: Donovan et al., 2016; [26]: Wu et al., 2020; [42]: Rand et al., 2020.

Figure 5: Left: SEM images of filters retaining suspended particles containing $\mathrm{TiO}_{2}$, with different shapes, present in sampled waters. Panels (a) and (c) showing a sample from the forested and urban watersheds, respectively. Right: Panel (b) and (d) showing the EDX analysis of corresponding particles highlighted by the green circle in panel (a) and the green square in panel (c).

Figure 6: Particle number concentration (PNC) of $\mathrm{NPs}^{-\mathrm{TiO}_{2}}$ as function of that of $\mathrm{Ag} \mathrm{NPs}$ in agricultural and forested watersheds. Ag-NPs concentrations are from [25]. The correlation coefficients $r$ corresponding to Agricultural orange and Forested green broken lines are equal to $r_{\text {Agricultural }}=0.96$ and $r_{\text {forested }}=0.89$. Their corresponding $p$ value are equal to 0.00003 and 0.0004 for a sampling size $n=9$ and 10 , respectively.

Figure 7: Mass concentration of $\mathrm{NPs}^{-\mathrm{TiO}_{2}}$ as function of $\mathrm{DOC}$ concentration in water samples from the forested watershed. The correlation coefficient $r$ corresponding to the orange broken line is equal to $r=0.91$ and it corresponds to a $p$ value equal to 0.0002 and a sampling size $n=9$

Figure 8: Mass concentration of $\mathrm{TiO}_{2} \mathrm{NPs}$ as function as that (bulk minus dissolved) of (a) $\mathrm{Sb}$ and (b) Ni in forested water. The correlation coefficients $r$ corresponding to the orange broken line are equal to $r=0.91$ and $r=0.89$ in panel (a) and (b), respectively. They correspond to a $p$ value equal to 0.0002 and 0.0005 with a sampling size $n=10$.

Figure 9: Export-rate of (a) nanoparticulate (b) dissolved $<1 \mathrm{kDa}$ (c) total Ti detected in three waters along the sampling year. 


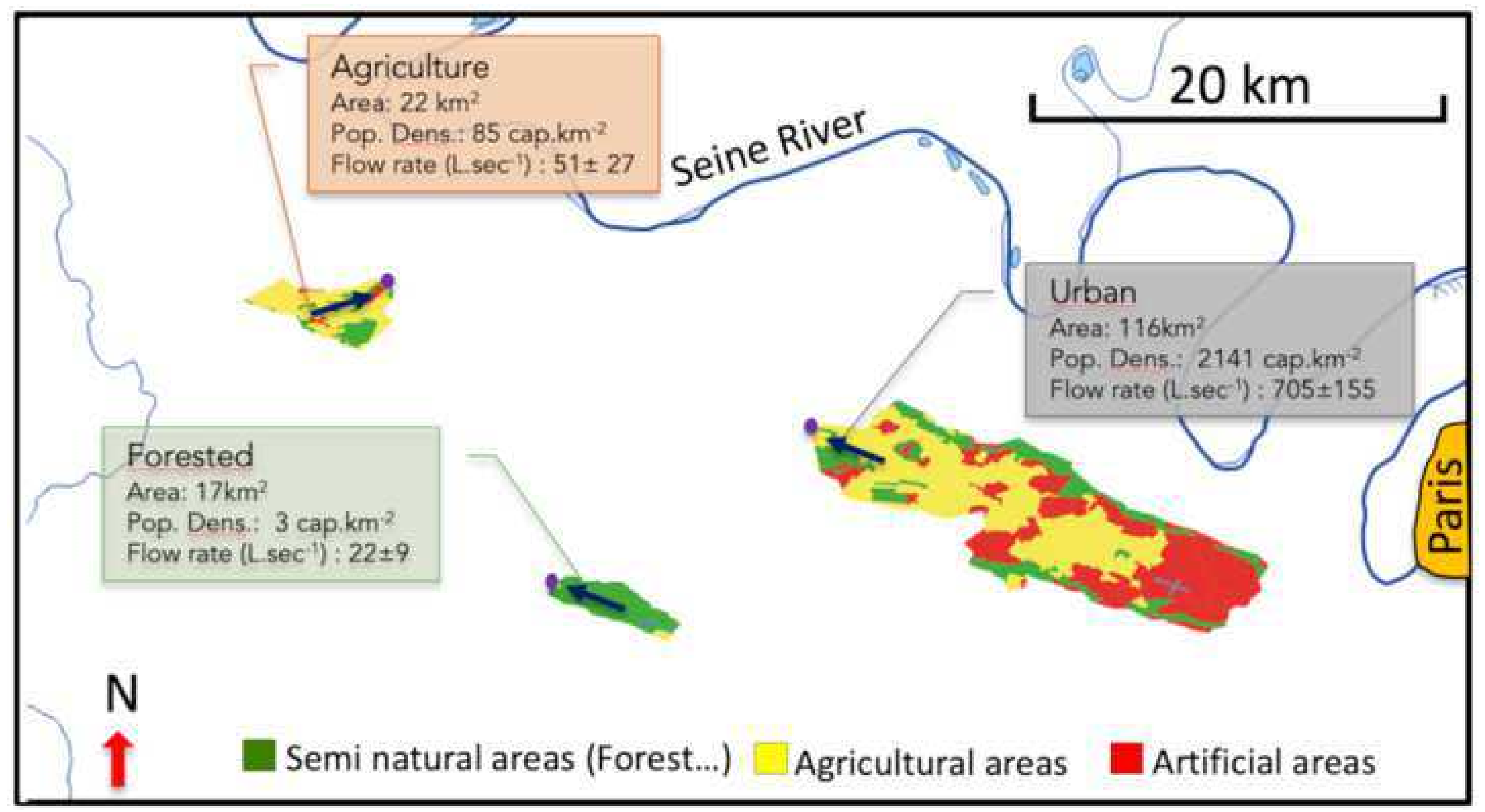


Eorested Agricultural E Urban

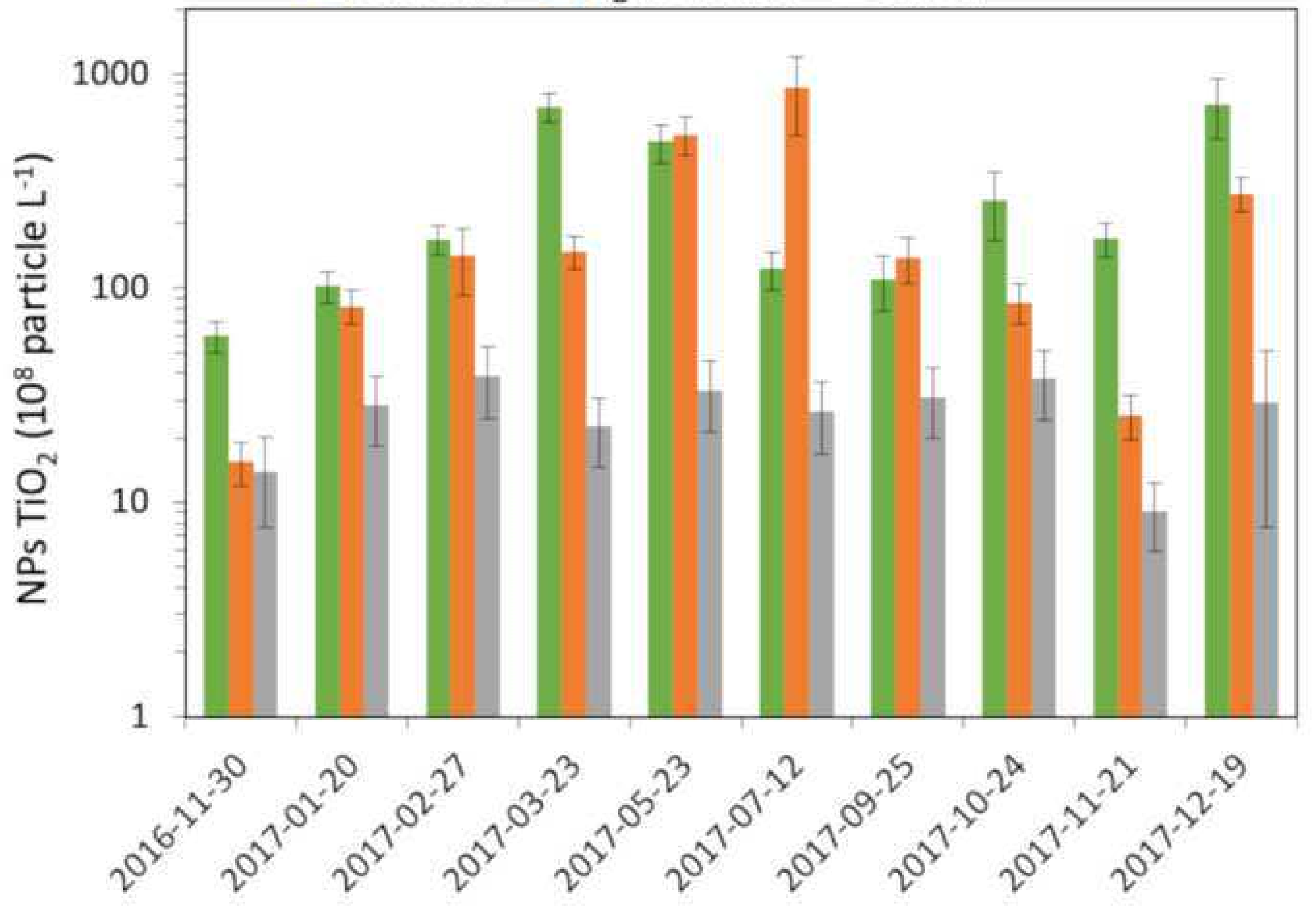




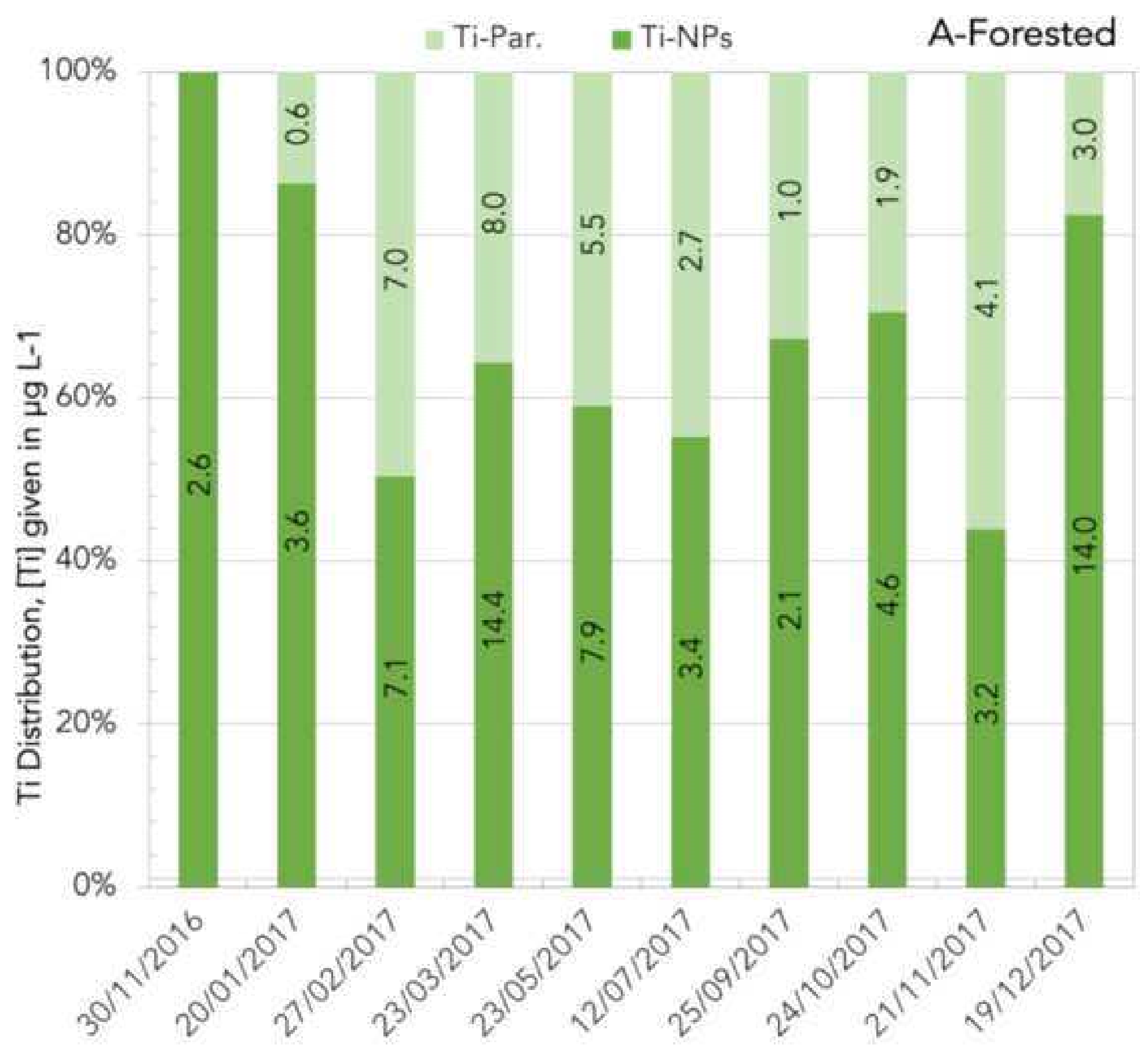




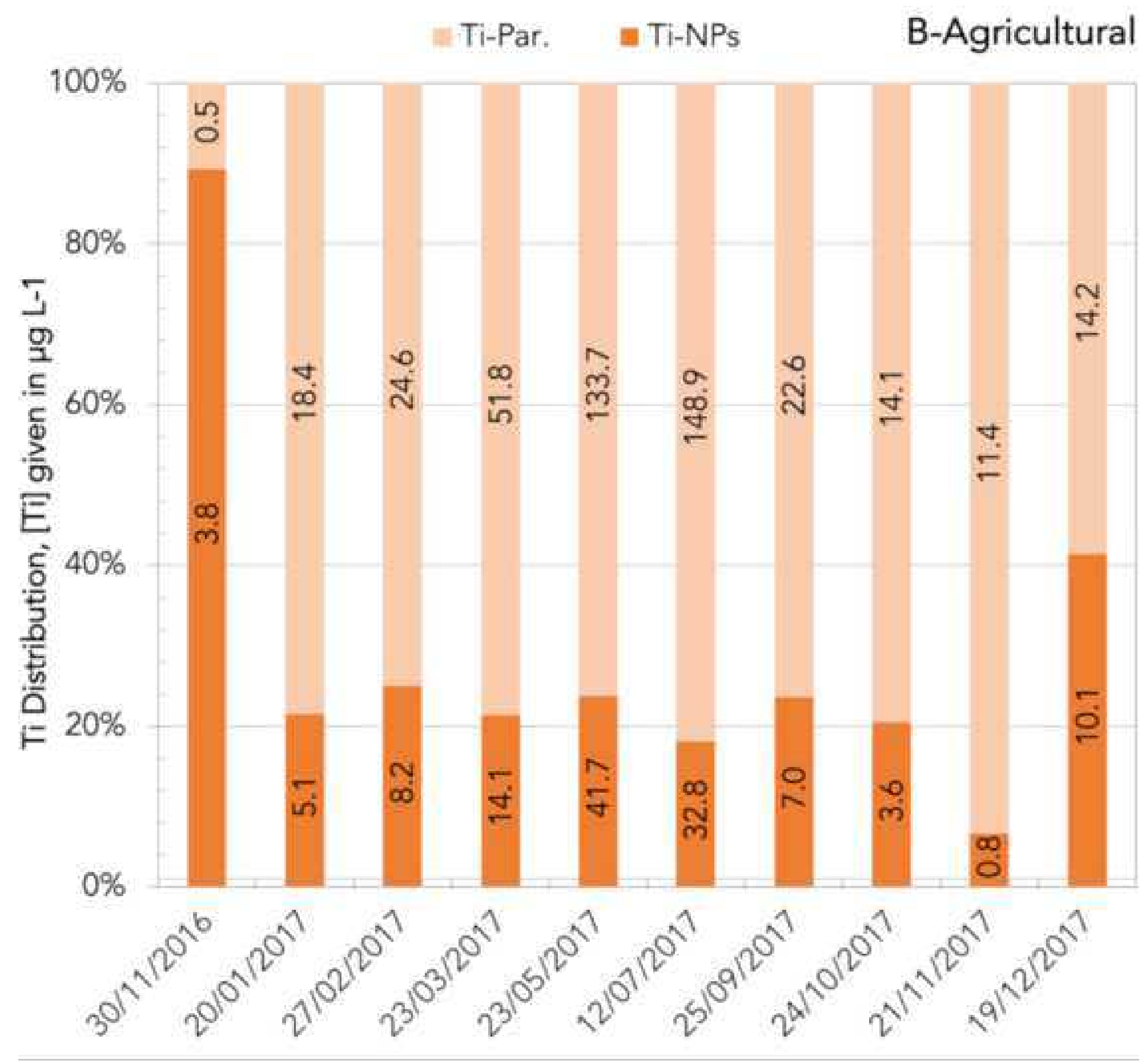




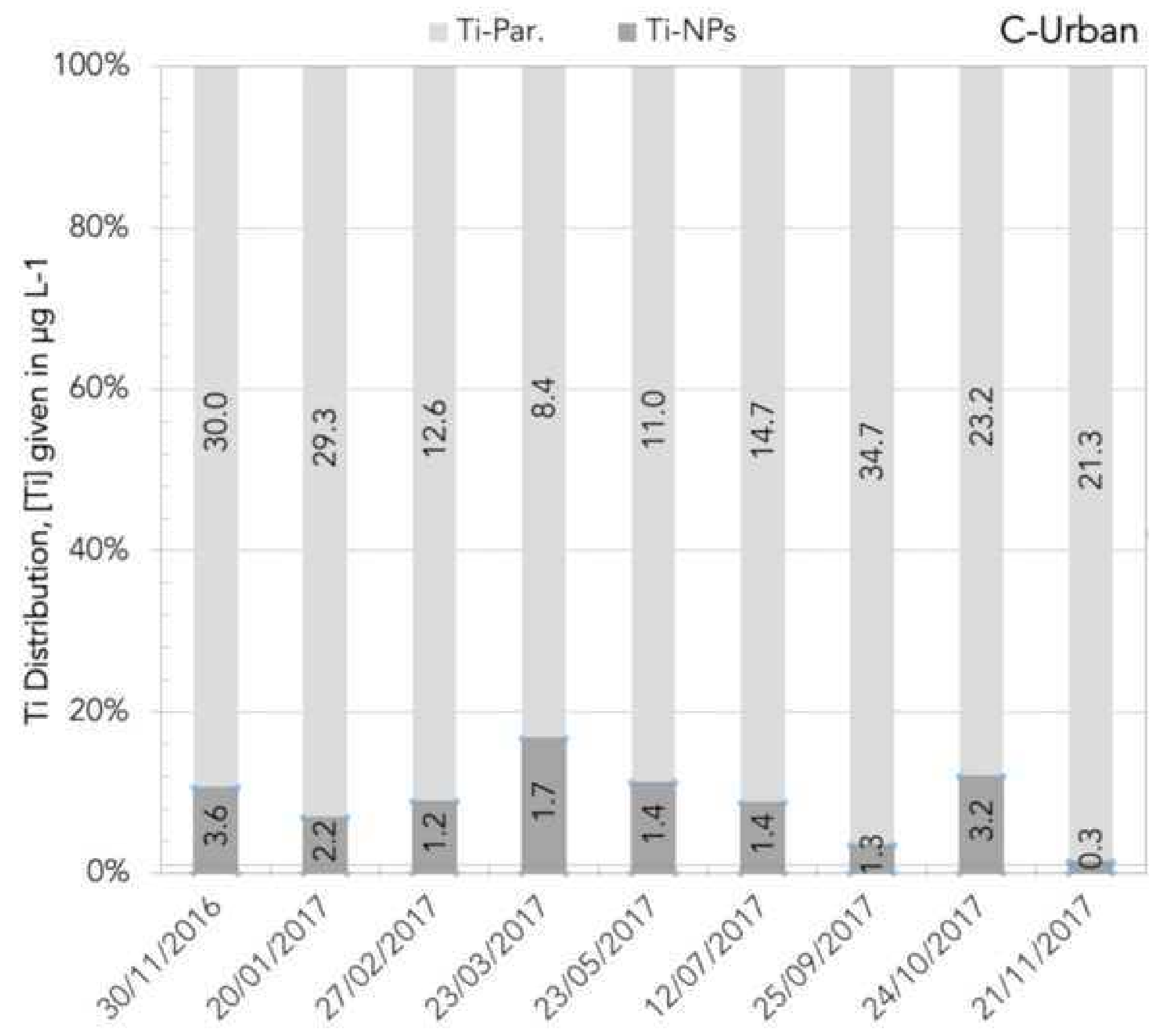




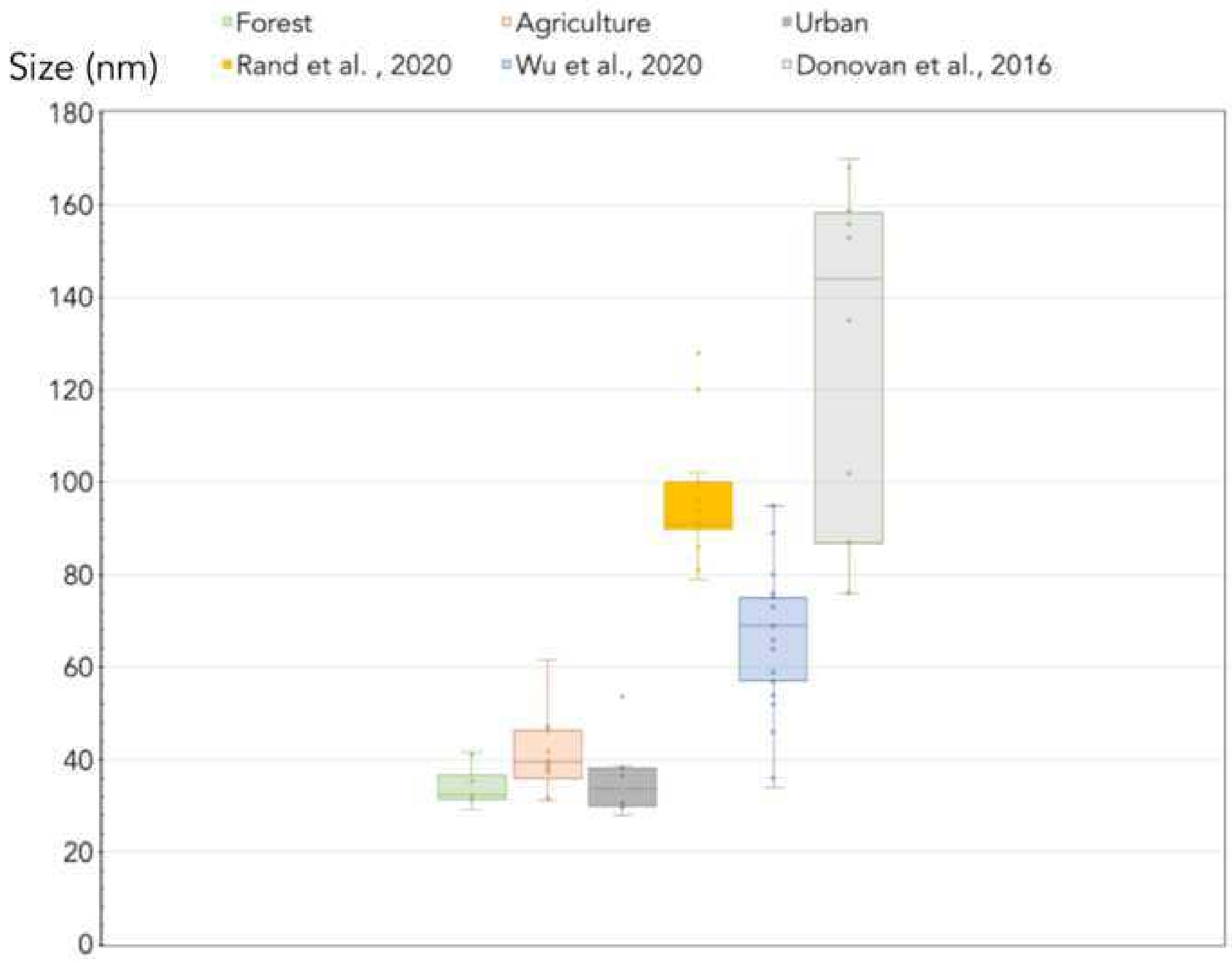



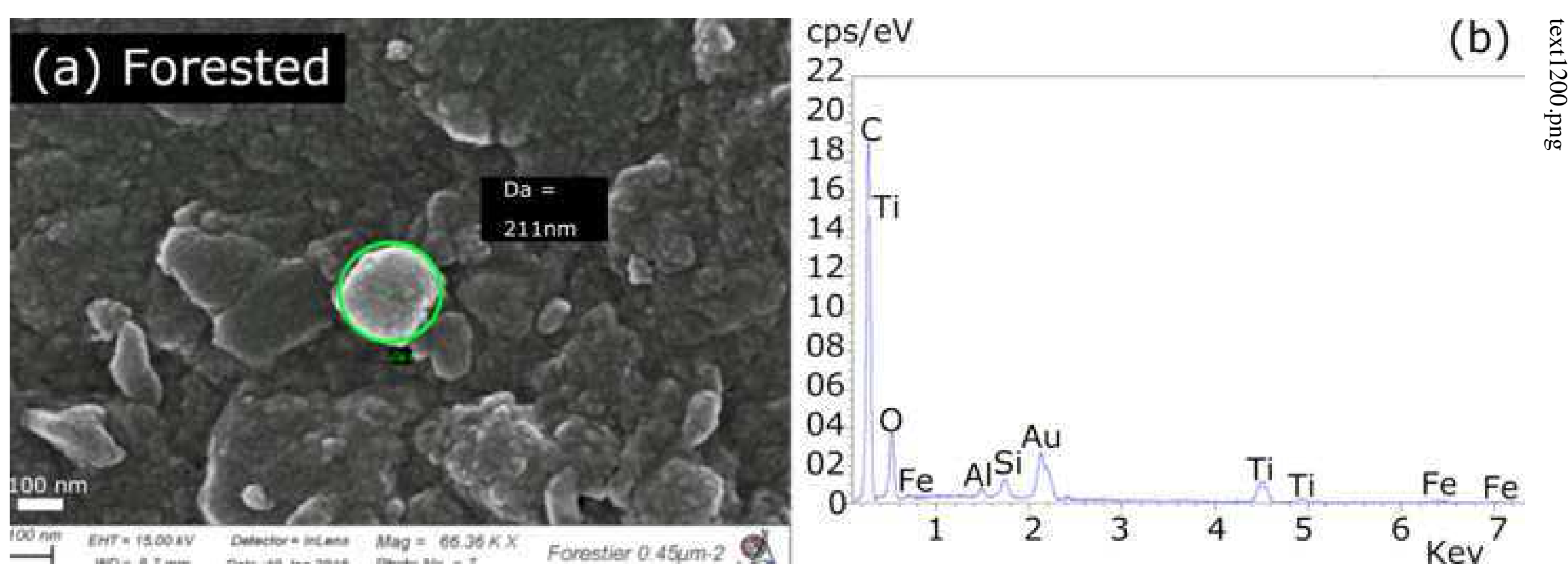

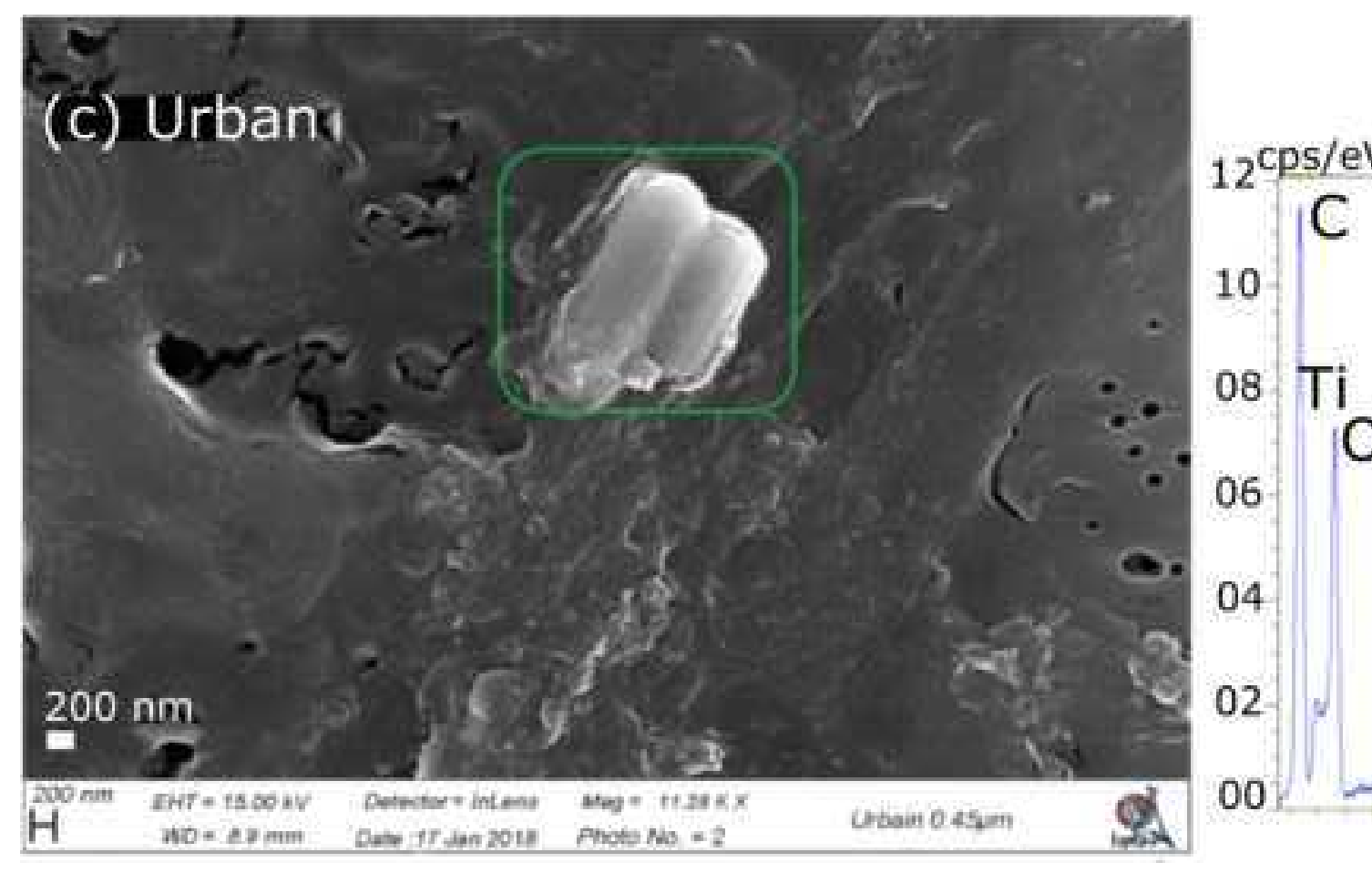
C

$\mathrm{Ti}$

Ca

$\mathrm{Ti} \quad \mathrm{FeFe}$ $56 \mathrm{KeV} 7$

(d) 高

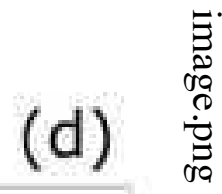


Click here to access/download;Figure;Figure 6.tif $\underline{\underline{\imath}}$

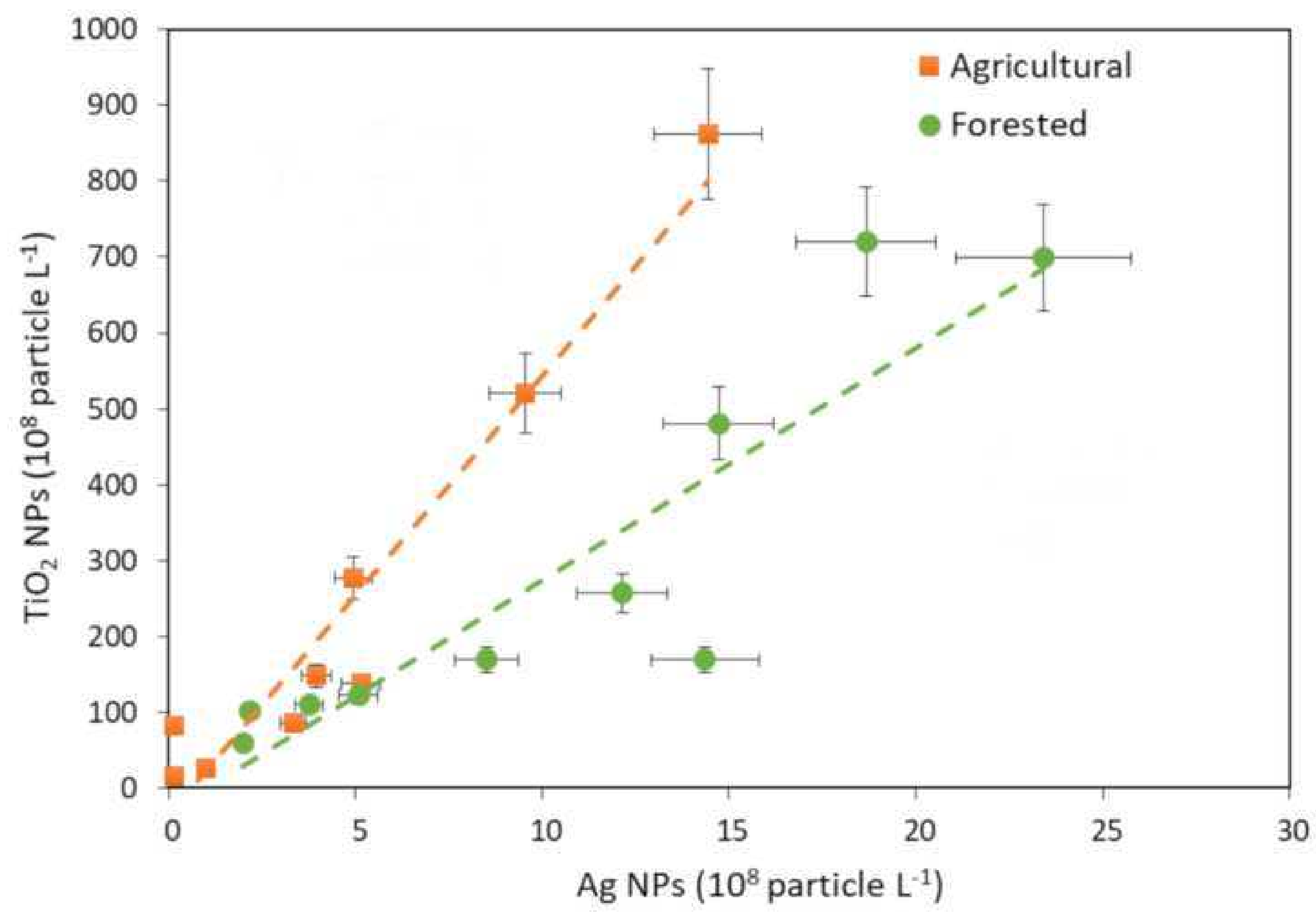


Click here to access/download;Figure;Figure 7.tif $\underline{\underline{\Perp}}$

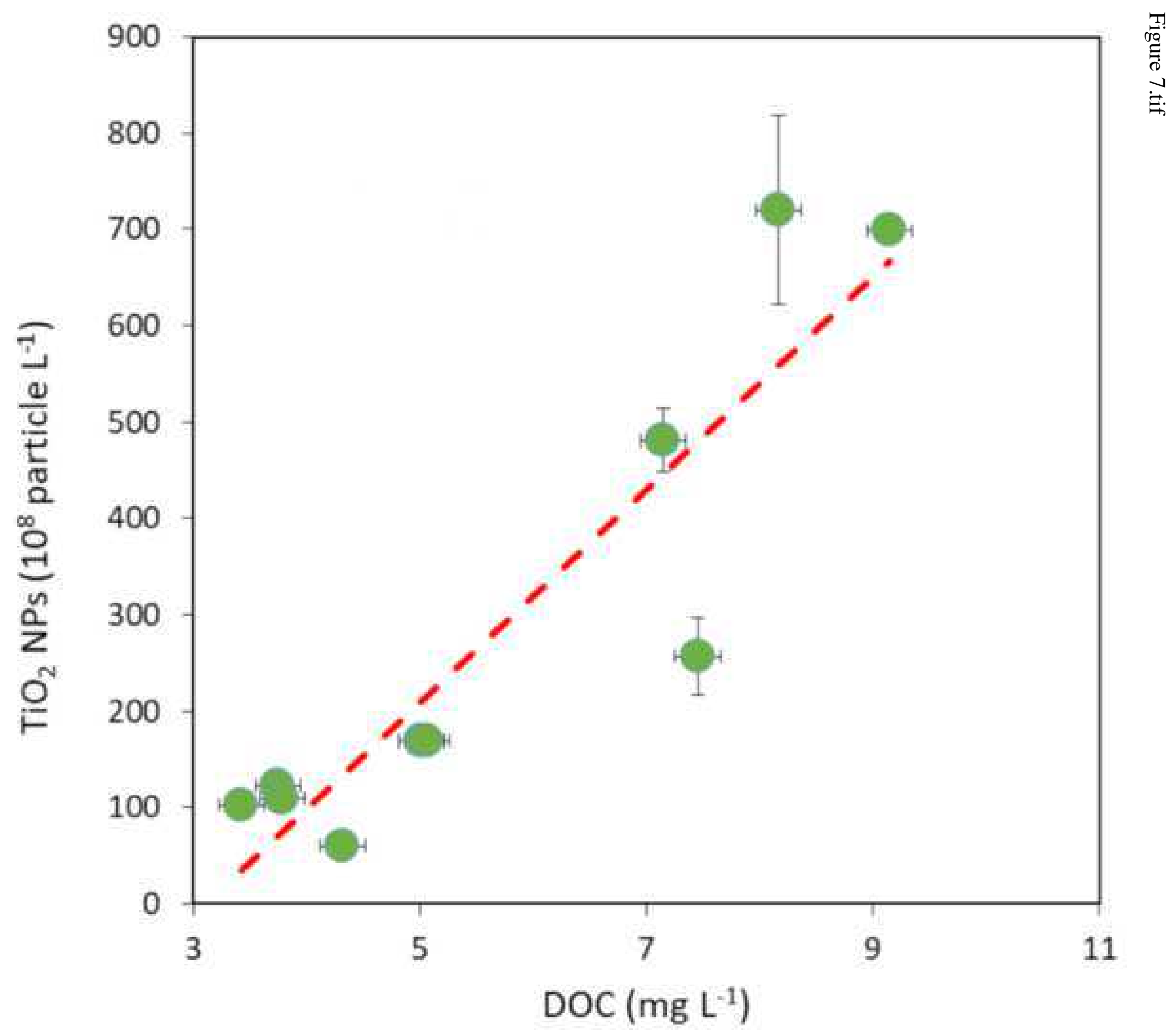


Click here to access/download;Figure;Figure 8 panel a.tif $\underline{\underline{ }}$

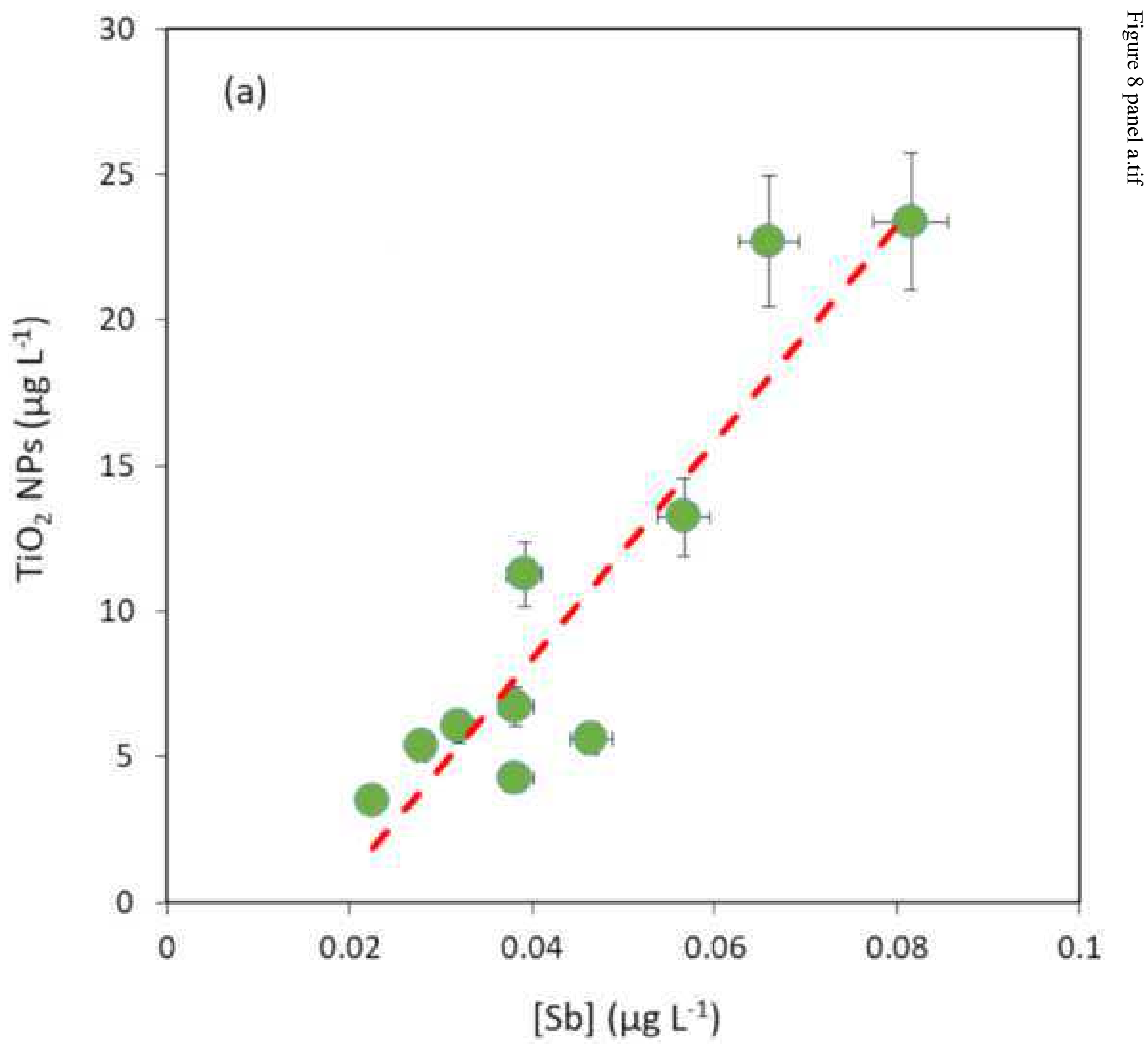


Click here to access/download;Figure;figure 8 panel b.tif $\stackrel{\underline{ }}{ }$

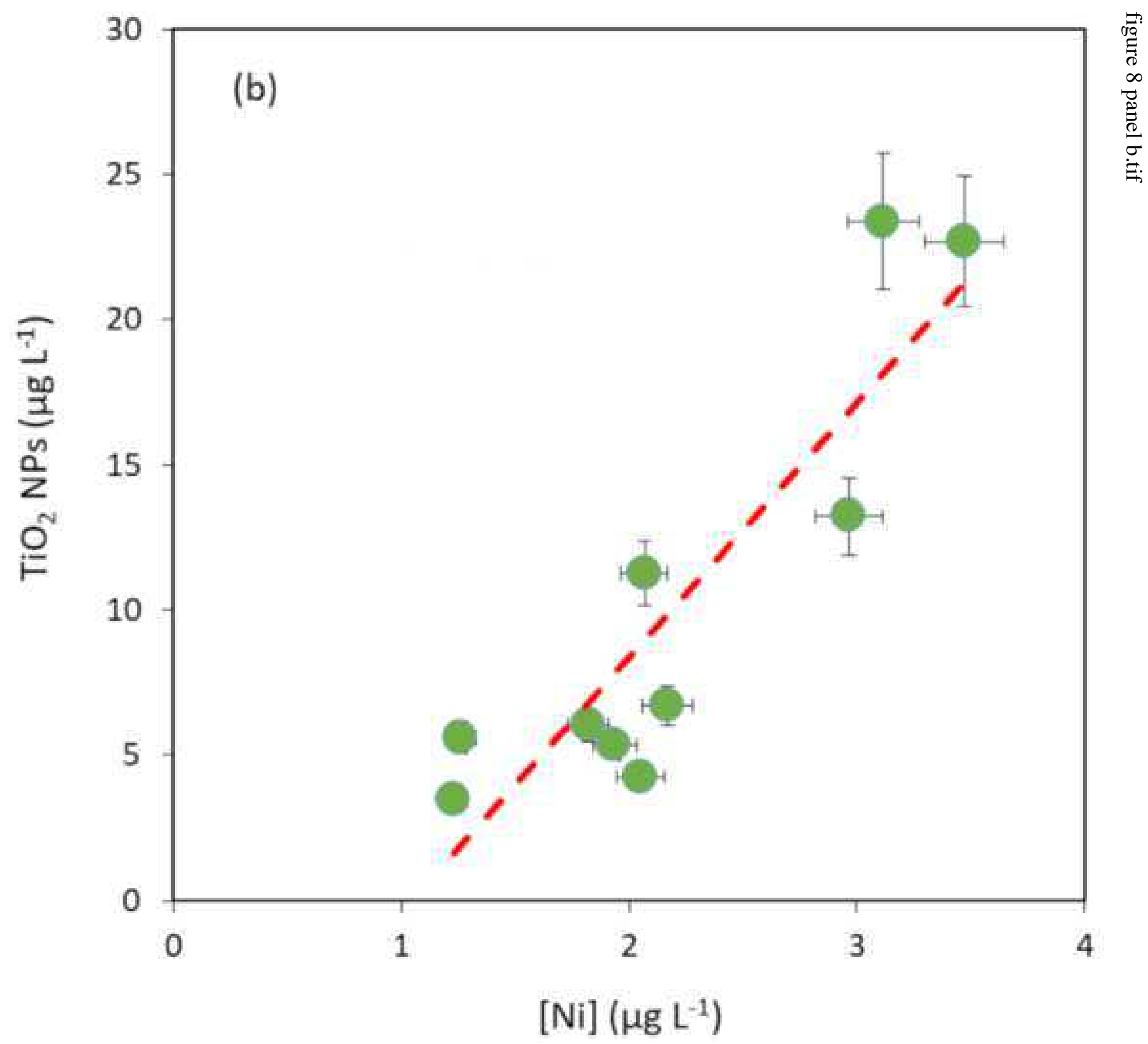




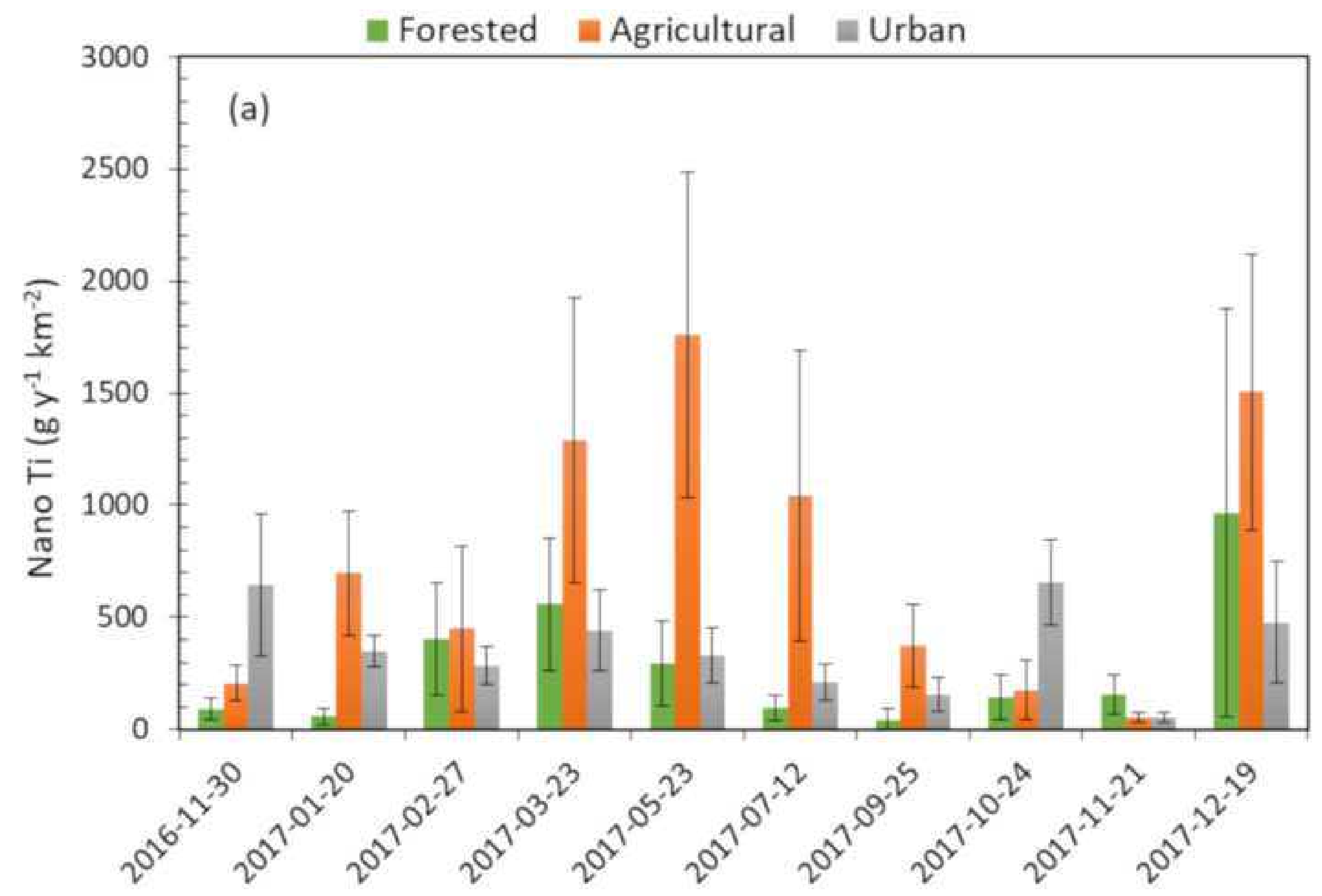




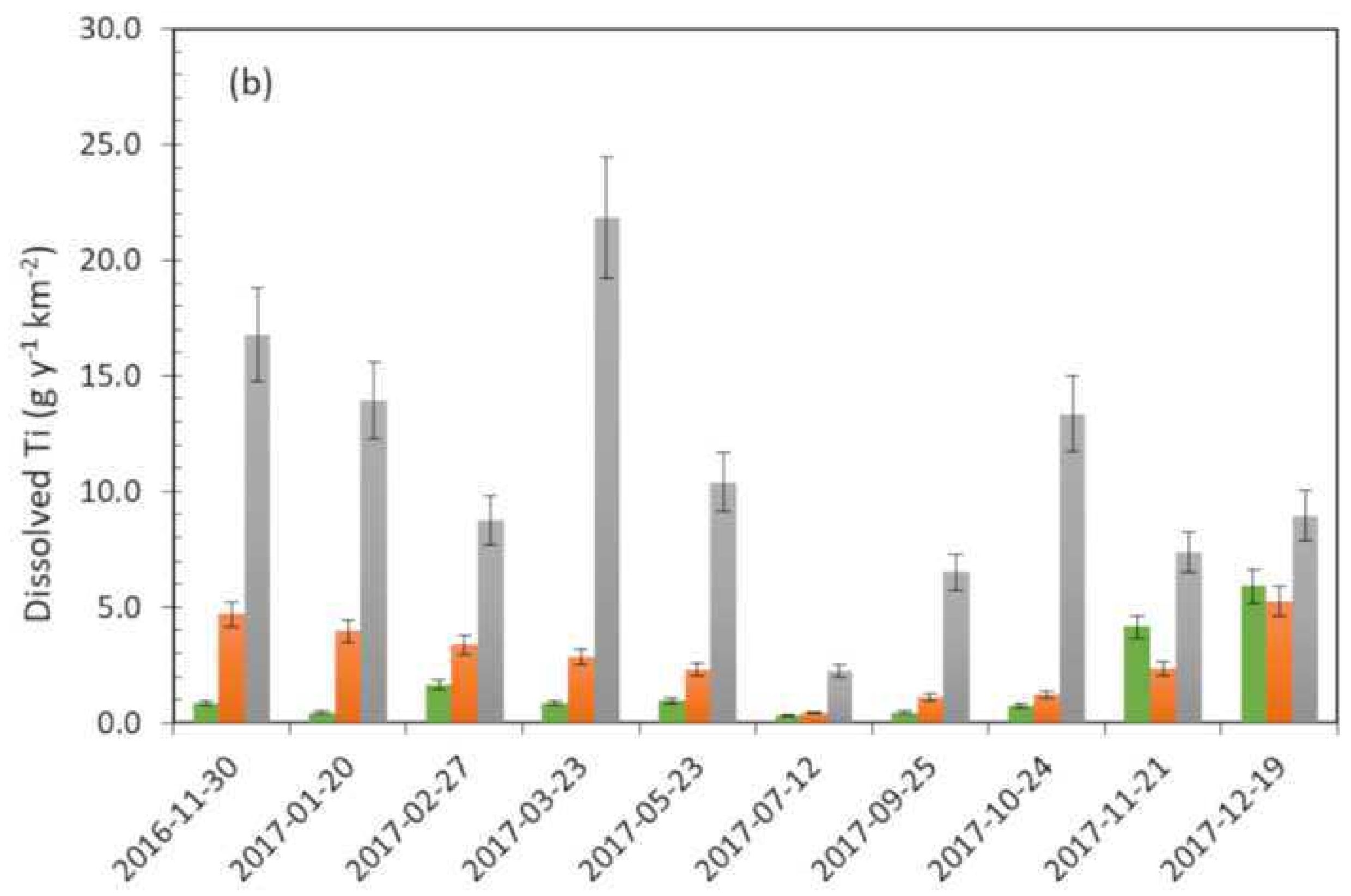




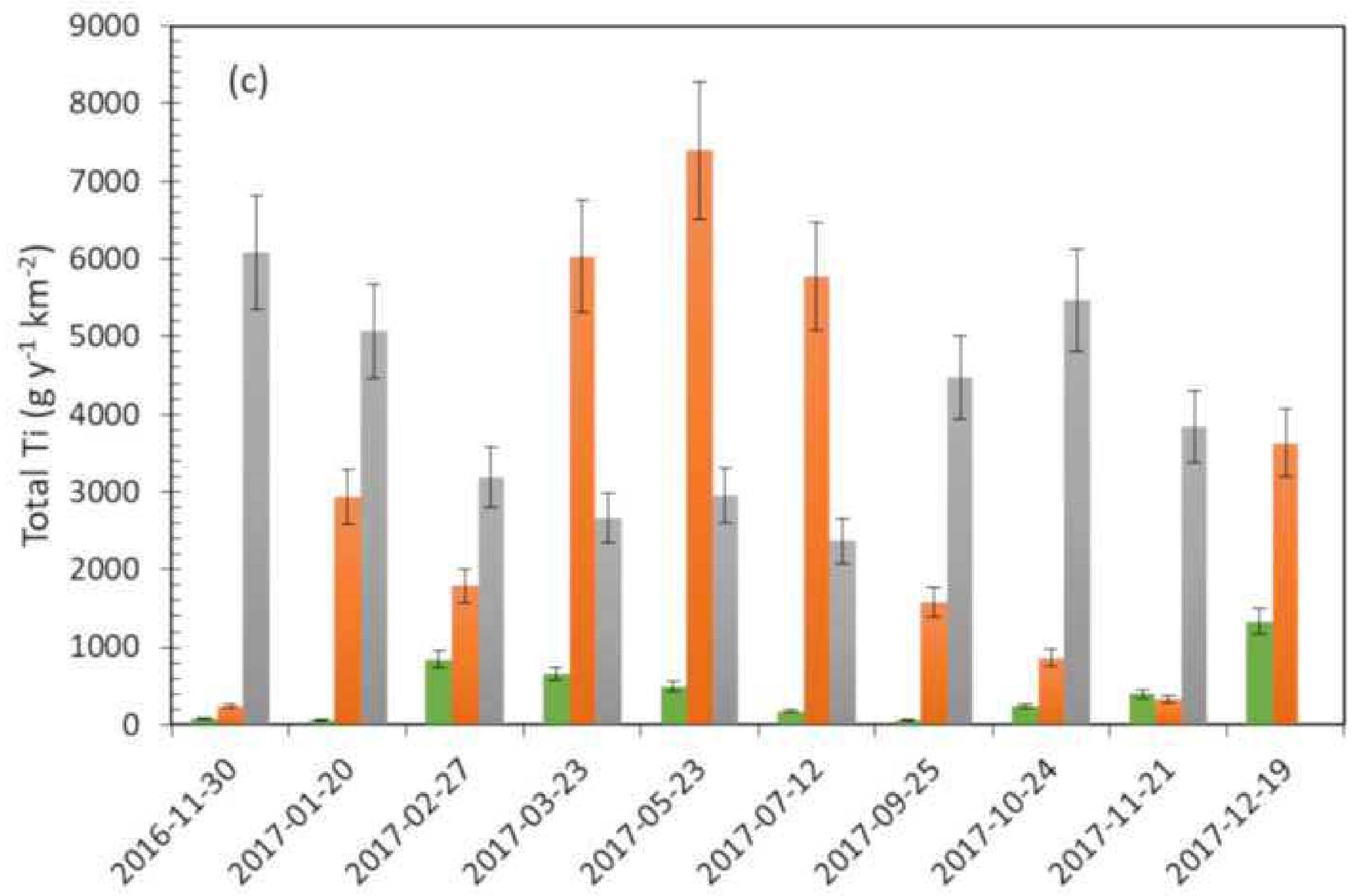


Titanium nanoparticles fate in small-sized watersheds under different land-uses

Additional Informations

Jia-Lan Wang ${ }^{1,2}$, Enrica Alasonati ${ }^{2}$, Paola Fisicaro ${ }^{2}$, Marc F. Benedetti ${ }^{1 *}$

${ }^{1}$ Université de Paris, Institut de physique du globe de Paris, CNRS, UMR 7154, F-75238 Paris, France

${ }^{2}$ Department of Biomedical and Inorganic Chemistry, Laboratoire National de Métrologie et d’Essais (LNE), 1 rue Gaston Boissier, Paris, 75015 France

*Corresponding author

Email: benedetti@ipgp.fr (M. F. Benedetti)

Phone number: +33183957695
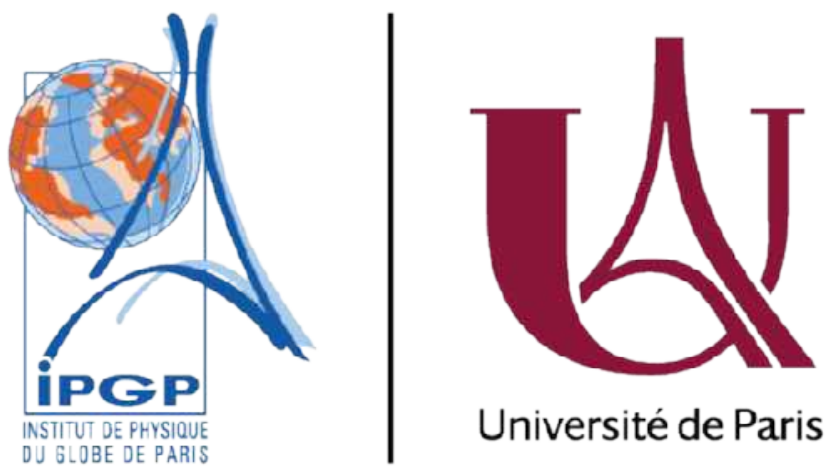
Table S1: Characteristics of three small watersheds of the Seine River.

\begin{tabular}{|c|c|c|c|c|}
\hline & Watershed & Forested & Agricultural & Urban \\
\hline & City & Gambaiseuil & Monchauvet & Beynes \\
\hline & Area $\left(\mathrm{km}^{2}\right)$ & 17 & 22 & 116 \\
\hline & River & Ponts Quentin & Vaucouleurs & Gally \\
\hline & Latitude & 48.7575 & 48.885736 & 48.870527 \\
\hline & Longitude & 1.735392 & 1.624297 & 1.889618 \\
\hline & ${ }^{(*)}$ Flow rate $\left(\mathrm{m}^{3} / \mathrm{s}\right)$ & 0.02 & 0.05 & 0.70 \\
\hline \multirow{3}{*}{ Land use } & Forestry & $95 \%$ & $22 \%$ & $19 \%$ \\
\hline & Agriculture & $5 \%$ & $72 \%$ & $44 \%$ \\
\hline & Artificial areas & & $6 \%$ & $37 \%$ \\
\hline \multirow{3}{*}{ Lithology } & Limestone & & $67 \%$ & $63 \%$ \\
\hline & Chalk & & & $20 \%$ \\
\hline & Sand & $100 \%$ & $33 \%$ & $17 \%$ \\
\hline
\end{tabular}

Table S2: Digestion efficiency of two commercial standards of $\mathrm{TiO}_{2} \mathrm{NPs}$ (Aerodisp and P25) in Milli Q and Evian waters.

\begin{tabular}{cccc}
\hline & $\mathrm{TiO}_{2}\left(\mu \mathrm{g} \mathrm{L}^{-1}\right)$ & Matrix & Recovery (\%) \\
\hline Aerodisp & 20 & $\mathrm{MQ}$ & 115 \\
Aerodisp & 100 & $\mathrm{MQ}$ & 102 \\
Aerodisp & 400 & $\mathrm{MQ}$ & 105 \\
P25 & 8000 & $\mathrm{MQ}$ & 111 \\
P25 & 15000 & Evian & 95 \\
P25 & 32000 & MQ & 111 \\
P25 & 40000 & MQ & 102 \\
\hline
\end{tabular}

\section{$\underline{\text { Quantification of } \mathrm{TiO}_{2}}$ particle number concentration (PNC) by single particle ICPMS (sp-ICPMS)}

\section{Subtraction approach used for sp-ICPMS data analysis}

The ultra-filtrate $(<1 \mathrm{kDa})$ of sampled water represents well the matrix environment and thus its signal was used as the blank of $\mathrm{TiO}_{2} \mathrm{NPs}$ present in sampled waters. Blanks have been prepared for each sampled water because the water chemistry varied from one site or one sample period to another. First, spectrums of intensity versus time for water sample and the corresponding ultra-filtered blank (Figure S1) were converted into the histograms of frequency versus intensity. Then, the frequency of the blank was subtracted from that of the unknown sample of the same matrix at the same intensity interval. This subtracted frequency was used to calculate the particle number concentration. The methodology validation is presented in the following section. 


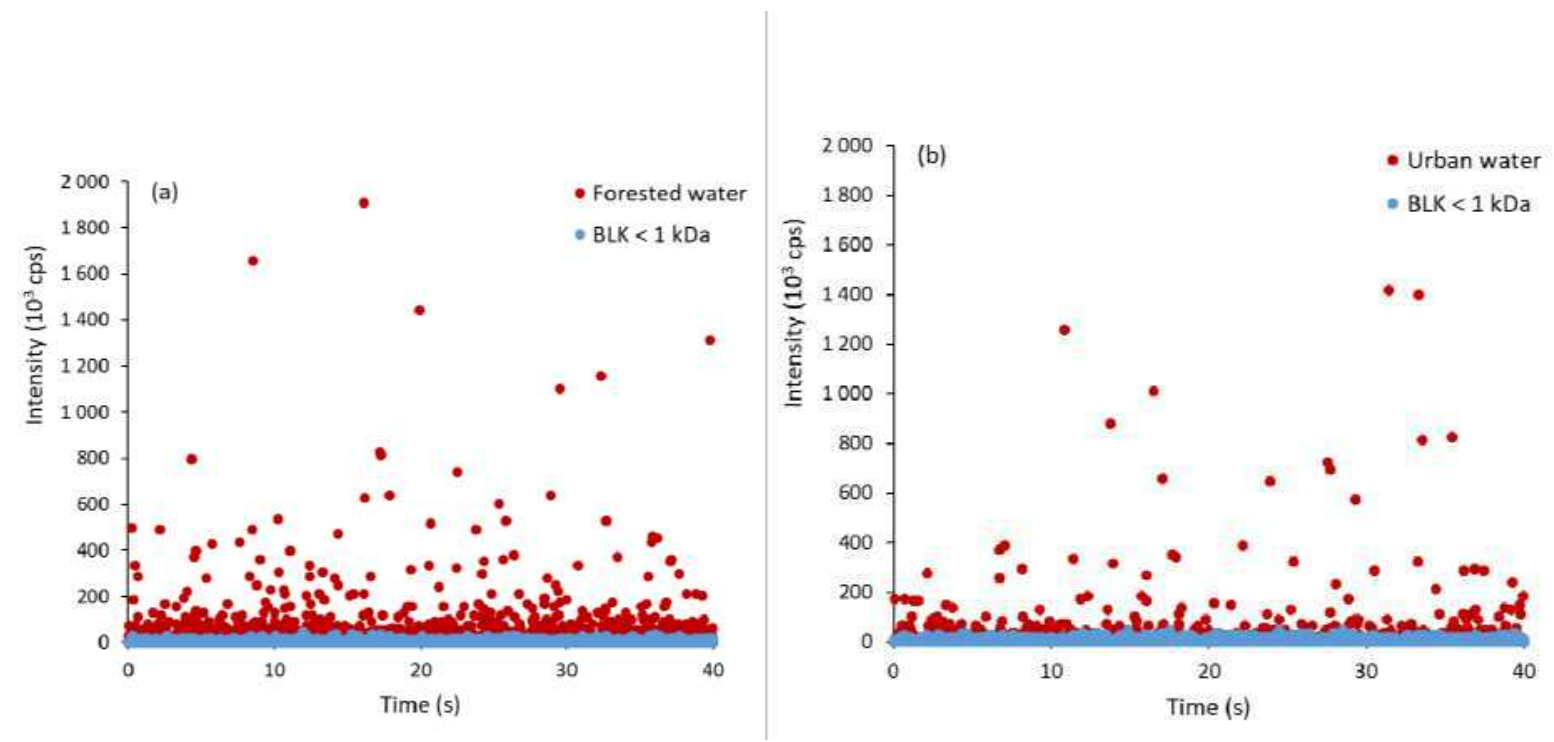

Figure S1: ${ }^{47} \mathrm{Ti}$ signal intensity of river samples and their blank (ultra-filtrate $<1 \mathrm{kDa}$ ) as function of the time for (a) forested and (b) urban watersheds.

\section{Methodology validation}

\subsection{Calculation of transport efficiency $(\eta)$}

In the spray chamber, more than $90 \%$ of sample is redirected into waste and only a small fraction is transported into plasma, leading to differences in mass delivery. This transport loss of sample is termed as "transport efficiency" $(\eta)$, an essential factor required to calculate the concentration and size of NPs. In the present study, the method referred to as the particle size method [S1] was applied to calculate $\eta$ since the applied reference material (Au-NPs) is certified for the particle size other than the concentration.

Given that transport efficiencies and sensitivity of particulate and dissolved standards are the same, $\eta$ is the ratio of the slope of calibration curve of Au-NPs $\left(R_{N P}, \mathrm{cps} \mathrm{g}^{-1}\right)$ to that of corresponding dissolved $\mathrm{Au}^{3+}\left(R_{\text {diss }}, \mathrm{cps} \mathrm{g}^{-}\right.$ $\left.{ }^{1}\right)$. $R_{N P}$ can be directly calculated from the mass $\left(m_{N P}, g\right)$ of one Au-NP with certified size and the corresponding ICPMS response $\left(I_{N P}, \mathrm{cps}\right)$. While, $R_{\text {diss }}$ equals to the response of dissolved ions calibration $\left(R F_{\text {ion }}, \mathrm{cps} \mathrm{g}^{-1} \mathrm{~L}^{-1}\right)$ divided by the uptake flow $\left(q_{\text {liq }}, \mathrm{L} \mathrm{s} \mathrm{s}^{-1}\right)$ and the dwell time $\left(t_{d}, \mathrm{~s}\right)$ :

$\eta=\frac{R_{\text {diss }}}{R_{N P}}=\frac{R F_{i o n} \times m_{N P}}{I_{N P} \times q_{\text {liq }} \times t_{d}}$

The standard suspension is certified for the size ( $55.4 \mathrm{~nm}$ in average) and the mass concentration of Au is given as $51.86 \mu \mathrm{g} \mathrm{mL}^{-1}$. Given that all $\mathrm{Au}$ is in form of nanoparticles of $55.4 \mathrm{~nm}$ and Au-NPs are spherical, the particle number concentration can be calculated $\left(3.0 \times 10^{10}\right.$ particle $\left.\mathrm{mL}^{-1}\right)$. Usually, the stock suspension is diluted $2.5 \times$ $10^{5}$ times to avoid NPs coincidence at very short dwell time. The suspension used to evaluate $\eta$ is at the concentration of $2.1 \times 10^{-4} \mathrm{gg} \mathrm{ml}^{-1}\left(1.2 \times 10^{5}\right.$ particle $\left.\mathrm{mL}^{-1}\right)$. Transport efficiency has been evaluated for each sampling mission and the average value was equal to $9 \% \pm 2 \%$.

\subsection{Experiments performed to confirm the methodology}

To confirm the methodology, three samples have been spiked with the smallest standards of NPs commercially available, the gold colloidal solutions of $10 \mathrm{~nm}$ (BBI, batch 026677). Certified nanoparticles of smaller size do not exist for $\mathrm{TiO}_{2}$, Au and Ag to the best of our knowledge. The ultrafiltration step was conducted the same day than sample collection to avoid any preparation artefacts. Samples have been prepared as follows:

1. Sample from the forest site (sample 19/12/2017) doped with Au NPs of $10 \mathrm{~nm}$.

2. Ultrafiltered fraction of the forest site sample (19/12/2017), doped with Au NPs of $10 \mathrm{~nm}$. 


\section{MQ water doped with Au NPs of $10 \mathrm{~nm}$.}

These experiments allowed to determine the ultrafiltration efficiency to remove nanoparticles with our methodology. They also allowed to evaluate whether the calculated NPs sizes in the three media were within the range of the certified one (i.e. $10 \mathrm{~nm}$ ) and to evaluate the detection limits. All samples were prepared and analysed the same day by HR-ICPMS in single particle mode. HR-ICPMS in the single particle mode conditions are similar to the one used for the data acquisition and described in the present paper. The gold calibration curve was in the range 0 to $1 \mathrm{\mu g} \mathrm{L}^{-1}$ in $1 \% \mathrm{HCl}$ solutions. The transport efficiency was $9.1 \%$, and was calculated as previously described.

Results are presented in Figures S2 to S4:

- Grey dots correspond to MQ water (MQ-D), the ultrafiltered water from the forested site sample treated the $19 / 5 / 2017$ (UF-D) and the raw water from the same forested site sampled the same day (19/5/2017) (Raw-D) doped with the $10 \mathrm{~nm}$ certified gold solution.

- Orange dots correspond to the same samples but after an ultrafiltration at $1 k D$ (MQ-D $<1 K D, U F-D<1 K D$, Raw$D<1 K D)$, conducted for all field water samples.

- Green dots correspond to the $\mathrm{Au}^{197}$ signal in $\mathrm{MQ}$ water acquired in low-resolution mode with HR-ICPMS in single particle mode.

Table S3: Summarizing the experiments performed to confirm the methodology and colour code of the data presented in figure 52 to 54 .

\begin{tabular}{|l|c|c|c|c|c|c|c|}
\hline & MQ-D & UF-D & Raw-D & MQ-D<1KD & UF-D<1KD & Raw-D<1KD & MQ \\
\hline Figure S2 & & & & & & & \\
\hline Figure S3 & & & & & & & \\
\hline Figure S4 & & & 0 & & & & \\
\hline
\end{tabular}

In addition, in each of the three figures a line has been added corresponding to 3 times the standard deviation of all values recorded for:

- the $M Q<1 k D$ (blue line)

- $\quad$ the fraction $<1 K D$ for samples UF-D $<1 K D$ (red line)

- Raw-D<1KD (red line).

Figures S2, S3 and S4 clearly show that most of the particles were removed by the ultrafiltration process at $1 \mathrm{kD}$. The \% of removal was calculated to be $94 \pm 5 \%, 95 \pm 5 \%$ and $93 \% \pm 5 \%$ for the Raw-D, UF-D and MQ-D samples, respectively. Table $\mathrm{S} 4$ gives 3 times the standard deviation values for the three conditions.

Table S4: Standard deviations for the three conditions

\begin{tabular}{|l|c|c|c|c|}
\hline Sample & MQ-D $<1 K D$ & UF-D $<1 K D$ & Raw-D $<1 K D$ & MQ \\
\hline $3 \times$ Std. Dev. (cps) & 19340 & 20770 & 19560 & 16500 \\
\hline
\end{tabular}

The detection limit of size $\left(D_{\mathrm{min}}\right)$ has been calculated according to [S1] and is given in Table S5.

Table S5: Detection limit of size, $D_{\min }$

\begin{tabular}{|l|c|c|c|c|}
\hline Sample & MQ-D<1KD & UF-D $<1 K D$ & Raw-D $<1 K D$ & $M Q$ \\
\hline$D_{\min }(\mathrm{nm})$ & 4 & 4 & 4 & 4 \\
\hline
\end{tabular}


With the data of each sample doped with $10 \mathrm{~nm}$ gold NPs and their corresponding ultrafiltrated sample, using our data treatment, we can determine the size of the gold NPs and compare it to the certified value: all values are given in Table S6.

Table S6: Determined average size for the three matrices compared to the reference value.

\begin{tabular}{|l|c|c|c|c|}
\hline Sample & MQ-D & UF-D & Raw-D & Certified \\
\hline$D(\mathrm{~nm})$ & $10 \pm 2$ & $9 \pm 2$ & $9 \pm 2$ & $10 \pm 1$ \\
\hline
\end{tabular}

The calculated size for the $10 \mathrm{~nm}$ certified gold nanoparticles is thus in perfect agreement with the certified value. We therefore believe that this is a strong demonstration that the calculation method for the particles number, nanoparticles mass and size for the present paper is solid and valid.

The smallest size we can detect for gold is $4 \mathrm{~nm}$. A test with $10 \mathrm{~nm} \mathrm{TiO} 2$ particle was not possible since such certified material does not exist. However, our data in the present manuscript allowed to calculate a size limit of $20 \pm 2 \mathrm{~nm}$.

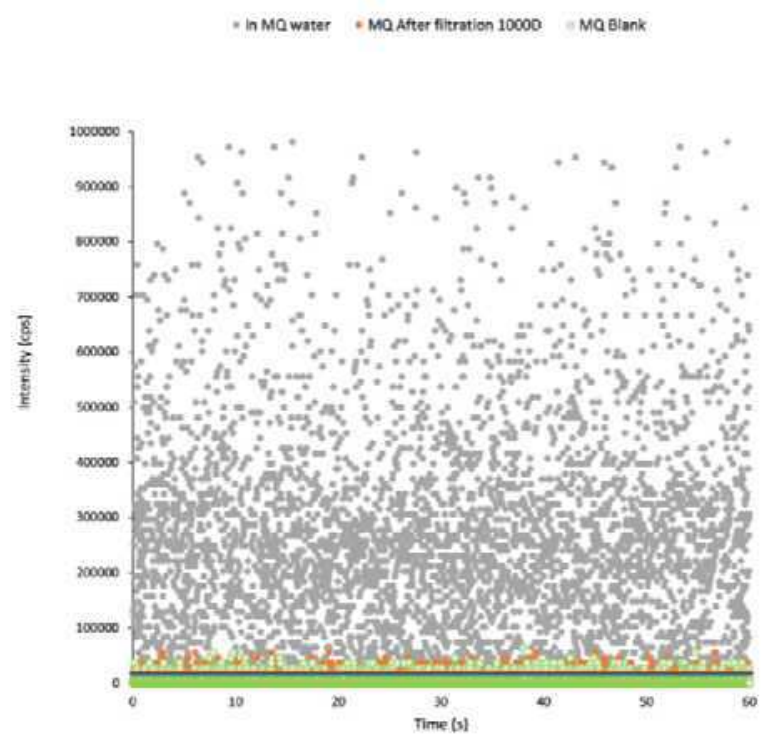

Figure S2: MQ solution doped with $10 \mathrm{~nm}$ gold NPs (gray dots), sample after ultrafiltration at $1 \mathrm{kD}$ (orange dots) and MQ signal (green dots). Red and blue lines correspond to three times the standard deviation of the orange and green data, respectively. 


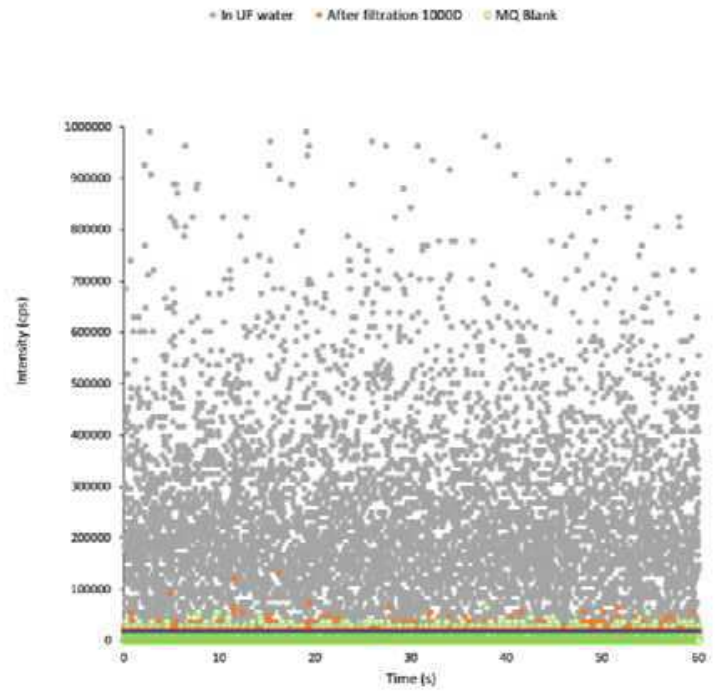

Figure S3: Forested sample (19/12/2017) ultra-filtered solution doped with $10 \mathrm{~nm}$ gold NPs (gray dots), sample after ultrafiltration $(1 \mathrm{kD})$ (orange dots) and $\mathrm{MQ}$ signal (green dots). Red and blue lines corresponding to three times the standard deviation of the orange and green data, respectively.

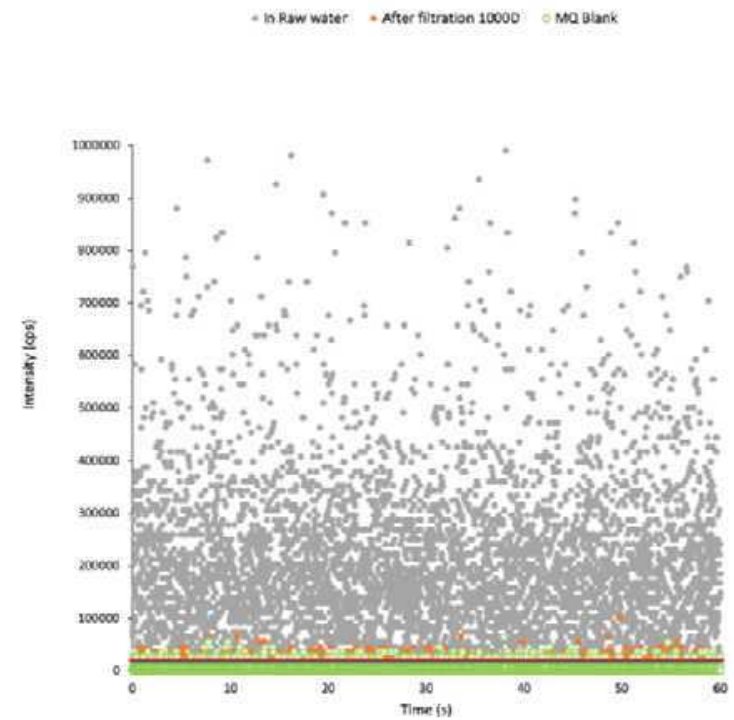

Figure S4: Forested raw sample (19/12/2017) solution doped with $10 \mathrm{~nm}$ gold NPs (gray dots), sample after ultrafiltration (1kD) (orange dots) and MQ signal (green dots). Red and blue lines corresponding to three times the standard deviation of the orange and green data, respectively.

\subsection{Limit of detection of size of $\mathrm{TiO}_{2} \mathrm{NPs}$ by sp-ICPMS}

The TiO2-NPs detection limit of size in blank from calibration curves $\left(\mathrm{D}_{\min }\right)$ has been calculated according to the reported equation [S1]: 


$$
D_{\min }=\left(\frac{6 \times 3 \sigma}{R \times f_{a} \times \rho \times \pi}\right)^{1 / 3}
$$

where $\sigma$ (cps) is the standard deviation of the matrix blank, $R\left(\operatorname{cps} \mu \mathrm{l}^{-1}\right)$ is the sensitivity of the instrument for the element of the analyte, $f_{a}$ is the mass fraction of the analysed metallic element in the NP and $\rho$ is the density of the NP. In the case of $\mathrm{TiO}_{2}-\mathrm{NPs}, f_{a}=0.6, \rho=4.23 \mathrm{~g} \mathrm{~cm}^{3} . R$ is the ratio of the slope of calibration curve of ionic standards solution ( $\mathrm{K}$ at cps $\mu^{-1}$ ) to $\eta$. Assuming $\mathrm{TiO}_{2} \mathrm{NPs}$ of spherical geometry, $\mathrm{D}_{\min }$ is equal to $20 \mathrm{~nm}$ in agreement with [S2].

\subsection{Limit of quantification of Ti concentration by sp-ICPMS}

The LOQ $\left(C_{\min }\right)$ can be calculated from the $D_{\min }$ calculated for MQ water used for the calibration and according to the following equation:

$$
C_{\text {min }}=\frac{\rho \times \pi \times\left(D_{\text {min }}\right)^{3}}{6 \times q_{\text {liq }} \times t_{d}}
$$

The value of $D_{\min -\mathrm{MQ}}$ equal to $20 \mathrm{~nm}$ gives a $C_{\min }$ of $7 \mathrm{ng} \mathrm{L}^{-1}$, which is applied as the LOQ of Ti concentration by spICPMS.

\section{Evaluation of the uncertainty on nanoparticles' number concentration}

According to the Guide to the expression of Uncertainty in Measurement (GUM), the standard uncertainty of measurand can be obtained by propagating the variances of the related parameters [41]. Several factors are identified as contributors to the uncertainty in case of sp-ICPMS measurements of nanoparticles in natural waters such as the solution preparation, calibration, sensitivity of ICPMS, field sampling and sample stability. Two main contributions are taken into account in this paper i.e., the measurement repeatability (u1) and the sampling variability effect (u2), for the concentration of nanoparticles determined by sp-ICPMS. The expanded uncertainty $(U)$ was obtained for three individual sampling matrices, based on Eq. (4) and (5):

$$
\begin{aligned}
& u=\sqrt{u_{1}^{2}+u_{2}^{2}} \\
& U=k * u \quad(k=2)
\end{aligned}
$$

Where $u$ is the standard uncertainty and $k$ is the coverage factor, chosen equal to 2 , defining a level of confidence of approximately $95 \%$. The standard uncertainty of the repeatability $\left(u_{1}\right)$ was calculated using the standard deviation from 3 measurements. To evaluate the standard uncertainty of the sampling effect $\left(u_{2}\right)$, six sampling replicates (F1-F6) were taken the 23/05/17, 12/07/17 and 25/09/17 in the forested, agricultural and urban catchments, respectively. Each sampling replicate is considered as one individual sample and independently analysed by sp-ICPMS with three measurements $(n=3)$. The six sampling replicates were quantified in two separate sequences and each sequence lasted about 10 hours. Thus, $u_{2}$ provides an evaluation of the sequence's effect on the NPs concentrations in addition to the sampling variability.

To evaluate the standard uncertainty of the sampling effect $\left(u_{2}\right)$, the analysis of variance (ANOVA) is applied. ANOVA is a statistical technique applied for comparing datasets, routinely used when more than two populations are involved. In this study, single-factor ANOVA, meaning comparing groups $(>3)$ based on independent factor variable, was applied to evaluate the sampling effect. The application of the ANOVA test to quantify an effect requires that the concerned data has a normal distribution. For each type of water, 6 
independent samples and 3 measurements for each sample resulted in 18 data in total. The Shapiro-Wilk test is used here to confirm normality of the 18 data.

The single-factor ANOVA test is performed with the significance level at $\alpha=0.05$ for all data analysis. One example is given in Fig. S5, with 18 values of F1-F6 and the resume of single-factor ANOVA analysis. When $F<$ $F_{\text {crit }}$, the sampling effect is not significant. Whereas, if $F>F_{\text {crit, }}$, the sampling effect needs to be taken into account for uncertainty evaluation. In this case, the uncertainty associated with this effect can be calculated with the equation given in Fig. S5. It can be expressed as absolute number (particles $\mathrm{mL}^{-1}$ ) or in relative uncertainty (\%).

\begin{tabular}{|c|c|c|c|c|c|c|}
\hline \multirow{4}{*}{$\begin{array}{c}\mathrm{NPs}_{\mathrm{SiO}} \mathrm{TiO}_{2} \\
\left(\text { particles } \mathrm{mL}^{-1} \text { ) }\right.\end{array}$} & F1 & $\mathbf{F 2}$ & F3 & F4 & F5 & F6 \\
\hline & $7310^{6}$ & $8110^{6}$ & $8410^{6}$ & $6310^{6}$ & $8410^{6}$ & $6410^{6}$ \\
\hline & $7010^{6}$ & $8010^{6}$ & $7710^{6}$ & $5310^{6}$ & $6210^{6}$ & $6210^{6}$ \\
\hline & $7610^{6}$ & $7510^{6}$ & $8410^{6}$ & $6710^{6}$ & $7210^{6}$ & $7210^{6}$ \\
\hline \multicolumn{7}{|c|}{ Anova: Single Factor } \\
\hline Source of Variation & SS & $d f$ & $M S$ & $F$ & $P$-value & Fcrit \\
\hline Between Groups & $8.9810^{14}$ & 5 & $1.8010^{14}$ & \multirow{3}{*}{4.390} & \multirow{3}{*}{0.017} & \multirow[t]{3}{*}{3.106} \\
\hline Within Groups & $4.9110^{14}$ & 12 & $4.0910^{13}$ & & & \\
\hline Total & $1.3910^{15}$ & 17 & & & & \\
\hline \multirow[b]{2}{*}{$\mathbf{u}_{2}$} & \multirow[b]{2}{*}{$\begin{array}{c}6810^{6} \\
9.4\end{array}$} & \multirow[b]{2}{*}{$\begin{array}{l}\text { Particles } \mathrm{mL}^{-1} \\
\%\end{array}$} & \multirow[b]{2}{*}{$u_{2}=$} & \multicolumn{2}{|c|}{$M S_{\text {between }}^{2}-M S_{\text {within }}^{2}$} & \multirow[b]{2}{*}{$n=3)$} \\
\hline & & & & \multicolumn{2}{|c|}{$n$} & \\
\hline
\end{tabular}

Figure S5: Example of single-factor ANOVA test for NPs-TiO ${ }_{2}$ in forested water sampled on the $23^{\text {th }}$ March 2017.

\section{Others supplementary information}

\begin{tabular}{|c|c|c|c|c|c|c|}
\hline \multirow{2}{*}{$\begin{array}{c}\text { Sampling } \\
\text { date }\end{array}$} & \multicolumn{3}{|c|}{ Ti total $\left(\mu \mathrm{g} \mathrm{L}^{-1}\right)$} & \multicolumn{3}{|c|}{$\mathrm{Ti}<1 \mathrm{kDa}\left(\mathrm{ng} \mathrm{L}^{-1}\right)$} \\
\hline & Forested & Agricultural & Urban & Forested & Agricultural & Urban \\
\hline $30 / 11 / 2016$ & 2 & 4 & 34 & 24 & 86 & 93 \\
\hline $20 / 01 / 2017$ & 4 & 21 & 32 & 29 & 29 & 87 \\
\hline $27 / 02 / 2017$ & 14 & 33 & 14 & 28 & 62 & 38 \\
\hline $23 / 03 / 2017$ & 16 & 66 & 10 & 21 & 31 & 83 \\
\hline $23 / 05 / 2017$ & 13 & 175 & 12 & 26 & 55 & 44 \\
\hline $12 / 07 / 2017$ & 6 & 182 & 16 & 11 & 14 & 15 \\
\hline $25 / 09 / 2017$ & 3 & 30 & 36 & 21 & 21 & 53 \\
\hline $24 / 10 / 2017$ & 7 & 18 & 26 & 20 & 25 & 65 \\
\hline $21 / 11 / 2017$ & 8 & 5 & 22 & 86 & 35 & 42 \\
\hline $19 / 12 / 2017$ & 19 & 24 & & 86 & 35 & 42 \\
\hline Average & 9 & 56 & 22 & 35 & 39 & 56 \\
\hline
\end{tabular}

Table S7: Concentration of total Ti after digestion and dissolved Ti in three watersheds throughout the year. 


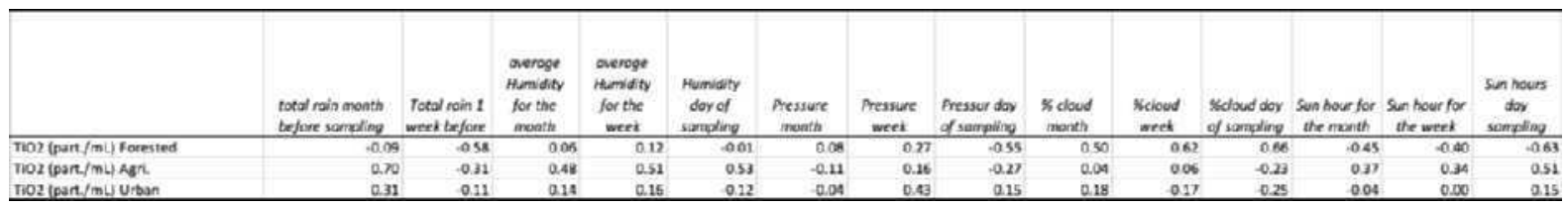

Table S8: Correlation matrix of average monthly nanoparticle number $(n=10)$ for each watershed and meteorological variables taken from https://www. historique-meteo.net/france/ile-de-france.

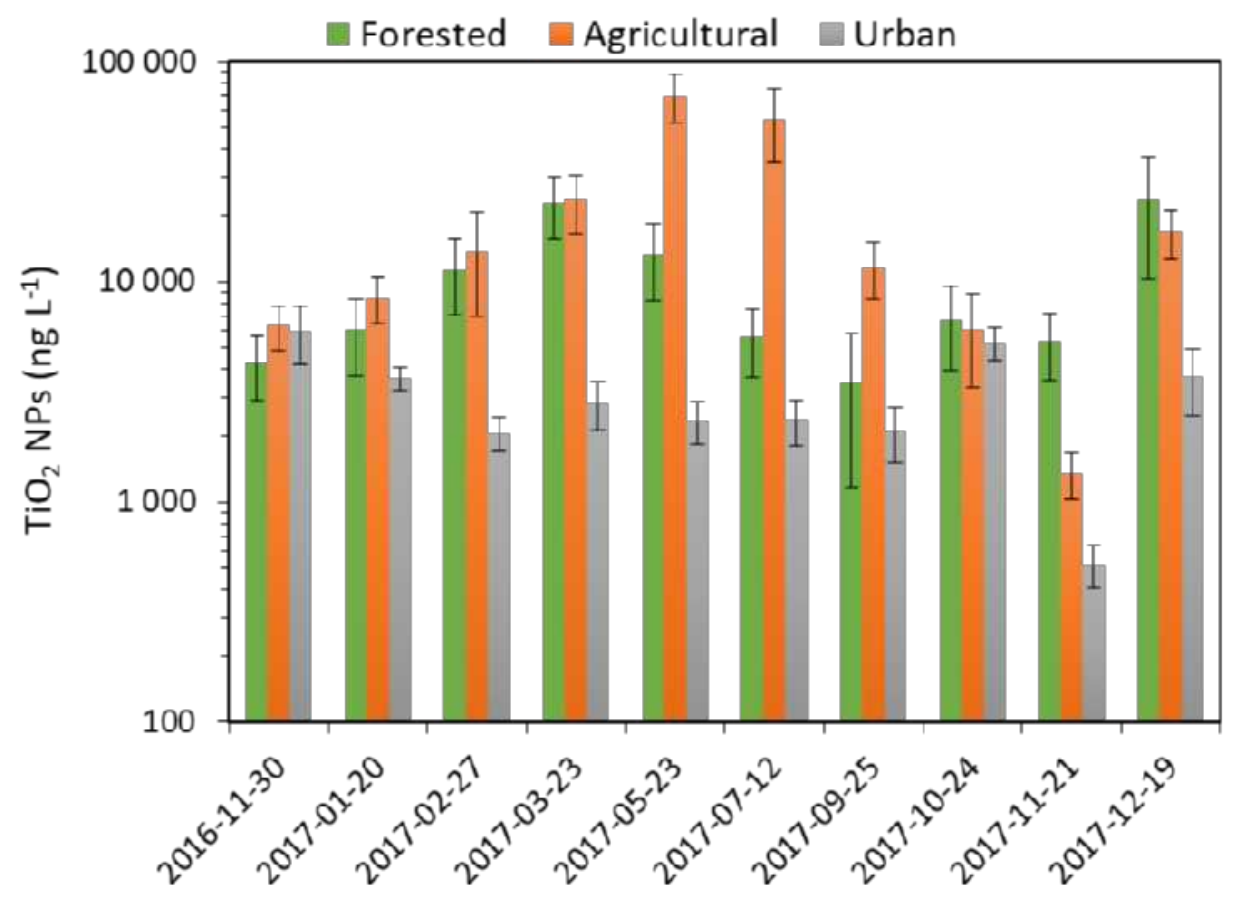

Figure S6: Mass concentration of $\mathrm{TiO}_{2} \mathrm{NPs}$ measured in water samples from three watersheds for one-year sampling. 


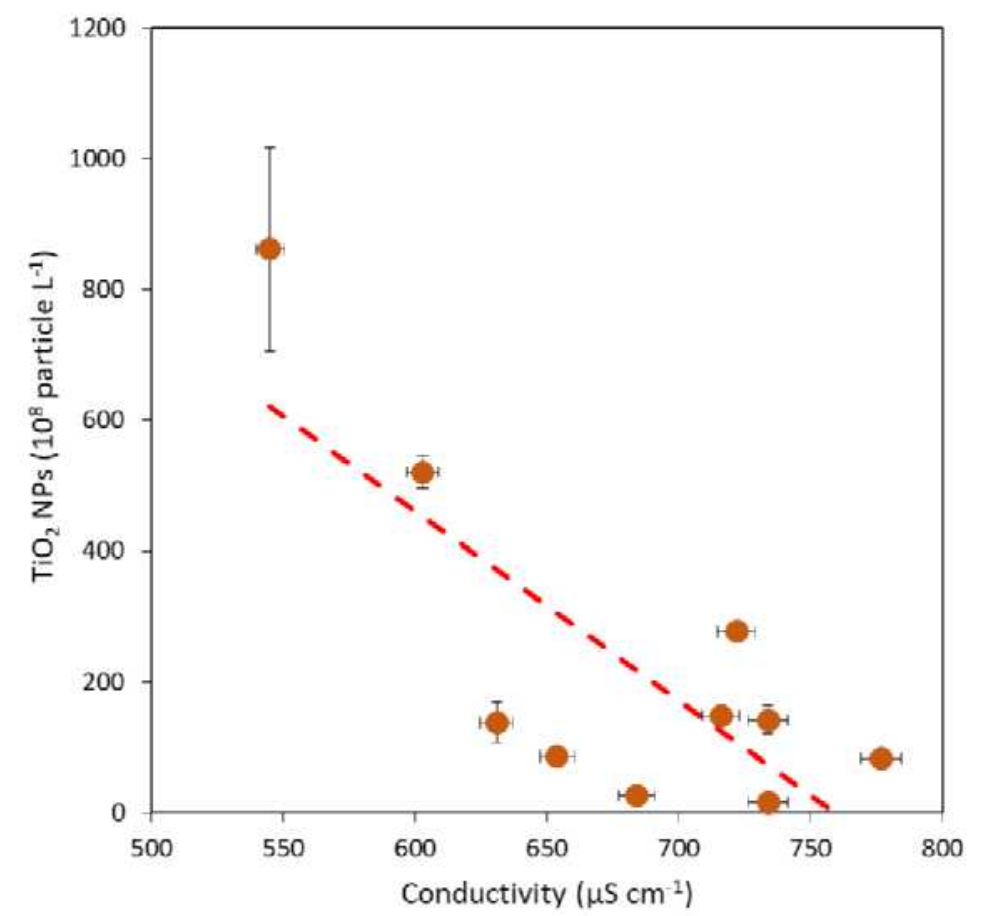

Figure S7: Particle number concentration of TiO2 NPs as function as conductivity in water samples from the agricultural watershed. The correlation coefficient $r$ corresponding to the orange broken line is equal to 0.77 for a sampling size $n=10$.

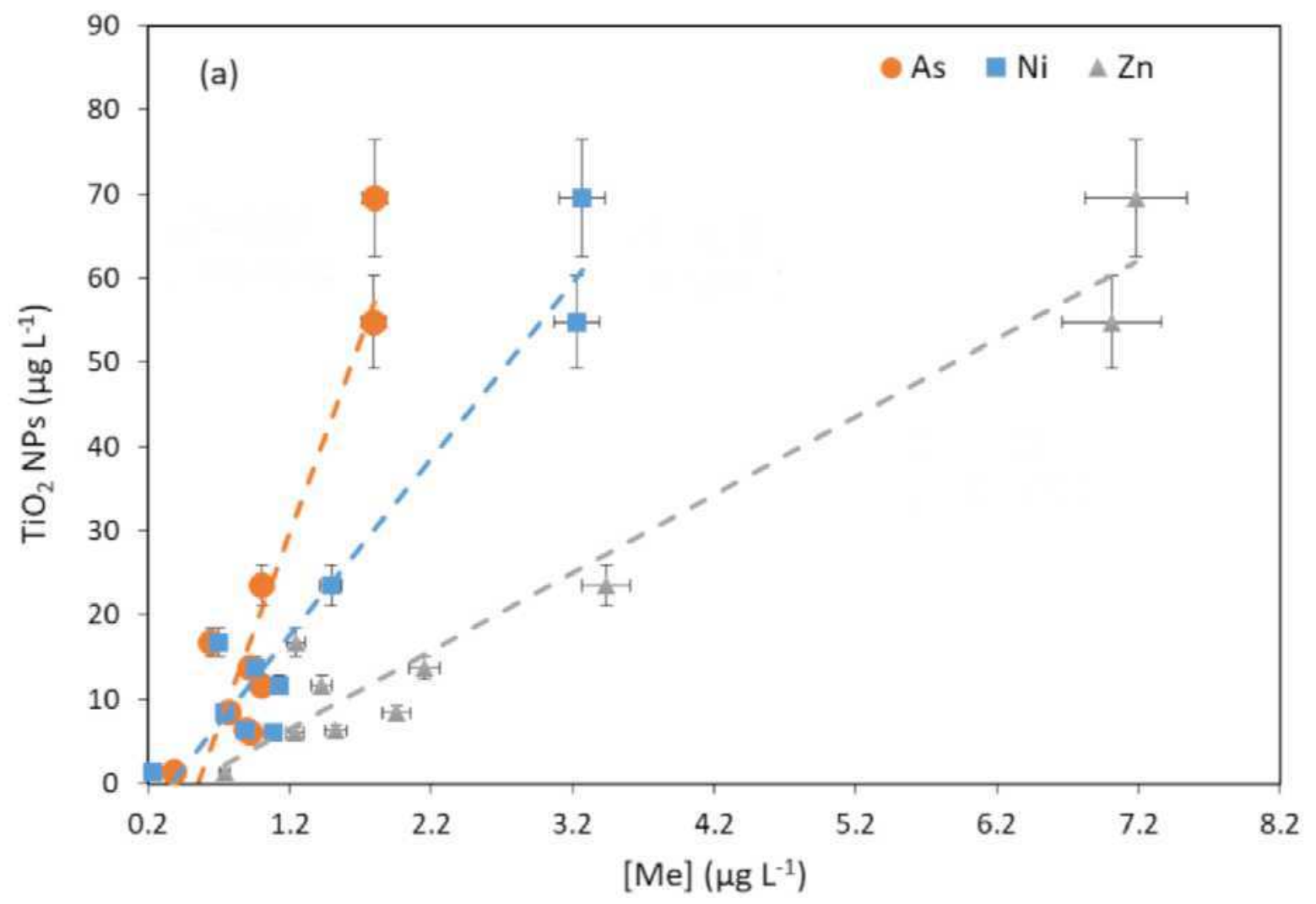

Figure S8: Mass concentration of TiO2 NPs as a function of that (bulk minus dissolved) of trace elements (Me) As, Ni, Zn, in agricultural water. The correlation coefficients $r$ corresponding to As orange, Ni blue and Zn grey broken lines are equal to $r_{A s}=0.92, r_{N i}=0.96$ and $r_{Z n}=0.97$. They all correspond to a $p$ value equal to 0.00001 and a sampling size $n=9$ 

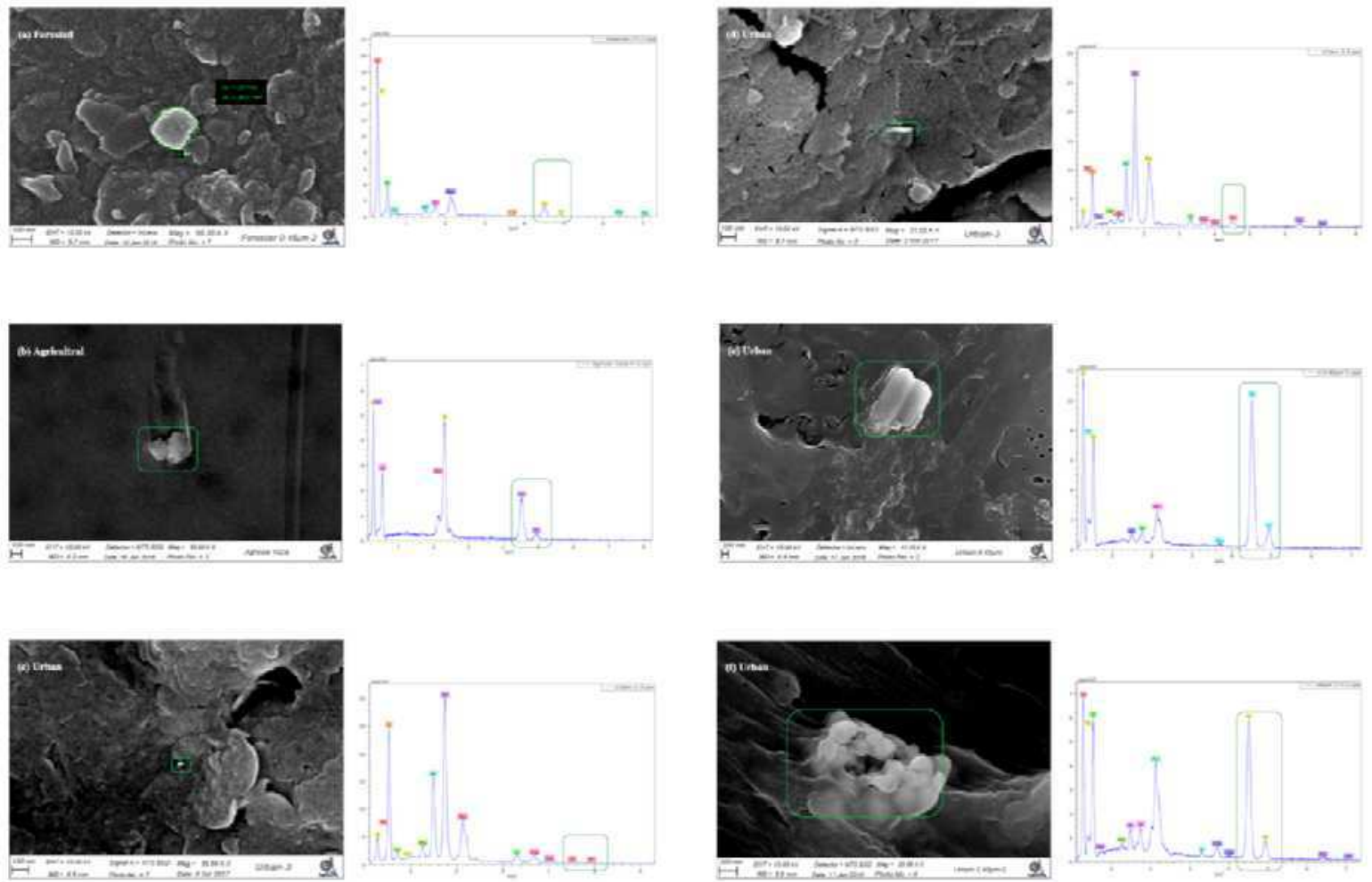

Figure S9: Pictures: SEM images of filters retaining suspended particles containing $\mathrm{TiO}_{2}$ of $(a, c, d)$ nano-scale; (e) micro-scale; (b) small aggregates; (f) large aggregates, with different shapes present in sampled waters. Graphics: showing the EDX analysis of corresponding particles highlighted by the green circle or square, showing their elemental composition.

\section{$\underline{\text { References }}$}

[S1] Lee, W.-W., Chan, W.-T., Calibration of single-particle inductively coupled plasma-mass spectrometry (SP-ICP-MS). J. Anal. At. Spectrom. 2015, 30, 1245-1254.

[S2] Tharaud, M., Gondikas, A.P., Benedetti, M.F., von der Kammer, F., Hofmann, T., Cornelis, G., TiO 2 nanomaterial detection in calcium rich matrices by spICPMS. A matter of resolution and treatment. J. Anal. At. Spectrom. 2017, 32, 1400-1411. https://doi.org/10.1039/C7JA00060J 